\title{
DETECTION OF RADIATION-INDUCED CHANGES IN ELECTROCHEMICAL PROPERTIES OF AUSTENITIC STAINLESS STEELS USING MINIATURIZED SPECIMENS AND THE SINGLE-LOOP ELECTROCHEMICAL POTENTIOKINETIC REACTIVATION METHOD
}

\author{
T. Inazumi \\ G. E. C. Bell \\ E. A. Kenik \\ K. Kiuchi
}

Date Published: January 1993

NOTICE: This document contains information of a preliminary nature. It is subject to revision or correction and therefore does not represent a final report.

Prepared for the DOE Office of Fusion Energy AT 1502053

Prepared by the

OAK RIDGE NATIONAL LABORATORY

Oak Ridge, Tennessee 37831-6285

managed by

MARTIN MARIETTA ENERGY SYSTEMS, INC.

for the

U. S. DEPARTMENT OF ENERGY

under contract DE-AC05-84OR21400 
TABLE OF CONTENTS

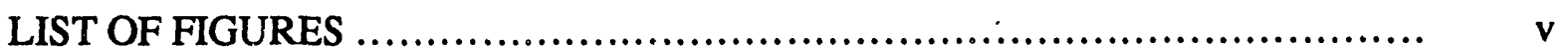

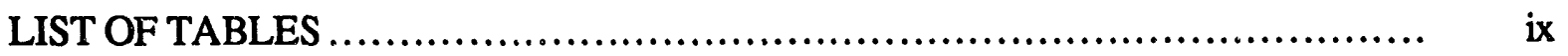

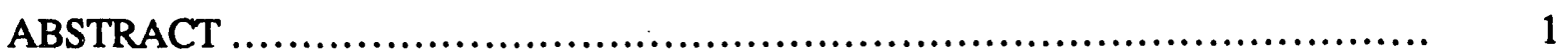

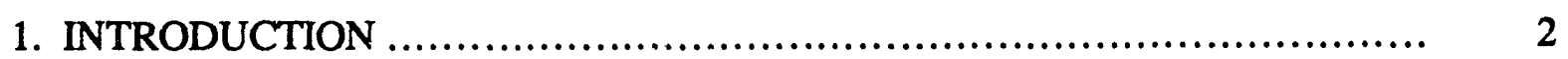

2. EXPERIMENTAL PROCEDURES ............................................. 6

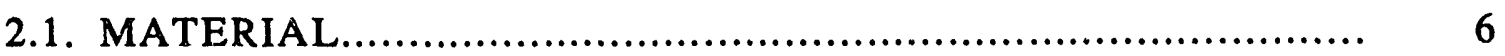

2.2. IRRADIATION CONDITIONS .......................................... 7

2.2.1. Fast Flux Test Facility/Materials Open Test Assembly .............. 7

2.2.2. ORR-MFE6J/7J................................................ 8

2.3. HEAVY-ION IRRADIATIONS ..................................... 8

2.4. SL-EPR TEST .......................................................... 8

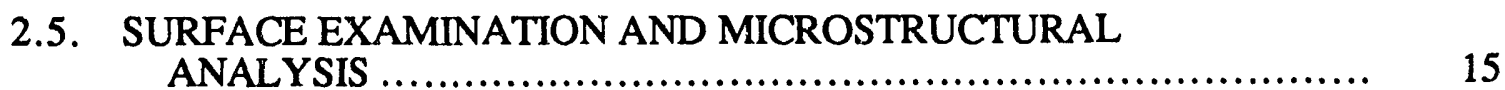

3. EXPERIMENTAL RESULTS ................................................ 15

3.1. DETECTION OF THERMALLY INDUCED SENSITIZATION.................................................. 15

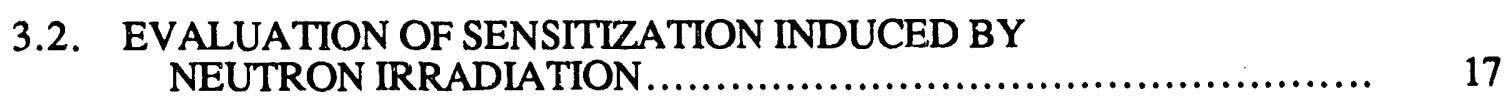

3.2.1. Specimens from the FFTF/MOTA Irradiation..................... 17

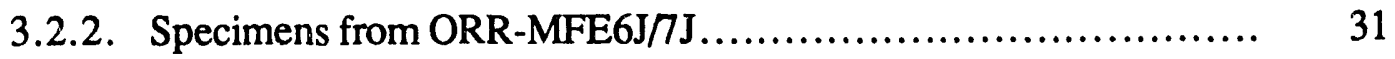

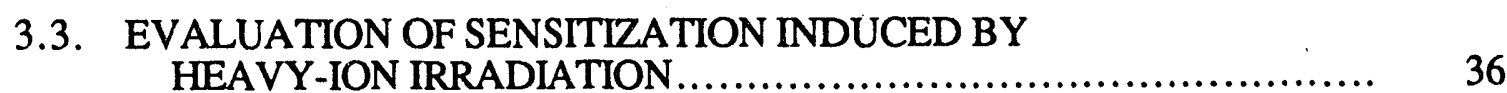

3.3.1. SL-EPR Test .................................................. 36

3.3.2. Surface Examination ............................................ 36

3.3.3. Microstructural Analysis ....................................... 40

4. DISCUSSION .................................................................. 43

4.1. VALIDITY OF THE MINIATURIZED TEST TECHNIQUE FOR THE SL-EPR..................................................... 43

4.2. IGSCC SUSCEPTIBILITY OF NEUTRON-IRRADIATED STAINLESS STEELS.................................................. 44

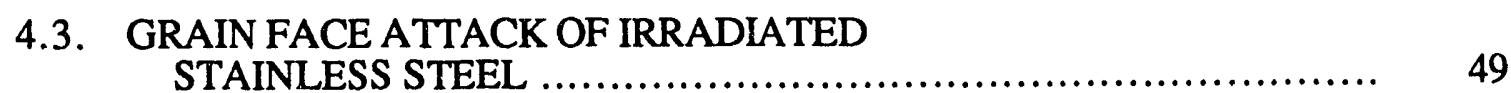

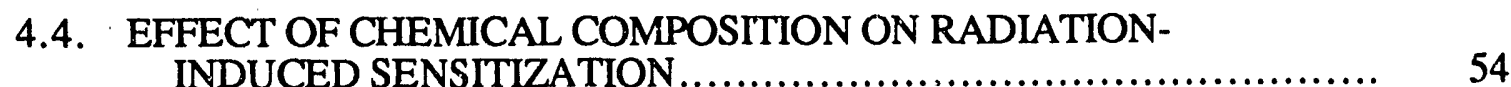

4.5. HEAVY-ION IRRADIATION FOR A SIMULATION OF RADIATION-INDUCED SENSITIZATION. 


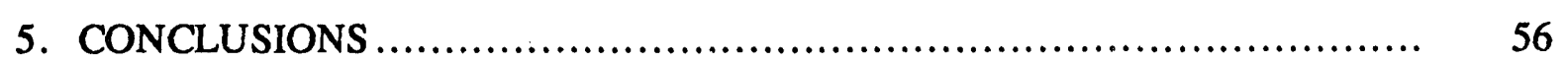

6. ACKNOWLEDGMENTS ................................................ 58

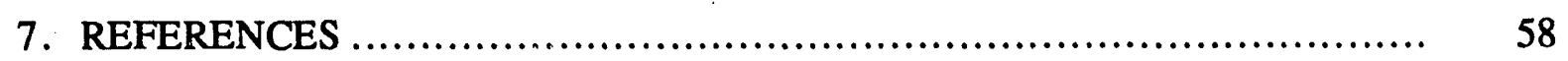




\section{LIST OF FIGURES}

Eigure

Page

1 Schematic of reactivation curves obtained by SL-EPR testing .............. 5

2 Schematic of heavy-ion-irradiated specimens ........................... 9

3 Electropolishing apparatus for specimen surface preparation................... 11

4 Schematic diagram of electrochemical testing system ..................... 12

5 Electrochemical testing system assembled in a ventilation hood ............ 12

6 Constant-temperature polarization cell ................................. 13

$7 \quad$ Method for mounting disk specimens .................................... 13

8 Specimen holder and loading stand..................................... 14

9 Comparison of SL-EPR test results for resin-mounted specimen and miniaturized disk specimen of thermally sensitized type 304SS

10 Comparison of SL-EPR test results for mechanically polished and electropolished thermally sensitized PCA ..................... 16

11 Reactivation curves for thermally aged SA PCA.......................... 18

12 DOS of PCA as a function of aging time .............................. 18

13 Reactivation curves of PCA irradiated in FFTF/MOTA at $420^{\circ} \mathrm{C}$ to $9 \mathrm{dpa}$

14 Reactivation curve of 20\% CW 316 DO-heat irradiated in FFTF/MOTA at $420^{\circ} \mathrm{C}$ to $9 \mathrm{dpa}$

15 Reactivation curves of $20 \% \mathrm{CW} 316 \mathrm{~N}$-lot, 316 DO-heat and $25 \%$ CW PCA irradiated in FFTF/MOTA at $420^{\circ} \mathrm{C}$ to $9 \mathrm{dpa}$

16 Optical micrographs of SA PCA after SL-EPR tests:

$(a)$ thermally aged and $(b)$ neutron irradiated

17 Optical micrographs of 25\% CW PCA specimen surfaces after SL-EPR tests: $(a)$ thermally aged and

(b) neutron irradiated

18 Optical micrographs of specimen surfaces of irradiated 20\% CW type 316 stainless steels after SL-EPR tests:

(a) 316 DO-heat and (b) $316 \mathrm{~N}-$ lot 
19 SEM micrographs of irradiated SA PCA specimen surface after SL-EPR test

20 SEM micrograph of irradiated $25 \% \mathrm{CW}$ PCA specimen surface after SL-EPR test

21 Optical micrograph of irradiated SA PCA specimen surface after SL-EPR test-interrupted halfway to the peak current

22 TEM micrograph of SA PCA irradiated in FFTF/MOTA at $420^{\circ} \mathrm{C}$ to $9 \mathrm{dpa}$

23 Dark-field images of SA PCA irradiated in FFTF/MOTA at $420^{\circ} \mathrm{C}$ to $9 \mathrm{dpa}$ : (a) dislocation loops, $1 / 2113$ reflection and $(b) \gamma^{\prime}\left(\mathrm{Ni}_{3} \mathrm{Si}\right), 110$ reflection.

24 (a) Iron, nickel, and chromium profiles across grain boundary of SA PCA irradiated in FFTF/MOTA at $420^{\circ} \mathrm{C}$ to $9 \mathrm{dpa}$ and (b) molybdenum, silicon, and titanium profiles across grain boundary of SA PCA irradiated in FFTF/MOTA at $420^{\circ} \mathrm{C}$ to $9 \mathrm{dpa}$

25 TEM micrographs of 25\% CW PCA irradiated in FFTF/MOTA at $420^{\circ} \mathrm{C}$ to $9 \mathrm{dpa}$

26 (a) Iron, nickel, and chromium profiles across grain boundary of $25 \% \mathrm{CW}$ PCA irradiated in FFTF/MOTA at $420^{\circ} \mathrm{C}$ to $9 \mathrm{dpa}$ and (b) molybdenum, silicon, and titanium profiles across grain boundary of $25 \% \mathrm{CW}$ PCA irradiated in FFTF/MOTA at $420^{\circ} \mathrm{C}$ to $9 \mathrm{dpa}$.

27 Composition of two grain boundaries and precipitates in

SA PCA and two grain boundaries in $25 \%$ CW PCA, both irradiated in FFTF/MOTA at $420^{\circ} \mathrm{C}$ to $9 \mathrm{dpa}$

28 Composition of voids in SA PCA irradiated in FFTF/MOTA at $420^{\circ} \mathrm{C}$ to $9 \mathrm{dpa}$

Composition of dislocation loops in SA PCA irradiated in FFTF/MOTA at $420^{\circ} \mathrm{C}$ to $9 \mathrm{dpa}$.

30 Reactivation curves of $25 \% \mathrm{CW}$ PCA irradiated in ORR-MFE6J/7J at 60 to $400^{\circ} \mathrm{C}$ to about $7 \mathrm{dpa}$

31 Reactivation charge value (Pa) [normalized by total tested area] of $25 \% \mathrm{CW}$ PCA irradiated in ORR-MFE6J/7J at 60 to $400^{\circ} \mathrm{C}$ to about $7 \mathrm{dpa}$. 
32 Optical micrographs of irradiated 25\% CW PCA after SL-EPR testing. Specimens were irradiated to about $7 \mathrm{dpa}$ at: $(a) 60^{\circ} \mathrm{C}$,

(b) $200^{\circ} \mathrm{C}$, (c) $330^{\circ} \mathrm{C}$, and (d) $400^{\circ} \mathrm{C}$

33 SEM micrographs of irradiated 25\% CW PCA after SL-EPR testing. Specimens were irradiated to about $7 \mathrm{dpa}$ at: (a) $200^{\circ} \mathrm{C}$, (b) $330^{\circ} \mathrm{C}$, and (c) $400^{\circ} \mathrm{C}$

34 Optical micrographs of $25 \%$ CW PCA irradiated at $200^{\circ} \mathrm{C}$.

SL-EPR testing was interrupted at: (a) Flade potential,

(b) $1 / 2$ peak, (c) peak, and (d) $-100 \mathrm{mV}$ from peak

35 Reactivation curves of heavy-ion-irradiated LS1A

36 SEM micrographs of irradiated LS1A after SL-EPR tests. Specimens were irradiated at $515^{\circ} \mathrm{C}$ to: (a) $1 \mathrm{dpa},(b) 10 \mathrm{dpa}$ and $(c) 30 \mathrm{dpa}$

37 TEM micrographs of irradiated LS1A. Specimens were irradiated at $515^{\circ} \mathrm{C}$ to: (a) $1 \mathrm{dpa},(b) 10 \mathrm{dpa}$, and

(c) $30 \mathrm{dpa}$

38 Grain boundary in LS1A irradiated at $515^{\circ} \mathrm{C}$ to $10 \mathrm{dpa}$

39 Iron, chromium, and nickel profiles at grain boundary of stainless steel similar to LS1A irradiated at $515^{\circ} \mathrm{C}$ to $30 \mathrm{dpa}$

40 Optical micrograph of thermally sensitized $25 \% \mathrm{CW}$ PCA

after SL-EPR test (aged at $650^{\circ} \mathrm{C}$ for $2 \mathrm{~h}, \mathrm{~Pa}=1.64 \mathrm{C} / \mathrm{cm}^{2}$ )

41 Comparison of reactivation curves for different irradiation conditions....

42. Dark field images of irradiated $25 \%$ CW PCA. Specimens were irradiated to about $7 \mathrm{dpa}$ at: $(a) 60^{\circ} \mathrm{C},(b) 200^{\circ} \mathrm{C}$, (c) $330^{\circ} \mathrm{C}$ (13 dpa), and (d) $400^{\circ} \mathrm{C}$.

43 Schematic of hypothesized RIS mechanism

44 Changes in current density of irradiated 25\% CW PCA as a function of time at a potential of $+200 \mathrm{mV}$ versus SCE.

45 Effect of chromium and molybdenum content on Pa values of cold-worked austenitic stainless steels irradiated in FFTF/MOTA at $420^{\circ} \mathrm{C}$ to $9 \mathrm{dpa}$ 


\section{LIST OF TABLES}

Table

$\underline{\text { Page }}$

1 Chemical composition of austenitic stainless steels studied (wt \%) .......................................................... 7

$2 \quad$ SL-EPR test conditions .............................................. 14

3 Reactivation charge value $(\mathrm{Pa})$ normalized by total grain-boundary area...... 19

$4 \quad$ Flade potentials and reactivation charges of thermally aged and heavy-ion-irradiated LS1A ............................................... 38

$5 \quad$ Reactivation charge value $(\mathrm{Pa})$ normalized by total tested area ............... 46 


\title{
DETECTION OF RADIATION-INDUCED CHANGES IN ELECTROCHEMICAL PROPERTIES OF AUSTENITIC STAINLESS STEELS USING MINIATURIZED SPECIMENS AND THE SINGLE-LOOP ELEC'TROCHEMICAL POTENTIOKINETIC REACTIVATION METHOD*
}

\author{
T. Inazumi ${ }^{\dagger}$, G. E. C. Bell, E. A. Kenik, and K. Kiuchi ${ }^{\ddagger}$
}

\begin{abstract}
A methodology was established to evaluate radiation-induced changes in the electrochemical properties of several austenitic stainless steels by the single-loop electrochemical potentiokinetic reactivation (SL-EPR) test technique using miniaturized specimens that were heav $y$ ion or neutron irradiated. The miniaturized specimens were standard transmission electron microscope (TEM) disks, $3 \mathrm{~mm}$ in diameter by $0.24 \mathrm{~mm}$ thick, and a specially designed TEM specimen holder allowed the miniaturized specimens to serve as the working electrode of an electrochemical cell. The materials used in this study included a solution-annealed (SA), titanium-stabilized version of type 316 steel, designated as LS1A, irradiated with $4 \mathrm{MeV} \mathrm{Ni}{ }^{++}$ions at $515^{\circ} \mathrm{C}$ to between 1 and 30 displacements per atom (dpa); an SA and cold-worked (CW) austenitic stainless steel developed by the U.S. Fusion Program; so-called "prime candidate alloy" designated as PCA; and two commercial heats of type 316 stainless steel irradiated at $420^{\circ} \mathrm{C}$ to $9 \mathrm{dpa}$ in the Materials Open Test Assembly (MOTA) of the Fast Flux Test Facility (FFTF) and at 60 to $400^{\circ} \mathrm{C}$ to 7 dpa in the spectrally tailored experiments (MFE6J/7J) in the Oak Ridge Research Reactor (ORR). Control specimens thermally aged at the irradiation temperatures for appropriate times were also tested.

Comparison SL-EPR tests on metallographic resin-mounted specimens (tested area $=0.42 \mathrm{~cm}^{2}$ ) yielded similar reactivation curves for a type 304 stainless steel and confirmed the validity of the use of the miniaturized specimen holder and small specimen areas for SL-EPR testing. Heavy-ionirradiated specimens of LS1A irradiated at $515^{\circ} \mathrm{C}$ to 1,10 , and $30 \mathrm{dpa}$ were first tested to simulate a neutron-irradiation-induced microstructure and to investigate the feasibility of using the SL-EPR technique for irradiated substrates before moving on to neutron-irradiated materials.

Significant changes in electrochemical properties of irradiated specimens, compared with thermally aged control specimens, such as increases in the reactivation charge and Flade potential, were detected for all austenitic stainless steels irradiated by heavy ions at $515^{\circ} \mathrm{C}$ and by neutrons at $200^{\circ} \mathrm{C}$ and above.
\end{abstract}

${ }^{*}$ Research sponsored by the Office of Fusion Energy, U.S. Department of Energy, under contract DE-AC05-84OR21400 with Martin Marietta Energy Systems, Inc., and the Japan Atomic Energy Research Institute.

†NKK Corporation Steel Research Center, Alloys and Corrosion Laboratory, Kawasaki, Japin.

†Department of Fuels and Materials Research, Japan Atomic Energy Research Institute, Tokai-mura, Japan. 
However, neutron irradiation at $60^{\circ} \mathrm{C}$ to $7 \mathrm{dpa}$ did not affect the electrochemical properties as measured by the SL-EPR test technique. The reactivation charge of the neutron-irradiated materials increased with increasing irradiation temperature, while increases in the reactivation charge and the Flade potential of the heavy-ion-irradiated material were found up to 10 and 30 dpa, respectively. Optical and scanning electron microscopy (SEM) of the specimen surfaces after SL-EPR testing showed grain-boundary etching and, thus, sensitization for both the heavy-ion-irradiated LS1A and SA and CW PCA irradiated by neutrons at $400^{\circ} \mathrm{C}$ and above. Grain-boundary etching was not observed for the neutron-irradiated type 316 stainless steels. Examination by analytical electron microscopy (AEM) and X-ray microanalysis of both SA and CW PCA irradiated at $420^{\circ} \mathrm{C}$ to $9 \mathrm{dpa}$ in FFTF/MOTA showed that significant radiationinduced segregation (RIS) had occurred at grain boundaries during irradiation. Grain boundaries were depleted in chromium, iron, and molybdenum and enriched in nickel and silicon. Depletion of chromium to apparent levels of 10 to $12 \mathrm{wt} \%$ was observed within $\sim 10-\mathrm{nm}$-wide regions near the grain boundaries. This depletion of chromium at the grain boundaries is the source of the grain-boundary etching and sensitization observed following SL-EPR testing. Surface examination of the specimens also showed grain face attack in the form of pits or dimples for all the materials irradiated by both neutrons and heavy ions at and above $200^{\circ} \mathrm{C}$. Grain face attack was not observed for any of the thermally sensitized control specimens. AEM and X-ray microanalysis indicated that the grain face attack may be related to the chromium depletion by RIS near dislocation loops and voids. Further, because the attack was observed on both neutron- and heavy-ion-irradiated materials, the grain face attack is not an artifact of testing radioactive specimens ( $\gamma$-radiolysis) but rather is characteristic of the changes in electrochemical behavior of the material due to irradiation. Because of grain face attack in addition to grain-boundary attack, the reactivation charge normalized by the total-grain boundary area $\left(\mathrm{P}_{\mathrm{a}}\right)$, a conventionally accepted EPR degree-of-sensitization (DOS) criterion, cannot be used as an indicator of the susceptibility of these irradiated materials to intergranular stress corrosion cracking (IGSCC). The results of SL-EPR testing and $\mathrm{X}$-ray microanalysis for the material irradiated by heavy ions at $515^{\circ} \mathrm{C}$ were similar to those of the materials irradiated by neutrons at $400^{\circ} \mathrm{C}$ and above. Therefore, heavy-ion irradiation (HII) may be a useful method for simulating the RIS caused by neutrons in the temperature range of this study. Further investigations, including stress corrosion cracking tests [e.g., slow strain rate test (SSRT) on the same irradiated materials], are necessary to rigorously correlate the SL-EPR test results obtained in the present study to the IGSCC susceptibility of the materials.

\section{INTRODUCTION}

Irradiation-assisted stress corrosion cracking (IASCC) is one form of intergranular stress corrosion cracking (IGSCC) and is considered a major environmental degradation mechanism for austenitic stainless steels in water-cooled nuclear power systems. ${ }^{1-5}$ IASCC has been observed in austenitic stainless steels and nickel-based alloys exposed to a fast neutron 
(E $>1 \mathrm{MeV}$ ) fluence greater than about $5 \times 10^{20} \mathrm{n} / \mathrm{cm}^{2}$ either in simulated or actual boiling water reactor (BWR) and pressurized water reactor (PWR) envirunments. 1,5 Although the precise mechanism of IASCC is currently not known, one theory suggests that enrichment of impurities, such as phosphorus, sulfur, and silicon, at grain boundaries via radiation-induced segregation (RIS) plays an important role in increasing the susceptibility of stainless steels to IASCC. 4-13 The lower susceptibility (i.e., lesser degree of "sensitization") of high-purity austenitic stainless steels to IASCC supports such a mechanism.7.8 However, chromium depletion at grain boundaries also occurs via RIS and has been suggested as a contributor to IASCC. 6,12-16 The chromium concentration at grain boundaries can be lowered by RIS to below $12 \mathrm{wt} \%$, the minimum chromium level required to form protective passive films on austenitic steel surfaces. ${ }^{14,15}$ In addition to less impurity element segregation, the extent of grain-boundary chromium depletion in high-purity alloys is less consistent than that in commercial-purity alloys. It varies among grain boundaries in a given material and from heat to heat, depending on metallurgical variables such as heat treatment. ${ }^{17,18}$

In the case of water-cooled stainless steel components for fusion reactors, IASCC may also be a degradation mechanism. ${ }^{19,20}$ In this case, RIS characteristics of materials may be different from those in light-water reactors (LWRs) due to different irradiation conditions, e.g., harder neutron spectrum and higher neutron flux for fusion reactors. Prime candidate alloy (PCA) is a titanium-modified austenitic stainless steel developed as a first-wall-andblanket (FWB) material in fusion reactors by the U.S. Fusion Program. Since the PCA was not originally intended for use in high-temperature water environments, the chromium content was reduced, as compared to conventional austenitic stainless steels for nuclear power systems (e.g., type 316 stainless steels), in order to increase the swelling resistance of the alloy. ${ }^{21}$ If PCA is used for water-cooled components in fusion reactors, such as the first wall, limiter, or diverter, the lower chromium content of the alloy may increase the susceptibility of components to radiation-induced corrosion phenomenon (in particular, IASCC).

When evaluating the susceptibility of materials to radiation-induced sensitization, it is important to select appropriate irradiation conditions for experiments because RIS behavior is strongly affected by irradiation temperature, dose rate, and microstructural development. ${ }^{22,23}$ The temperature range over which RIS occurs for a given dose rate is limited: at lower temperatures, RIS is suppressed because lower vacancy mobility results in higher vacancy concentrations and, thus, a higher defect recombination rate; at higher temperatures, RIS is also reduced because larger thermal vacancy concentrations cause increased solute diffusion and, thus, faster back-diffusion of solute atoms, which tends to "anneal" the effects of RIS. The temperature range over which RIS occurs shifts toward higher temperatures with 
increasing dose rate. ${ }^{22,23}$ In the case of fusion reactors, effects of higher helium generation rates, as compared with fission reactors, may also have to be considered. ${ }^{24}$ In order to better simulate the anticipated nuclear environment of a fusion reactor, the spectrally tailored experiment [magnetic fusion energy (MFE)6J/7J] in the Oak Ridge Research Reactor (ORR) was recently completed after reaching the damage level of about $7 \mathrm{dpa} .{ }^{25}$ In this experiment, the dose rate and helium generation rate (He/dpa ratio) of materials were maintained at values typical of components for fusion reactors, e.g., International Thermonuclear Experimental Reactor (ITER) FWB. ${ }^{26}$ The irradiation temperatures in the MFE6J/7J experiment covered typical operating temperatures of both water-cooled components for LWRs ( 288 to $340^{\circ} \mathrm{C}$ ) and ITER (50 to $200^{\circ} \mathrm{C}$ ).

In assessing the effects of RIS on corrosion resistance, it is desirable to develop experimental techniques that utilize miniaturized specimens because of the limited space available in irradiation facilities and the need to minimize radiation exposure of personnel who handle and test specimens. For successful application of experimental techniques to corrosion tests of miniaturized specimens, it is essential that the test methods have sufficient sensitivity to yield meaningful results from small specimen areas. Furthermore, nondestructive corrosion testing techniques that can be applied to specimens suitable for transmission electron microscopy (TEM) are preferable because corrosion properties can be directly related to the microstructure by subsequent analysis of the same specimen.

The single-loop electrochemical potentiokinetic reactivation (SL-EPR) method is a nondestructive, quantitative test technique that evaluates the degree of sensitization (DOS) of austenitic stainless steels associated with chromium depletion near grain boundaries. ${ }^{27-31}$ The SL-EPR technique was developed to detect thermally induced sensitization caused by chromium-rich carbide precipitation at grain boundaries. Thermal sensitization occurs when chromium-rich carbides precipitate and locally deplete the matrix near grain boundaries of chromium during thermal aging at temperatures between 400 and $700^{\circ} \mathrm{C}$. During the SL-EPR test, passivation is accomplished by setting the specimen potential in the passive region and, then, the potential is scanned toward the active region (reactivation) where the passive film is metastable (Fig. 1). The passive film may remain intact only for a limited time in the active region. However, if an austenitic stainless steel has local chromium depletion (e.g., along grain boundaries due to chromium carbide precipitation), then the passive film formed on those areas is generally less stable than that on the average matrix. This situation leads to earlier local breakdown of the passive film and preferential dissolution during the potential scan. ${ }^{30,31}$ The local breakdown is detected as an increase in reactivation current, which accompanies local (e.g., grain-boundary) etching in the region of the chromium 
ORNL-DWG92-5192

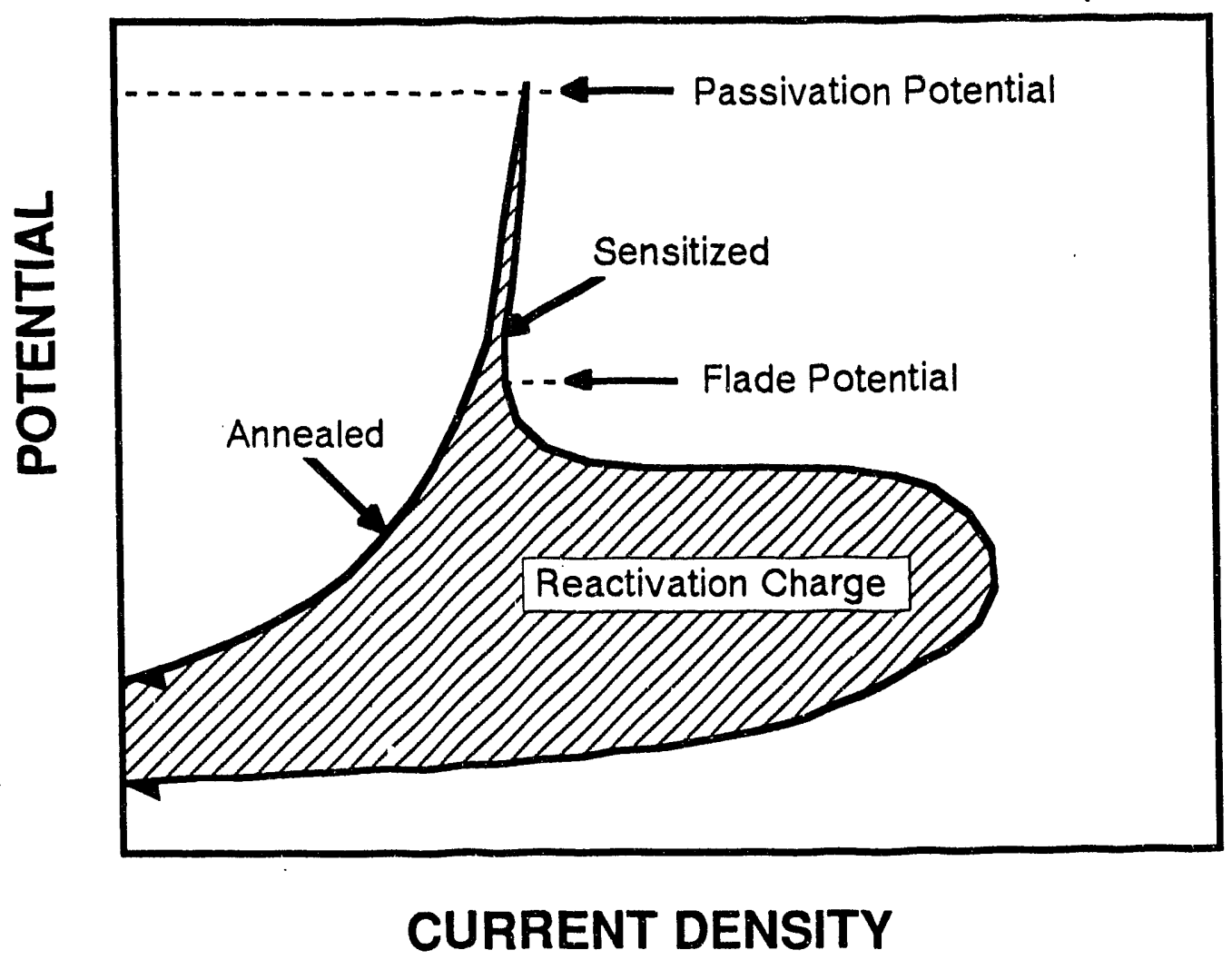

Fig. 1. Schematic of reactivation curves obtained by SL-EPR testing.

depletion (Fig. 1). A conventionally accepted EPR-DOS criterion is the reactivation charge as determined by the integrated area below the reactivation curve (Fig. 1). Since, for thermal sensitization (chromium depletion near grain boundaries), the reactivation current flows only from the area near the grain boundary, the reactivation charge is normalized by the grainboundary area of the tested surface (assuming a fixed depletion width near the grain boundary, usually $\sim 1 \mu \mathrm{m}$ ), and the normalized value is designated as Pa. ${ }^{27.28}$ Sensitized stainless steels show higher $\mathrm{Pa}$ values as compared to annealed (non-sensitized) steels. Previous studies have shown that the SL-EPR method was more sensitive than the conventional wet chemical tests [e.g., Practices A, B, and E of American Society for Testing and Materials (ASTM) Standard A262], particularly for the moderate degrees of sensitization of practical importance for industrial application. ${ }^{27,28,32}$ In the present study, the SL-EPR method was chosen for the detection of chromium depletion in miniaturized specimens. 
Heavy-ion irradiation (HII) has long been utilized to investigate radiation effects (e.g., RIS) and microstruciural evolution under irradiation in materials. ${ }^{22}$ Although the differences in dose rates and prime knock-on atom (PKA) energy spectrum between heavy-ion and neutron irrc liation make it difficult to establish exact correlations between the damage induced by these two different types of irradiation, HII offers the advantage of rapid accumulation of displacement damage $\left(\sim 10^{-3}\right.$ to $\left.10^{-4} \mathrm{dpa} / \mathrm{s}\right)$ as compared to neutron irradiation $\left(<10^{-6} \mathrm{dpa} / \mathrm{s}\right)$ [refs. 33 and 34] and is a convenient technique for both basic research and alloy development. In addition, the HII does not induce significant radioactivity in the material and, therefore, eliminates the complications of specimen handling, testing, and waste disposal associated with neutron-irradiated materials. In heavy-ion-irradiated materials, the total damage range is small $(\sim 1 \mu \mathrm{m})$ and is located within a few microns of the irradiated surface. ${ }^{33,34}$ However, most electrochemical methods are suited to detect the radiation effects in such small volumes of materials because these techniques detect changes in tihe charge transfer reactions occurring at the specimen surface (e.g., for the SL-EPR test, the instability of the surface oxide layer as described above). The combination of electrochemical methods, such as SL-EPR, and HII is well suited to investigate radiation-induced sensitization and other changes in electrochemical properties due to irradiation. In the present study, an electrochemical testing system for miniaturized specimens was developed and validated for thermaliy sensitized materials. The system was then utilized to assess the degree of radiationinduced sensitization associated with chromium depletion by the SL-EPR method for TEM disk specimens of neutron- and heavy-ion-irradiated austenitic stainless steels.

\section{EXPERIMENTAL PROCEDURES}

\subsection{MATERIAL}

The chemical compositions of the austenitic stainless steels used in this study are shown in Table 1. As compared to the two type 316 stainless steels, PCA and LS1A contain more titanium to improve swelling resistance. In the PCA, chromium was reduced and nickel increased to increase the swelling resistance. ${ }^{21}$ These materials were solution annealed (SA) at the conditions shown in Table 1. Cold-worked (CW) samples were also prepared for the PCA and type 316 stainless steels ( 25 and $20 \%$, respectively).

Disk-type specimens, $3 \mathrm{~mm}$ diam by $0.25 \mathrm{~mm}$ thick, were chosen for their availability from irradiation experiments and for ease of specimen preparation for microstructural analysis by TEM/analytical electron microscopy (AEM) after SL-EPR testing. By performing 
Table 1. Chemical composition of austenitic stainless steels studied (wt \%)

\begin{tabular}{|c|c|c|c|c|c|c|c|c|c|c|}
\hline Steel & C & $\mathrm{Si}$ & $\mathrm{Mn}$ & $\mathbf{P}$ & $s$ & $\mathrm{Ni}$ & $\mathrm{Cr}$ & Mo & $T_{i}$ & $\mathrm{Fe}$ \\
\hline $\mathrm{PCA}^{1}$ & 0.05 & 0.4 & 1.8 & 0.01 & 0.003 & 16.2 & 14.0 & 2.3 & 0.24 & bal \\
\hline 316 DO-heat ${ }^{2}$ & 0.05 & 0.8 & 1.9 & 0.01 & 0.016 & 13.0 & 18.0 & 2.6 & 0.005 & bal \\
\hline $316 \mathrm{~N}-\mathrm{lot}^{3}$ & 0.05 & 0.5 & 1.6 & 0.01 & 0.006 & 13.5 & 16.5 & 2.5 & & bal \\
\hline${\operatorname{LS} 1 A^{4}}^{4}$ & 0.08 & 1.0 & 2.0 & & & 13.7 & 16.4 & 1.7 & 0.15 & bal \\
\hline $304 S S^{5}$ & 0.06 & 0.6 & 1.9 & 0.03 & 0.008 & 9.1 & 18.1 & 0.5 & & bal \\
\hline
\end{tabular}

${ }^{1} 1100^{\circ} \mathrm{C}$ for $0.5 \mathrm{~h}$.

${ }^{2} 1050^{\circ} \mathrm{C}$ for $1 \mathrm{~h}$.

${ }^{3} 1050^{\circ} \mathrm{C}$ for $1 \mathrm{~h}$.

${ }^{4} 1150^{\circ} \mathrm{C}$ for $1 \mathrm{~h}$.

$51050^{\circ} \mathrm{C}$ for $1 \mathrm{~h}$.

microstructural analysis on the same specimen after SL-EPR testing, changes in electrochemical properties of the specimen can be directly related to changes in the microstructure. The disk specimens were punched from 0.25 -mm-thick sheets of the materials, and SA specimens were re-annealed before aging or irradiation to remove effects of the punching operation.

Specimens of the PCA, LS1A, and type 316 stainless steels were thermally aged to obtain control data for irradiated specimens and to examine their thermal sensitization behavior. The PCA was aged at $420^{\circ} \mathrm{C}$ for 300,1000 , and $5000 \mathrm{~h}$ and at $550^{\circ} \mathrm{C}$ for 300 and $1000 \mathrm{~h}$, while the LS1A and type 316 stainless steels were aged at $515^{\circ} \mathrm{C}$ for $9 \mathrm{~h}$ and $420^{\circ} \mathrm{C}$ for $5000 \mathrm{~h}$, respectively.

Both resin-mounted specimens meeting the recommendation for the SL-EPR test 28,31 and miniaturized disk specimens were prepared from a thermally sensitized $\left(650^{\circ} \mathrm{C}\right.$ for $\left.2 \mathrm{~h}\right)$ type 304 stainless steel in order to examine the sensitivity of the miniaturized specimen technique as compared to the standard specimen geometry of the SL-EPR technique. The chemical composition of the type 304 stainless steel used for this comparison is also shown in Table 1.

\subsection{IRRADIATION CONDITIONS}

\subsubsection{Fast Flux Test Facility/Materials Open Test Assembly}

The SA PCA, the CW PCA, and the CW type 316 stainless steels were irradiated at $420^{\circ} \mathrm{C}$ to $9 \mathrm{dpa}$. The irradiation was carried out in the Materials Open Test Assembly (MOTA) of the Fast Flux Test Facility (FFTF) in Hanford, Washington, at a dose rate of 
9 by $10^{-7} \mathrm{dpa} / \mathrm{s}$ and He/dpa ratio of 0.4 . The specimens from FFTF/MOTA were selected for the first experiments with neutron-irradiated materials because of their low residual activity. Control specimens were prepared as described in Sect. 2.1 to simulate the thermal history of the irradiated specimens.

\subsubsection{ORR-MFE6J/7J}

In the spectrally tailored experiment in the ORR, 25\% CW PCA was irradiated at 60 , 200,330 , and $400^{\circ} \mathrm{C}$ to 6.9 to $7.4 \mathrm{dpa}$. The dose rate and He/dpa ratio were maintained at values typical for components of fusion reactors, e.g., ITER FWB designs. For example, the dose rate and $\mathrm{He} / \mathrm{dpa}$ ratio at $400^{\circ} \mathrm{C}$ were 1.8 by $10^{-7}$ and 16 (calculated from the data for type 316 stainless steel), ${ }^{25}$ respectively. As compared to the irradiation in FFTF/MOTA, the dose rate was lower by a factor of 5 , while the He/dpa ratio was 40 times higher.

\subsection{HEAVY-ION IRRADIATIONS}

SA specimens of the LS1A were m, unted on a thermally controlled block and irradiated at $515^{\circ} \mathrm{C}$ to 1 to $30 \mathrm{dpa}$ at a dose rate of approximately $10^{-3} \mathrm{dpa} / \mathrm{s}$. The irradiation was done by $4 \mathrm{MeV} \mathrm{Ni}^{++}$, which produces the maximum damage and the maximum concentration of implanted nickel ions at approximately 0.7 and $0.9 \mu \mathrm{m}$ below the original irradiation surface, respectively, as illustrated in Fig. 2. The implanted nickel ions have been reported to work as excess interstitials and reduce void formation. ${ }^{33,34}$ This may also affect RIS to defect sinks. Prior to the SL-EPR testing, the specimens were sectioned to $0.5 \mu \mathrm{m}$ below the original surface by a gravity-flow, vertical-jet electropolishing ${ }^{35}$ so that the region near the maximum damage with the minimum effect of nickel implantation will be exposed during the SL-EPR testing. Control specimens were prepared as described in Sect. 2.1 to simulate the thermal history of the most heavily irradiated specimen.

\subsection{SL-EPR TEST}

Prior to the SL-EPR test, thermally aged and neutron-irradiated specimens were polished to remove surface oxide films and to obtain a smooth surface so as to obtain the maximum electrochemical sensitivity. ${ }^{27,32}$ An electropolishing technique was adopted for the surface preparation because of technical difficulties (e.g., holding the specimen), increased personnel radiation exposure, and spread of contamination resulting from the use of the recommended mechanical polishing technique 28,31 with miniaturized, radioactive specimens. The gravityflow, vertical-jet electropolishing apparatus ${ }^{35}$ was modified for handling radioactive specimens 
ORNL-DWG92-5193
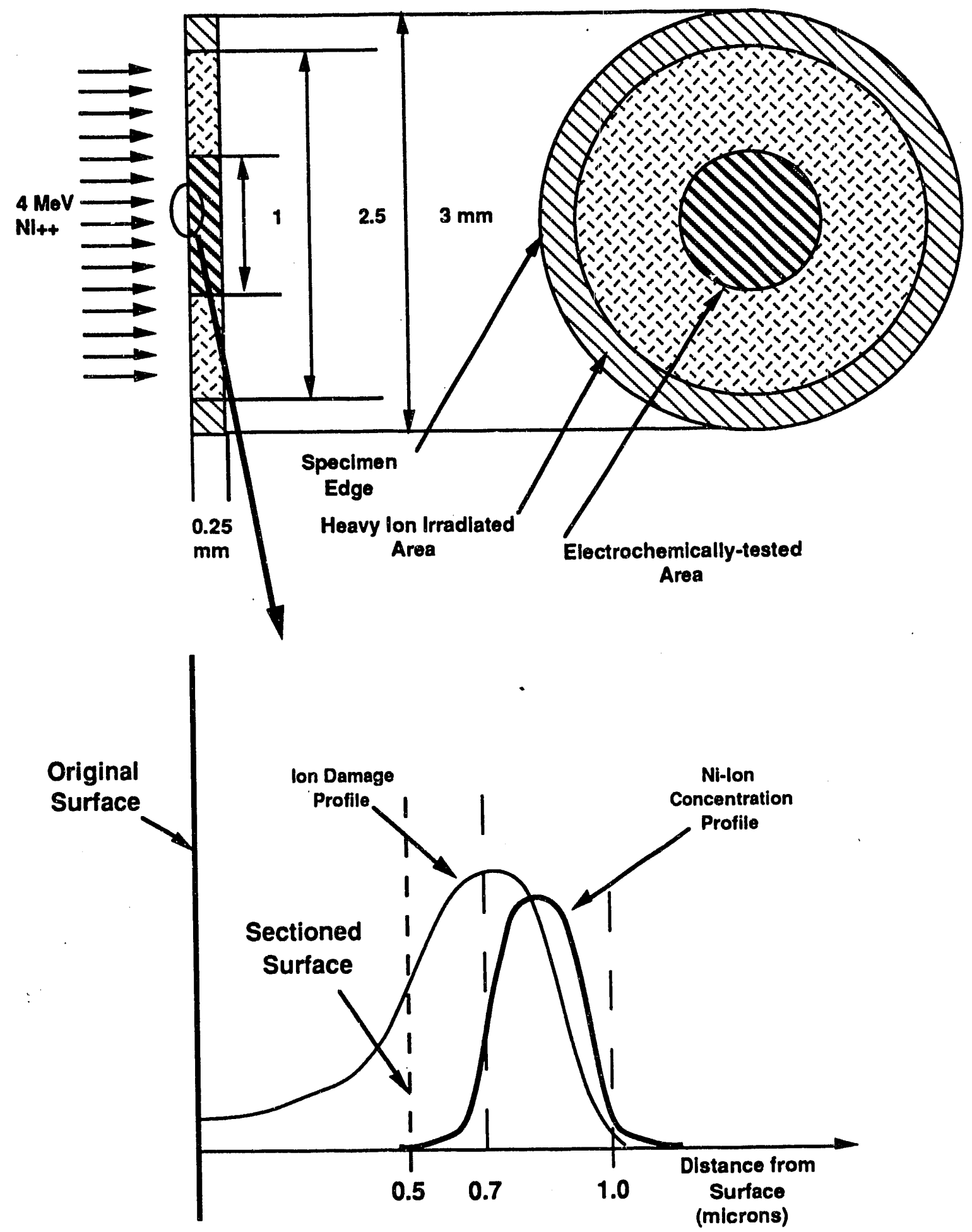

Fig. 2. Schematic of heavy-ion-irradiated specimens. 
and waste electrolyte. The schematic drawing of the modified electropolishing apparatus is shown in Fig. 3. The electrolyte, room-temperature acetic acid, containing $10 \%$ perchloric acid, was carried up to the column above the nozzle by pressurized air to create a vertical steady flow. Specimens were polished at 100 to $120 \mathrm{~V}$ for 180 to $240 \mathrm{~s}$ to remove a surface layer approximately $50 \mu \mathrm{m}$ thick that sometimes showed unusual microstructures (e.g., finer grains, carburization) produced during the specimen manufacturing process. After electropolishing, the specimens were rinsed in methyl alcohol and then acetone prior to testing. For comparison with electropolished surfaces, tests were also conducted on thermally aged control specimens, which were mechanically polished with $0.05-\mu \mathrm{m}$ alumina slurry, and then rinsed in methyl alcohol and acetone.

The schematic diagram of the electrochemical testing system is shown in Fig. 4. The system consists of the potential/current measurement system, the polarization cell, and the specimen holder. The measurement system is an EG\&G model 273/342, computer-controlled potentiostat/galvanostat with current resolution of $100 \mathrm{~Pa}$. The polarization cell was constructed as specified in ASTM Standard G5-87 and modified to have an exterior cooling jacket for temperature control by circulating temperature-controlled water. The remotely operated electric drain systems, salt bridge/calomel reference electrode adjusting system, and test solution supply/cell rinsing system were installed to minimize personnel exposure during handling of radioactive specimens and waste. Photographs of the testing system assembled in a hood and the polarization cell are shown in Figs. 5 and 6, respectively.

To perform an experiment, an electrochemically polished specimen was mounted in the holder, which allows the specimen to serve as the working electrode. A platinum plate $\left(4 \mathrm{~cm}^{2}\right)$ was used for the counter electrode. The method for mounting the specimens on the holder is shown in Fig. 7. The specimen holder was made of acrylic and silicone rubber for resistance to the sulfuric acid electrolyte recommended for the SL-EPR test. Specimens were placed on a platinum lead wire protruding through the silicone rubber "specimen bed" on the body of the specimen holder. A hinged face plate with a silicone rubber seal containing a 2-mm-diam hole was pressed down onto the specimen and specimen holder body. This promoted contact of the specimen with the platinum lead wire and sealed the edges of the specimen. Only the central $2-\mathrm{mm}$-diam area of specimen $\left(0.0314 \mathrm{~cm}^{2}\right)$ was exposed to the electrolyte during the SL-EPR tests. A photograph of the specimen holder and specimen loading stand is shown in Fig. 8.

SL-EPR tests were performed following the test conditions recommended by Clarke et al., ${ }^{28}$ and these are summarized in Table 2 . A reactivation scan rate of $6 \mathrm{~V} / \mathrm{h}$ was normally used; however, in order to increase the sensitivity of the technique, it was necessary 
ORNL-DWG 89-18529

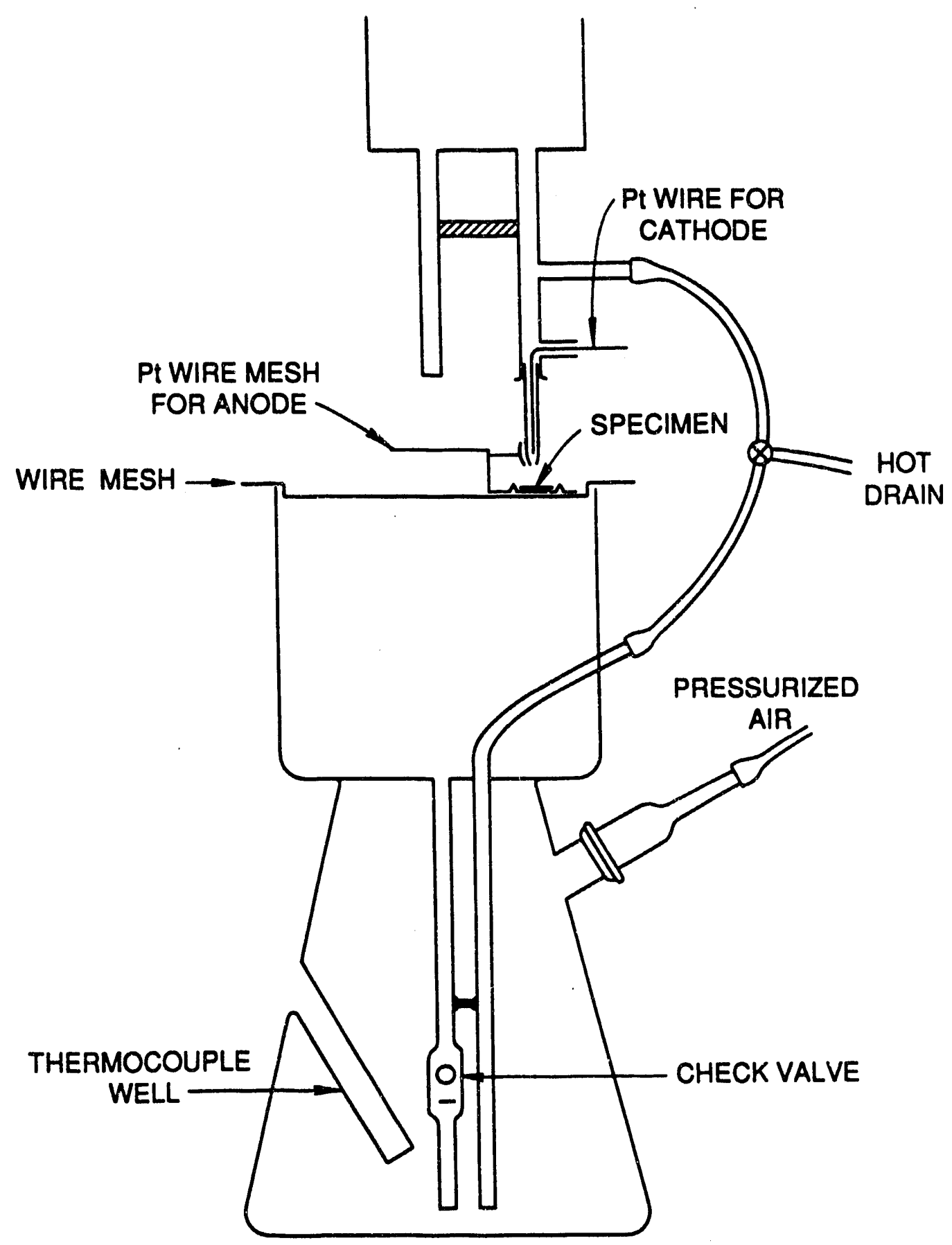

Fig. 3. Electropolishing apparatus for specimen surface preparation. 
ORNL-DWG 88M-17042

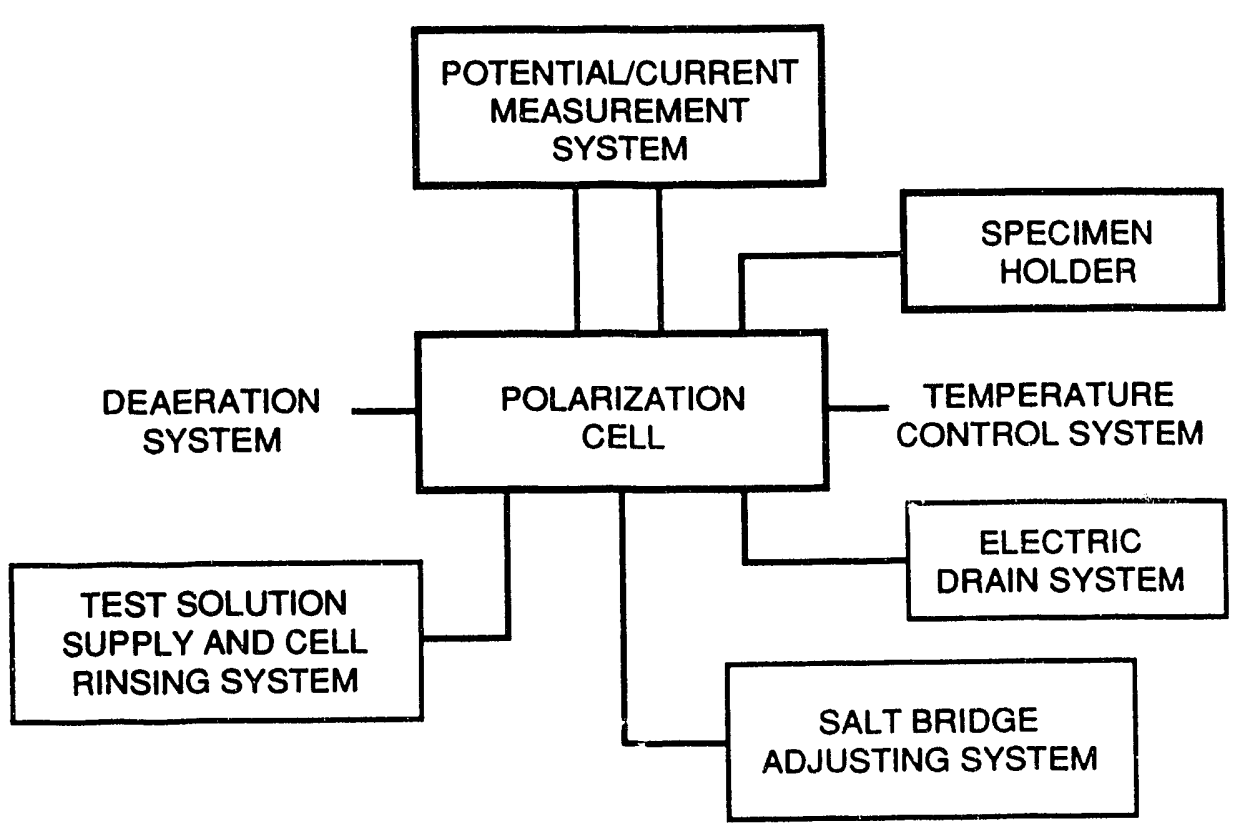

Fig. 4. Schematic diagram of the electrochemical testing system.

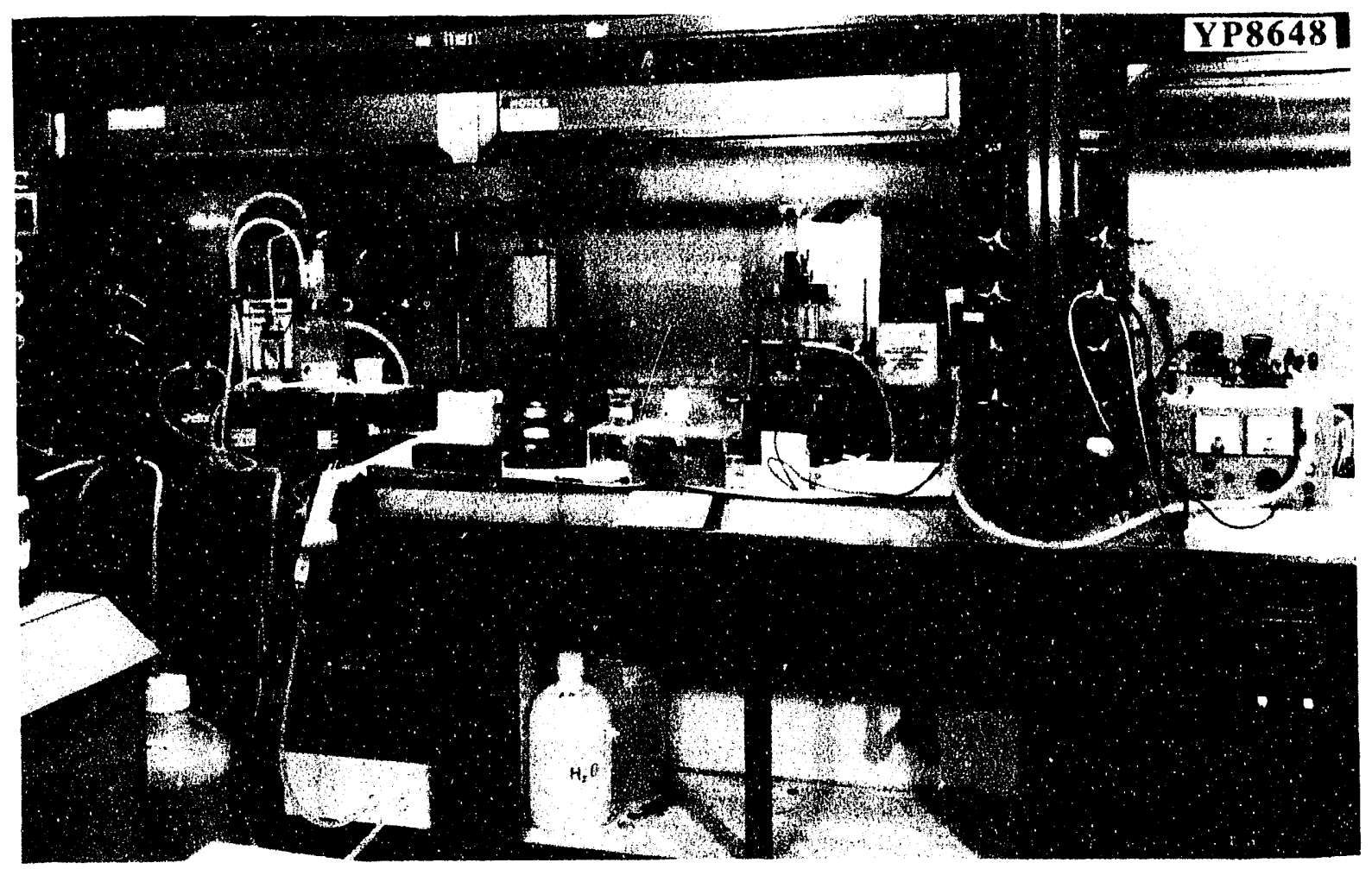

Fig. 5. Electrochemical testing system assembled in a ventilation hood. 


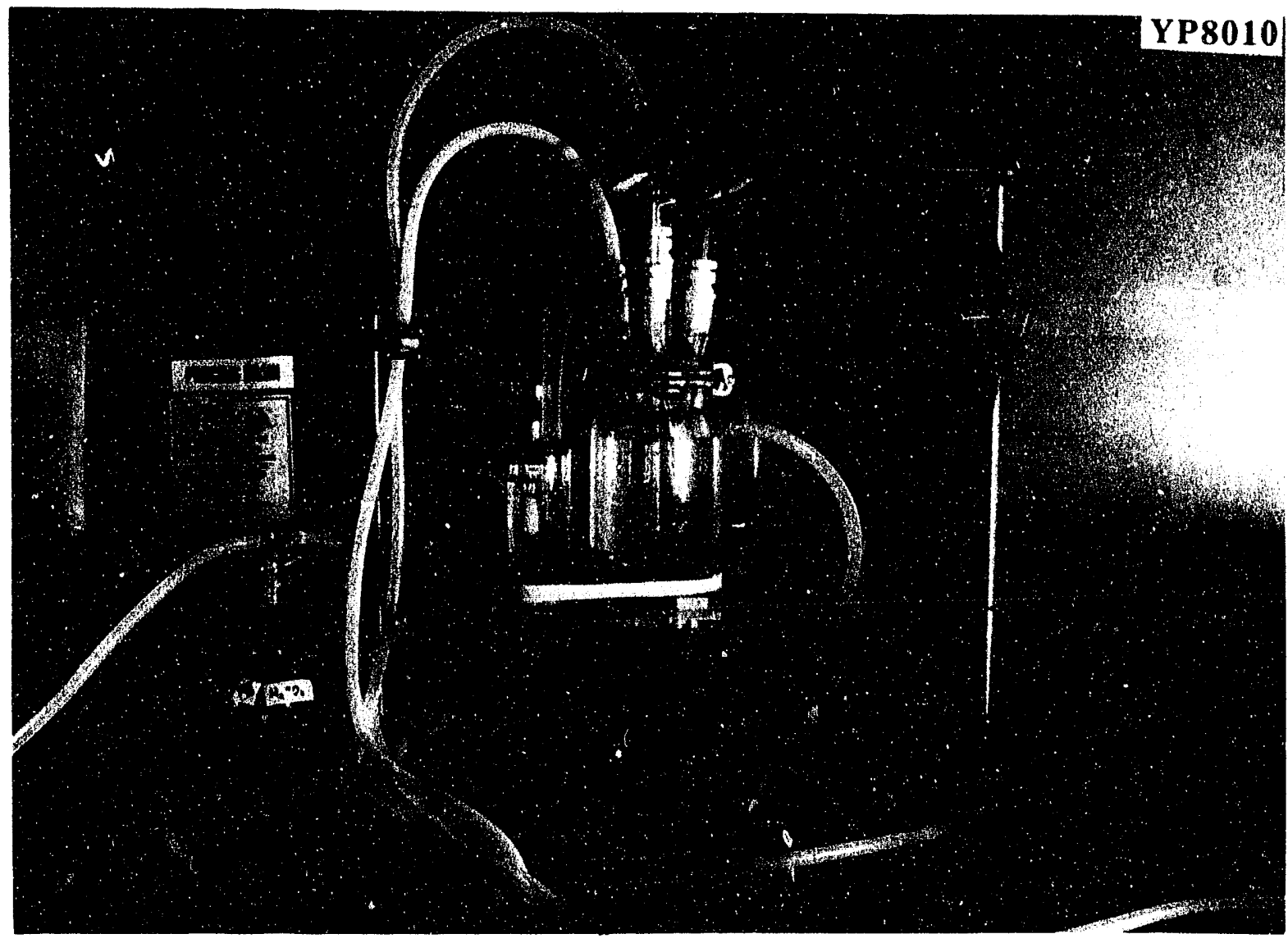

Fig. 6. Constant-temperature polarization cell.

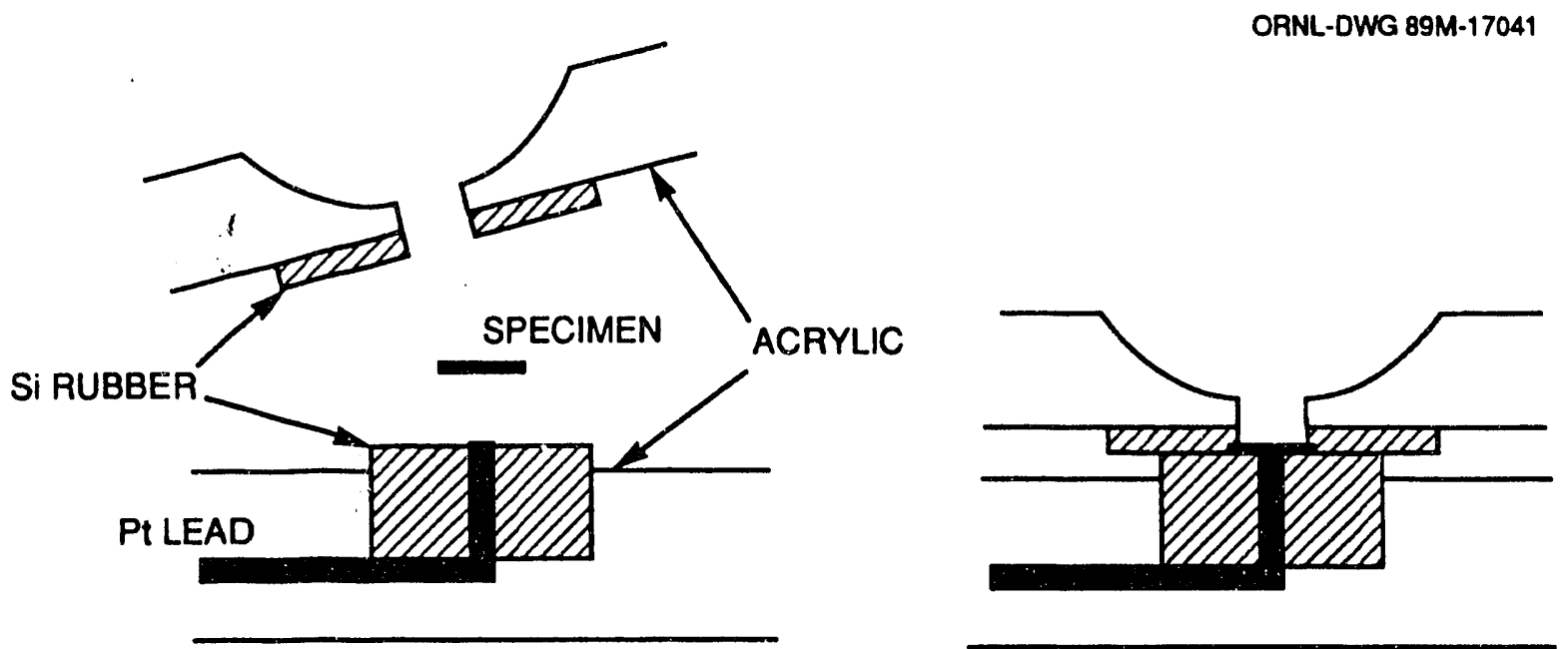

Fig. 7. Method for mounting disk specimens. 


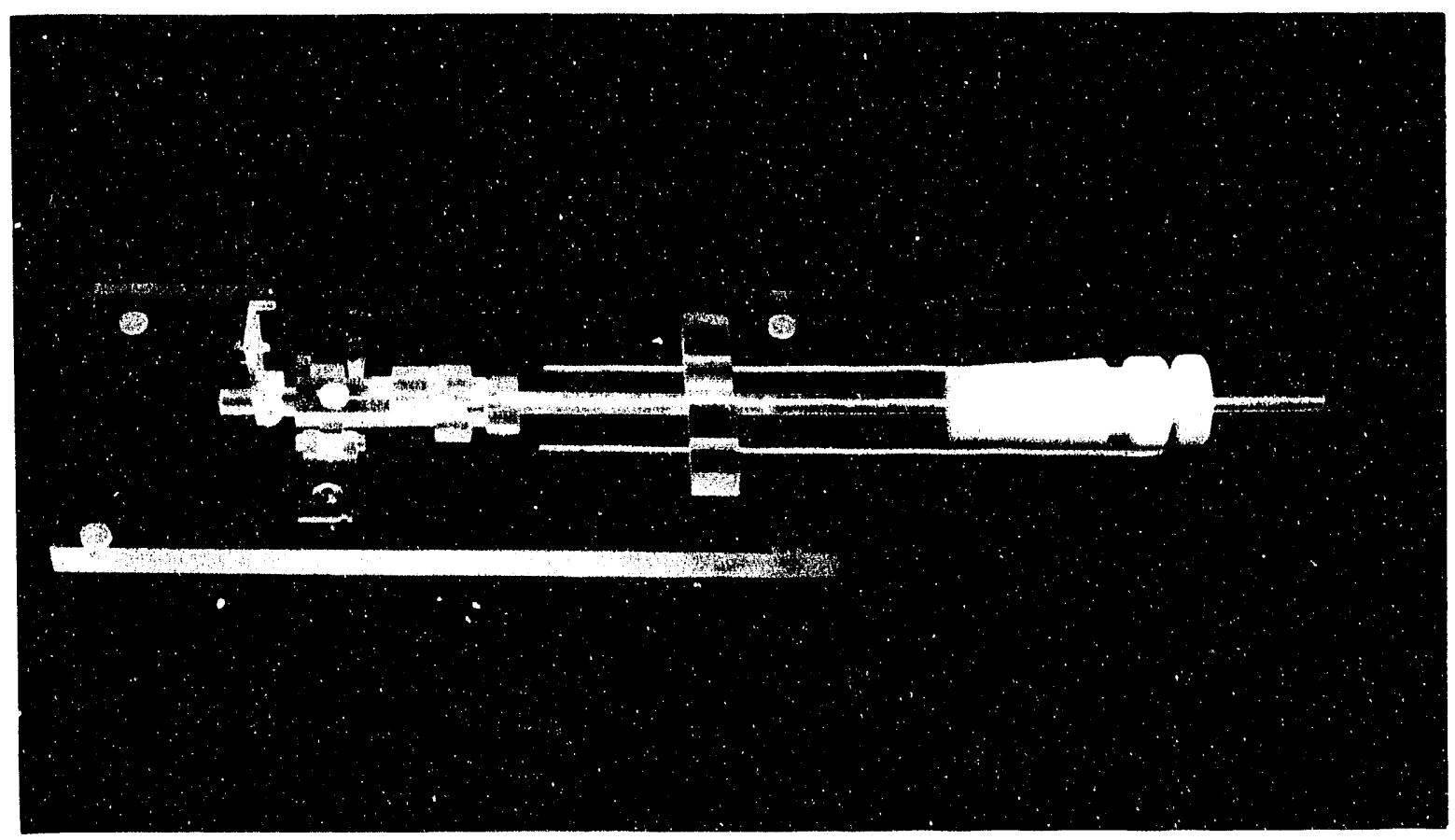

Fig. 8. Specimen holder and loading stand.

Table 2. SL-EPR test conditions

\begin{tabular}{ll}
\hline Test solution & $0.5 \mathrm{M} \mathrm{H}_{2} \mathrm{SO}_{4}+0.01 \mathrm{M} \mathrm{KSCN}$ \\
Temperature & $30^{\circ} \mathrm{C}$ \\
Surface preparation & Electropolishing \\
Surface conditioning & $120 \mathrm{~s}$ at $-600 \mathrm{mV}$ versus SCE \\
Passivation & $120 \mathrm{~s} \mathrm{at}+200 \mathrm{mV}$ versus SCE \\
Reactivation scan & $+200 \mathrm{mV}$ versus SCE \\
& to $-50 \mathrm{mV}$ versus Ecorr \\
Reactivation scan rate & $6 \mathrm{~V} / \mathrm{h}, 3 \mathrm{~V} / \mathrm{h}$
\end{tabular}


to use a scan rate of $3 \mathrm{~V} / \mathrm{h}$ for the case of the specimens from ORR-MFE6J/7J. The reactivation current was recorded during the potential scan from $+200 \mathrm{mV}$ (versus SCE) toward the iritial corrosion potential. The DOS was determined by calculating the normalized reactivation charge, $\mathrm{Pa}$, as described above. ${ }^{28}$

\subsection{SURFACE EXAMINATION AND MICROSTRUCTURAL ANALYSIS}

Specimen surfaces after SL-EPR testing were examined with both optical microscopes and scanning electron microscopes (SEMs) to determine the morphology of sensitization. Subsequently, several specimens were prepared for TEM and AEM by electropolishing at $-10^{\circ} \mathrm{C}$ in 10:6:1 methanol:butyl cellusolve:perchloric acid solution. Microstructural analysis was performed in a Philips EM400T field-emission gun (FEG) with a field-emission source. Grain-boundary composition was measured by energy dispersive X-ray spectroscopy (EDS) with a probe size of 1 to $2 \mathrm{~nm}$ in the scanning transmission electron microscopy (STEM) mode. 36

\section{EXPERIMENTAL RESULTS}

\subsection{DETECTION OF THERMALLY INDUCED SENSITIZATION}

Figure 9 shows reactivation curves of a thermally sensitized $\left(650^{\circ} \mathrm{C}\right.$ for $\left.2 \mathrm{~h}\right)$ type 304 stainless steel for resin-mounted and miniaturized disk-type specimens mechanically polished with 1000-grit SiC papers prior to the SL-EPR tests. Both specimens showed similar reactivation peaks resulting from the sensitizing heat treatment. The peak current density and the Flade potential (the potential at which the current started increasing as shown in Fig. 1) were essentially the same for both specimens. These results indicate that thermal sensitization can be evaluated using the miniaturized specimen technique with the same level of sensitivity as the standard test technique (i.e., larger specimen areas).

The effects of the electropolished surface finish were examined for the aged PCA alloy. An example of the results for the SA PCA aged at $550^{\circ} \mathrm{C}$ for $1000 \mathrm{~h}$ is shown in Fig. 10. The peak current density and the Flade potential were the same after electropolishing or the recommended mechanical polishing $\left(0.05-\mu \mathrm{m}\right.$ alumina slurry). ${ }^{28}$ No significant differences between the two reactivation curves were noted, and similar results were obtained for the other aging conditions. These results indicate that, under the conditions used, electropolishing 


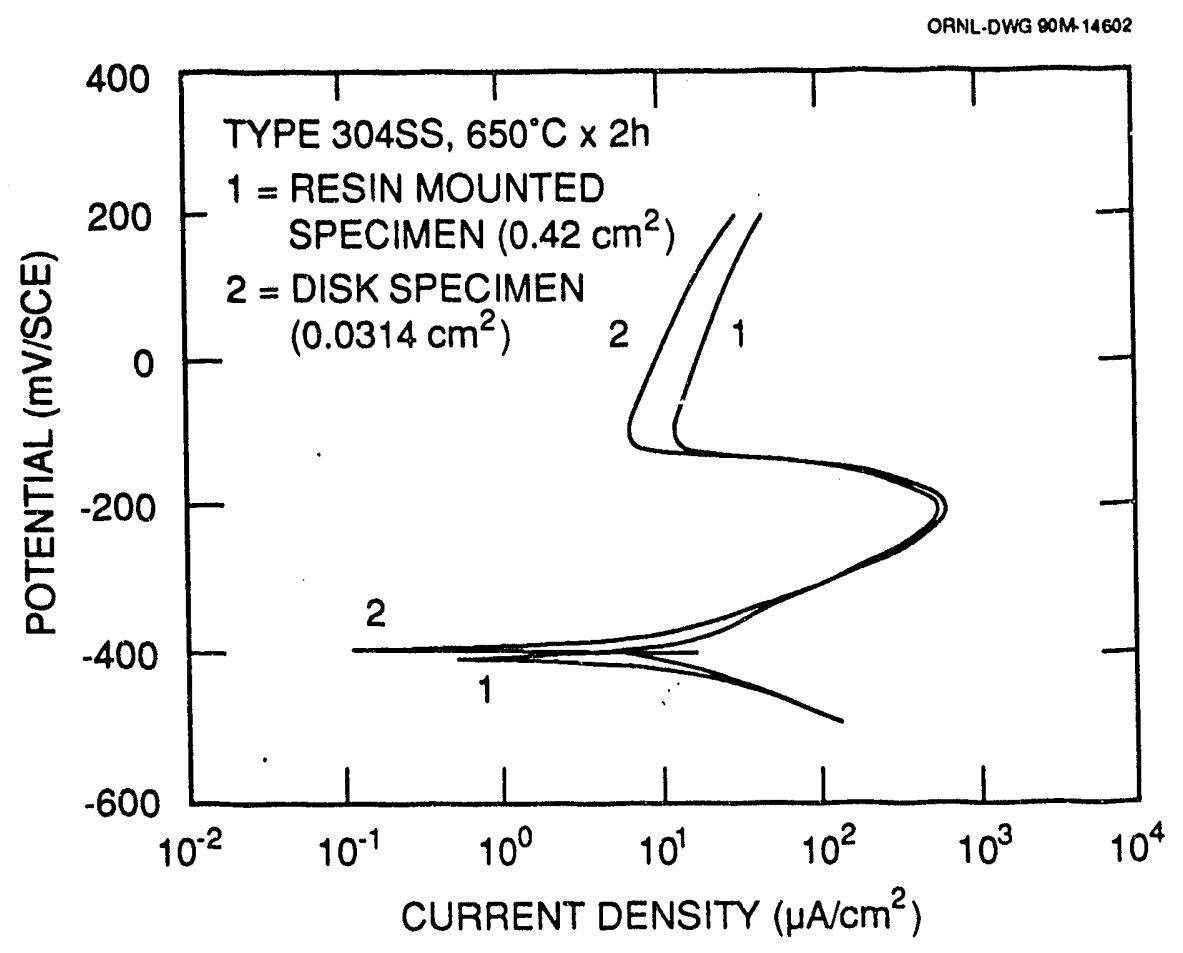

Fig. 9. Comparison of SL-EPR test results for resin-mounted specimen and miniaturized disk specimen of thermally sensitized type 304SS $\left(650^{\circ} \mathrm{C} \times 2 \mathrm{~h}\right)$.

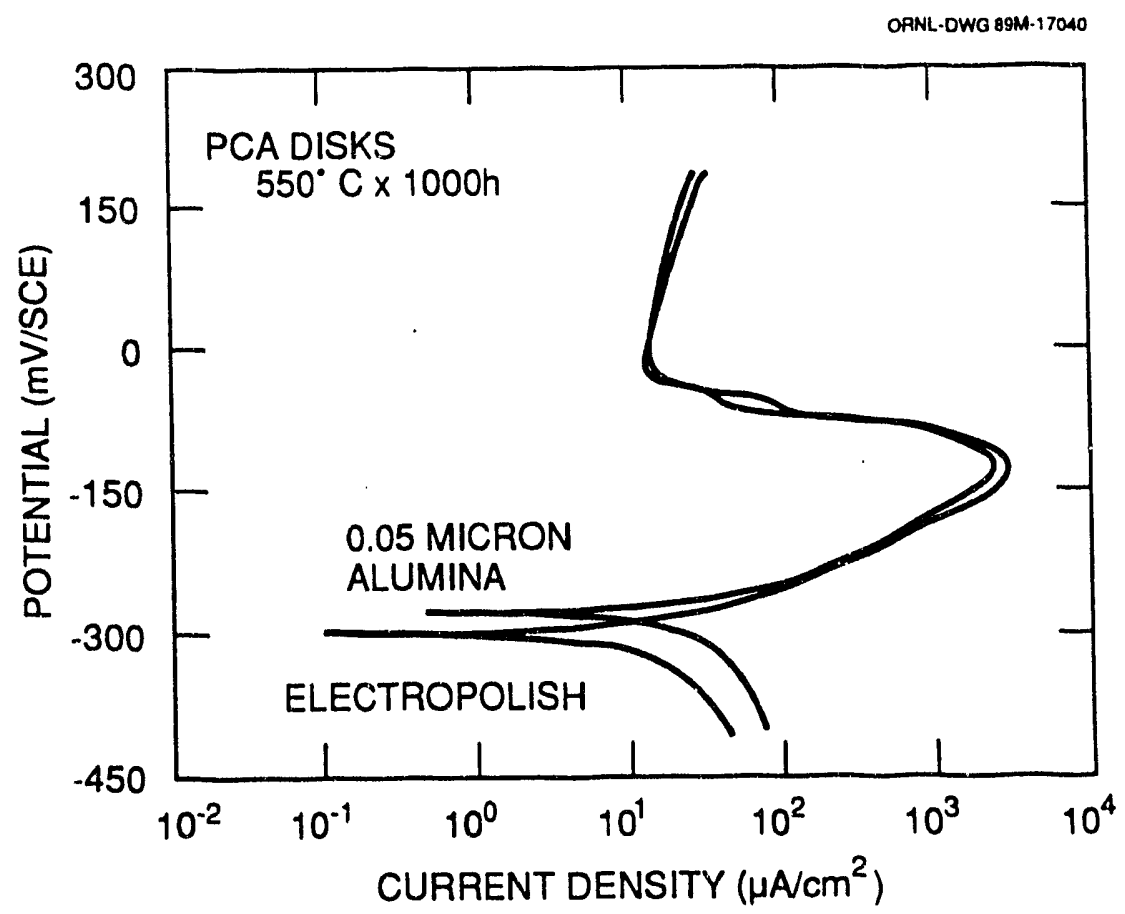

Fig. 10. Comparison of SL-EPR test results for mechanically polished and electropolished thermally sensitized PCA. 
yielded the same results as the recommended mechanical polishing for SL-EPR testing thermally sensitized material.

Reactivation curves for the SA and aged PCA are shown in Fig. 11. The peak current density for the specimen aged at $550^{\circ} \mathrm{C}$ for $1000 \mathrm{~h}$ was approximately two orders of magnitude higher than that of the SA specimen, and the Flade potential was also higher. There was no significant difference in reactivation behavior between the specimen aged at $420^{\circ} \mathrm{C}$ for $5000 \mathrm{~h}$ and the SA specimen. The reactivation charges normalized by grainboundary area of the tested surface, $\mathrm{Pa}$ (coulombs $/ \mathrm{cm}^{2}$ ), were calculated for the specimens tested and are plotted versus aging time in Fig. 12. The Pa value of the SA PCA was significantly increased by aging at $550^{\circ} \mathrm{C}$ for $1000 \mathrm{~h}$, while $\mathrm{Pa}$ was not affected by aging at $420^{\circ} \mathrm{C}$ up to $5000 \mathrm{~h}$. Therefore, any observed increase in Pa for the irradiated PCA in this study is purely the result of irradiation and not a thermal aging effect.

\subsection{EVALUATION OF SENSITIZATION INDUCED BY NEUTRON IRRADIATION}

\subsubsection{Specimens from the FFTF/MOTA Irradiation}

\subsubsection{SL-EPR Test}

Reactivation curves of the irradiated and thermally aged control specimens are shown for the SA PCA and CW PCA in Fig. 13. The reactivation current density peak for all specimens appeared at approximately $-120 \mathrm{mV}$ versus SCE. However, the peak current densities for the irradiated specimens were approximately three orders of magnitude higher than those of the thermally aged specimens for both the SA and CW conditions. There was no significant difference between the reactivation curves for the $\mathrm{SA}$ and $\mathrm{CW}$ conditions, although the $\mathrm{CW}$ specimens consistently exhibited a higher Flade potential. The Flade potentials were substantially higher for the irradiated specimens as compared to those of thermally aged specimens (by approximately 75 and $125 \mathrm{mV}$ for the $\mathrm{SA}$ and $\mathrm{CW}$ conditions, respectively).

The reactivation charge normalized by grain-boundary area $\left[\mathrm{Pa}\left(\right.\right.$ coulombs $\left.\left./ \mathrm{cm}^{2}\right)\right]$ was calculated for each specimen of the SA PCA and CW PCA, and the results are shown in Table 3. The $P a$ values of the irradiated specimens were more than two orders of magnitude higher than those of the thermally aged control specimens for both the SA and CW conditions. There was no significant difference in the $\mathrm{Pa}$ values between the $\mathrm{SA}$ and $\mathrm{CW}$ conditions. The $\mathrm{Pa}$ measured for each of two specimens in each condition (SA and $\mathrm{CW}$ ) were in good agreement, and reactivation curves for each specimen were reproducible within experimental error limitations. 


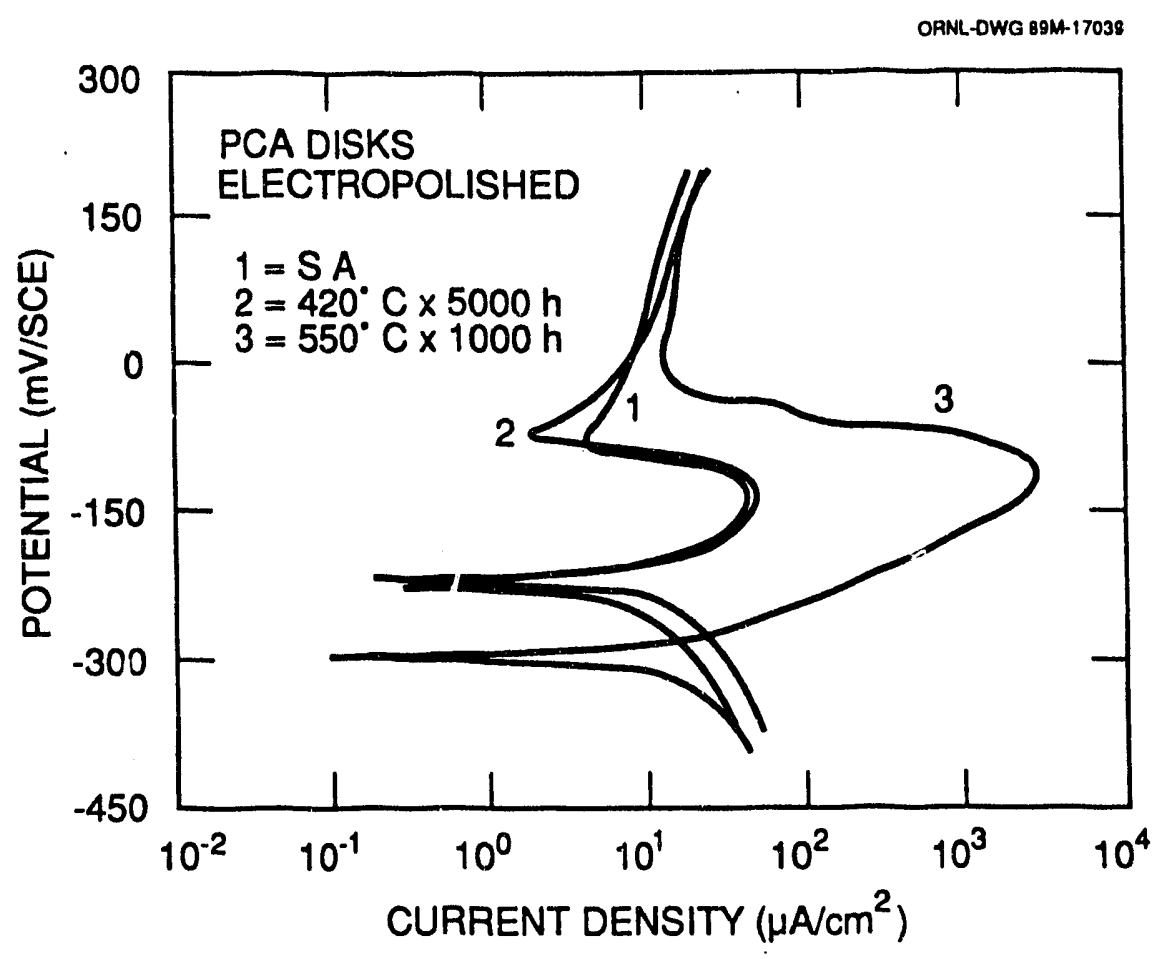

Fig. 11. Reactivation curves for thermally aged SA PCA.

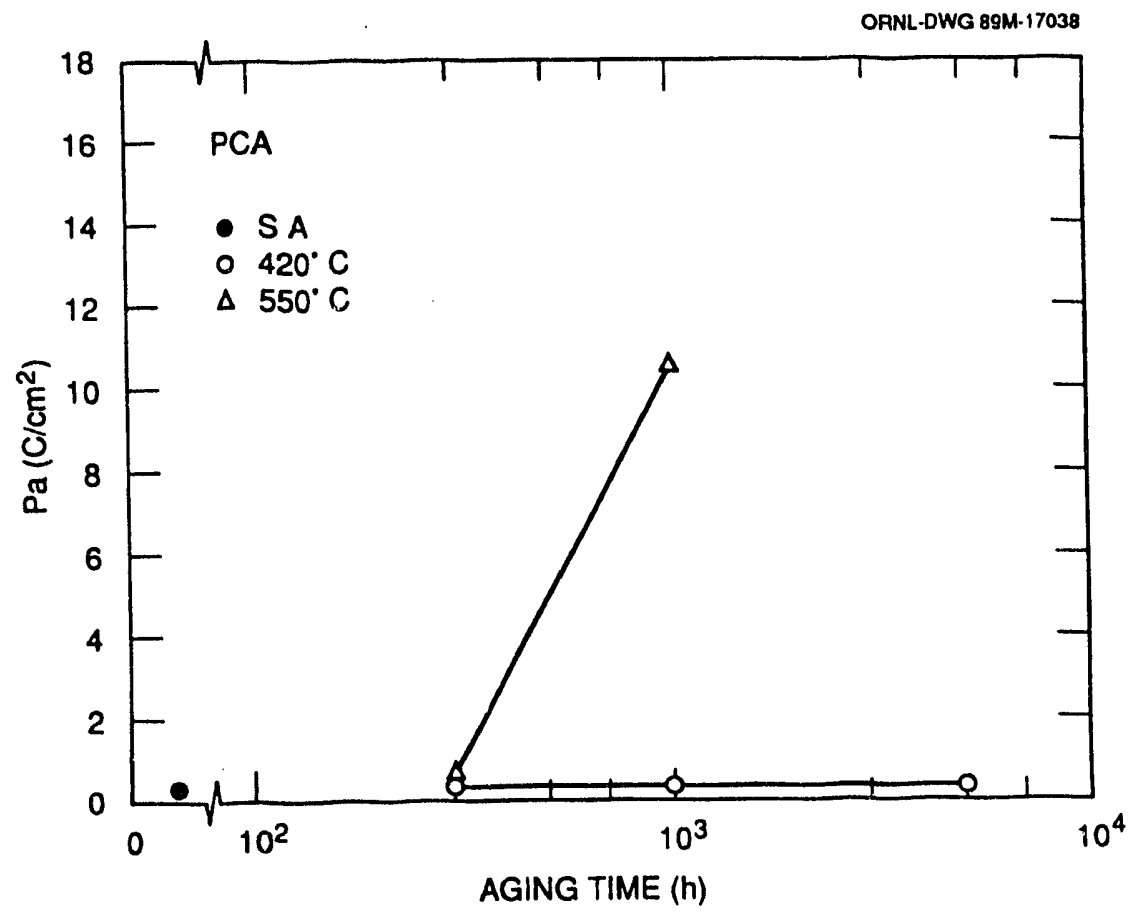

Fig. 12. DOS of PCA as a function of aging time. 


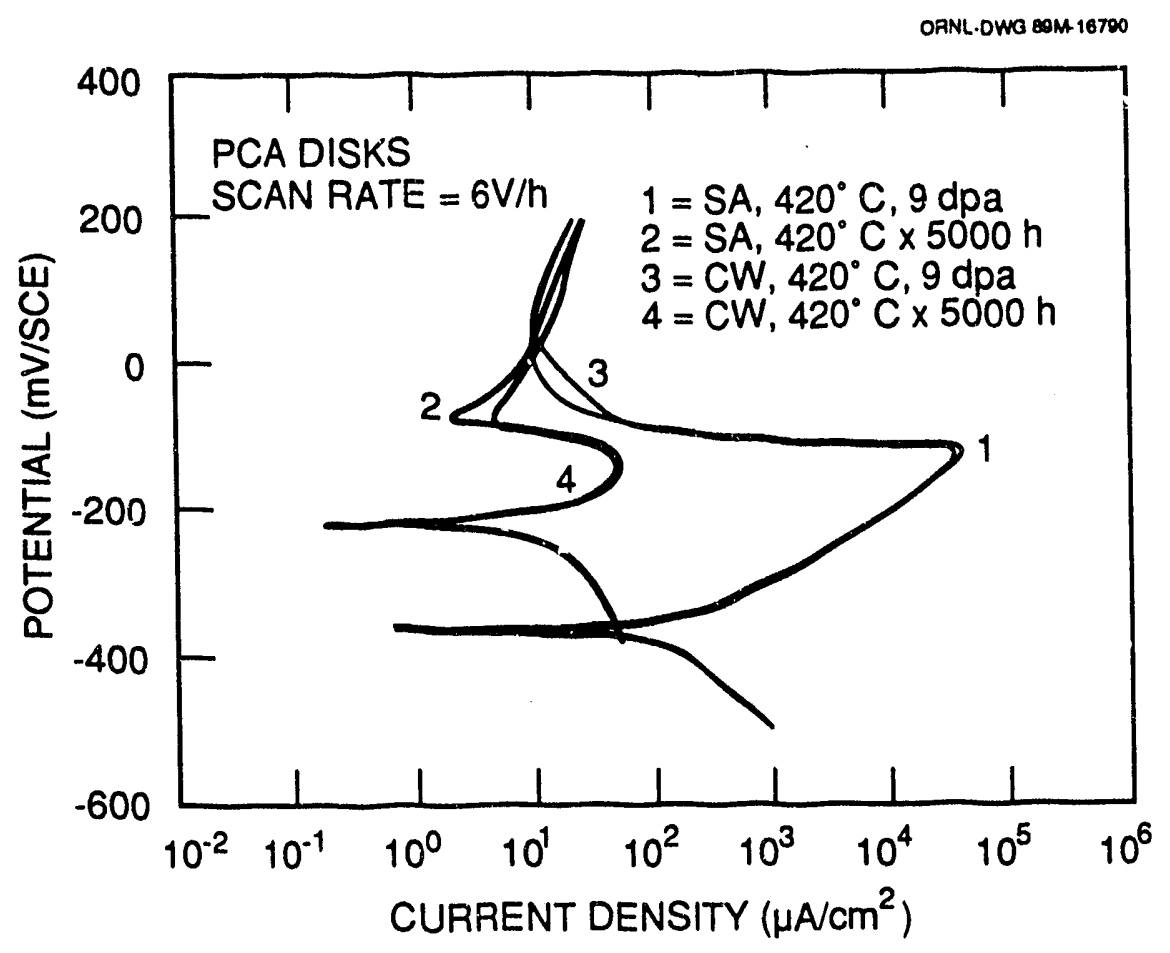

Fig. 13. Reactivation curves of PCA irradiated in FFTF/MOTA at $420^{\circ} \mathrm{C}$ to $9 \mathrm{dpa}$.

Table 3. Reactivation charge value $(\mathrm{Pa})$ normalized by total grain-boundary area

\begin{tabular}{|c|c|c|}
\hline \multirow[b]{2}{*}{ Steel } & \multicolumn{2}{|c|}{$\mathrm{Pa}$ coulombs $/ \mathrm{cm}_{2}$} \\
\hline & Aged* & Irradiated \\
\hline PCA solution annealed & 0.14 & $\begin{array}{l}64.1 \\
59.9\end{array}$ \\
\hline PCA $25 \%$ cold worked & 0.24 & $\begin{array}{l}53.0 \\
54.0\end{array}$ \\
\hline
\end{tabular}

*Average value of two specimens aged at $420^{\circ} \mathrm{C}$ for $5000 \mathrm{~h}$. 
Reactivation curves for the CW 316 DO-heat are shown in Fig. 14. A reactivation current density peak appeared for the irradiated material, while the thermally aged material did not exhibit such a peak during SL-EPR testing. Figure 15 shows the reactivation curve of the irradiated CW $316 \mathrm{~N}$-lot with the results of the irradiated CW 316 DO-heat and CW PCA. The peak current densities and the Flade potentials were apparently lower for the 316 DO-heat and $316 \mathrm{~N}$-lot as compared to the CW PCA. The 316 DO-heat showed the lowest peak current density and Flade potential of these similarly irradiated steels.

\subsubsection{Surface Examination}

Optical micrographs of the SA PCA and CW PCA specimen surfaces after SL-EPR testing are shown in Figs. 16 and 17, respectively. Thermally aged PCA showed no etching in either the SA or CW condition [Figs. 16(a) and 17(a)]. On the other hand, the irradiated specimens were etched in both conditions [Figs. $16(b)$ and $17(b)$ ]. The irradiated SA PCA showed etching along grain boundaries and a very fine etched structure in grain faces [Fig. 16(b)]. The CW PCA showed similarly etched grain boundaries, grain faces, and some etched slip lines [Fig. 17(b)]. Similar grain face etching was observed for the irradiated CW 316 DO-heat and $316 \mathrm{~N}$-lot after SL-EPE testing, but grain-boundary etching was not observed [Fig. 18].

SEM micrographs of the specimen surface afer SL-EPR testing are shown for the irradiated SA PCA in F:g. 19. The grain-boundary etching was discontinuous, and the width of the etching was not uniform [Fig. 19(a)]. It appears that the finely etched structure observed on the grain faces [Figs. $16(b)$ and $17(b)$ ] resulted from corrosion-induced dimpling with an average dimple diameter of $0.5 \mu \mathrm{m}$ [Fig. 19(b)]. The depth of etching associated with dimpling was much less than that at the grain bcundaries. The width of the etched grain boundaries was approximately $1 \mu \mathrm{m}$ at the widest portion and narrowed to less than $100 \mathrm{~nm}$ near the bottom [Fig. 19(c)]. An SEM micrograph of the irradiated CW PCA is shown in Fig. 20. The grain-boundary etching and dimpiing over grain faces were also observed for the CW specimen.

Figure 21 shows a specimen surface of the irradiated SA PCA after interrupting the SL-EPR test at halfway to the peak currerit density. Initiation of fine etching was observed in grain faces, while grain-boundary etching was not observed yet. The dimple-shape etching of the grain faces apparently results from the continuing increase in density of this fine etching. Initiation of passive film instability and the formation of the fine etching indicates the presence of local chromium depletion in the matrix. 


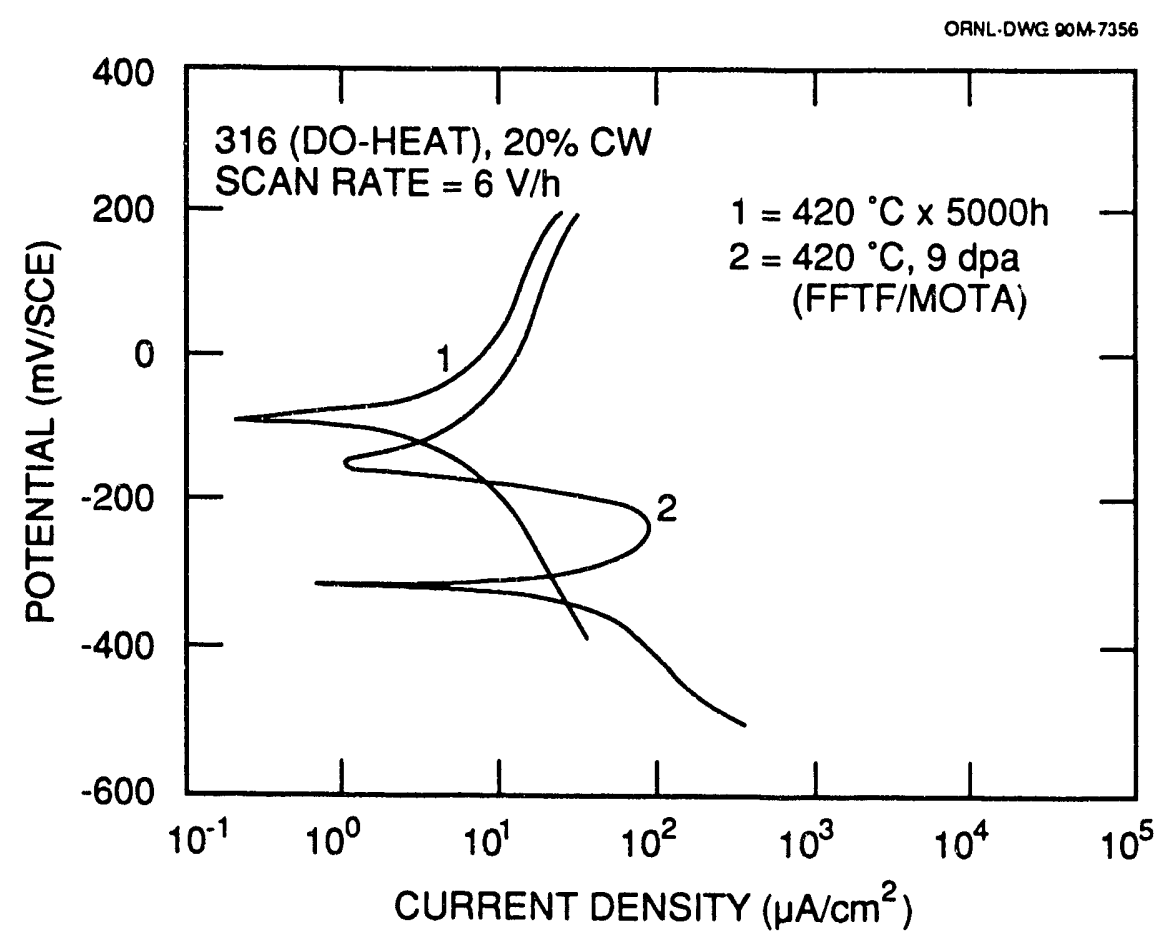

Fig. 14. Reactivation curve of $20 \% \mathrm{CW} 316 \mathrm{DO}$-heat irradiated in FFTF/MOTA at $420^{\circ} \mathrm{C}$ to $9 \mathrm{dpa}$.

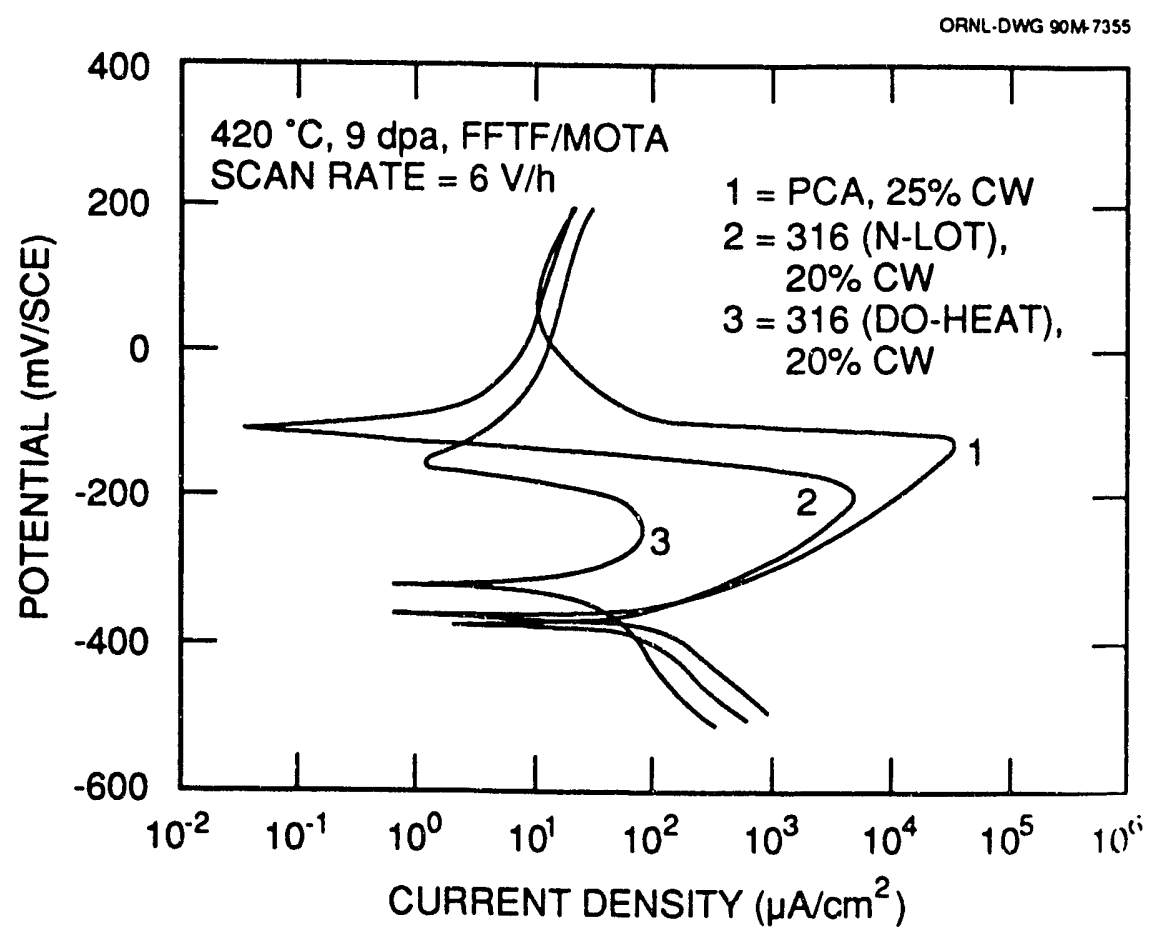

Fig. 15. Reactivation curves of $20 \%$ CW $316 \mathrm{~N}$-lot, $310(\mathrm{~K})$ heat and $25 \% \mathrm{CW}$ PCA irradiated in FFTF/MOTA at $420^{\circ} \mathrm{C}$ (10) (1p:t. 


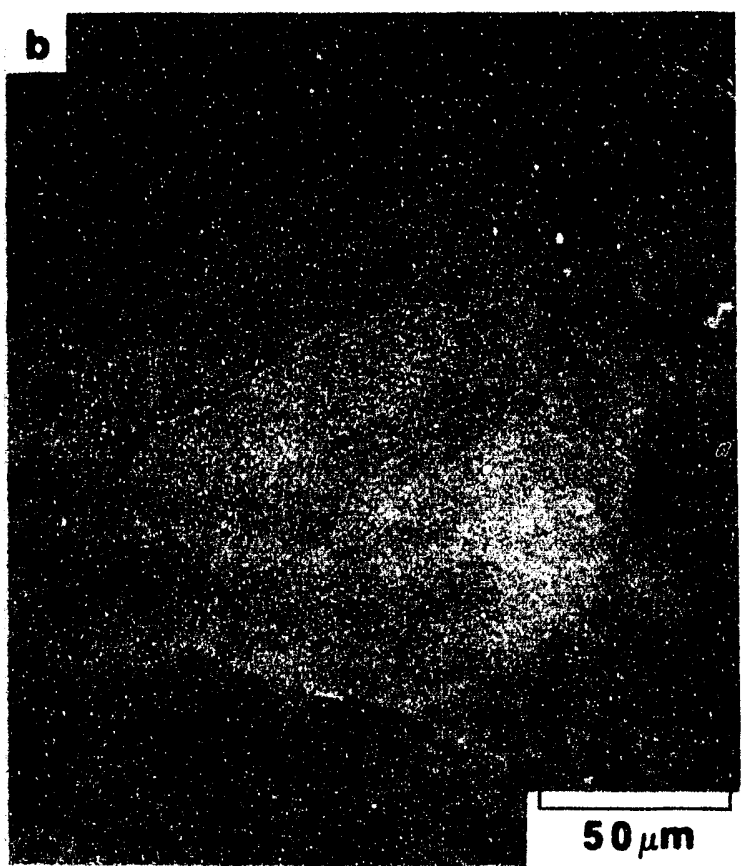

Fig. 16. Optical micrographs of SA PCA after SL-EPR tests: (a) thermally aged and $(b)$ neutron irradiated.

ORNI-PHOTO 6317-90

2

:

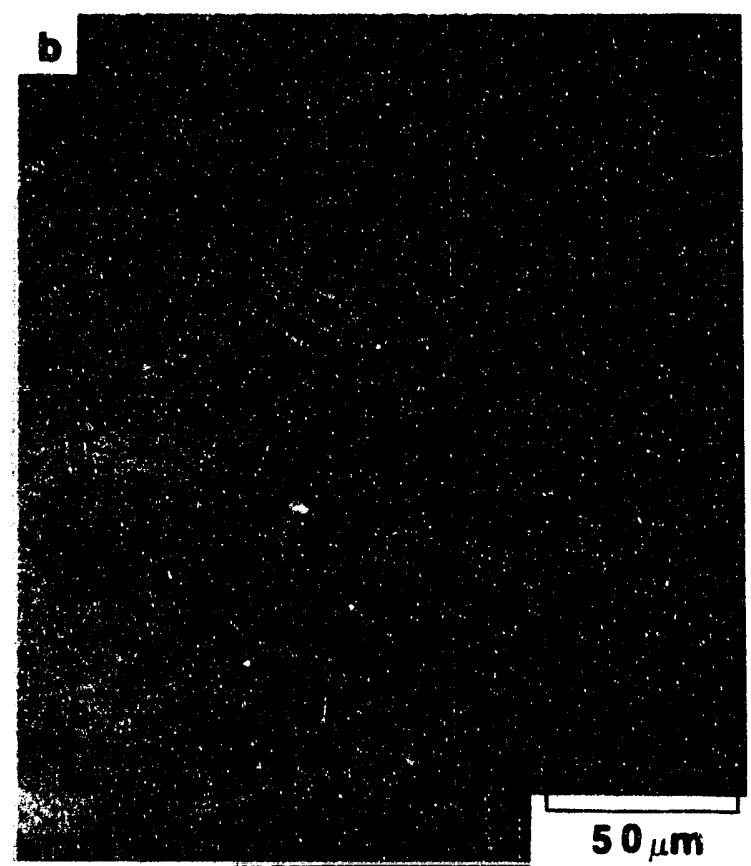

Fig. 17. Optical micrographs of $25 \%$ CW PCA specimen surfaces after SL-EPR tests: $(a)$ thermally aged and $(b)$ neutron irradiated. 


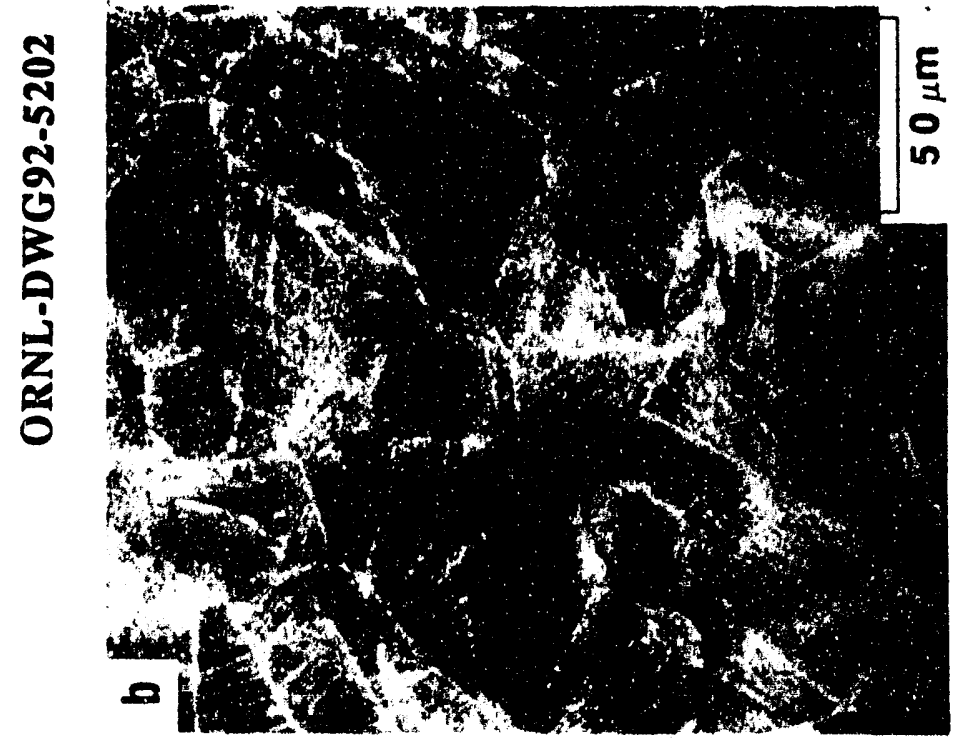

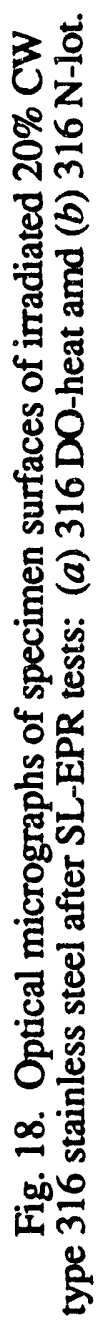


ORNI PHOTO 6318-90.

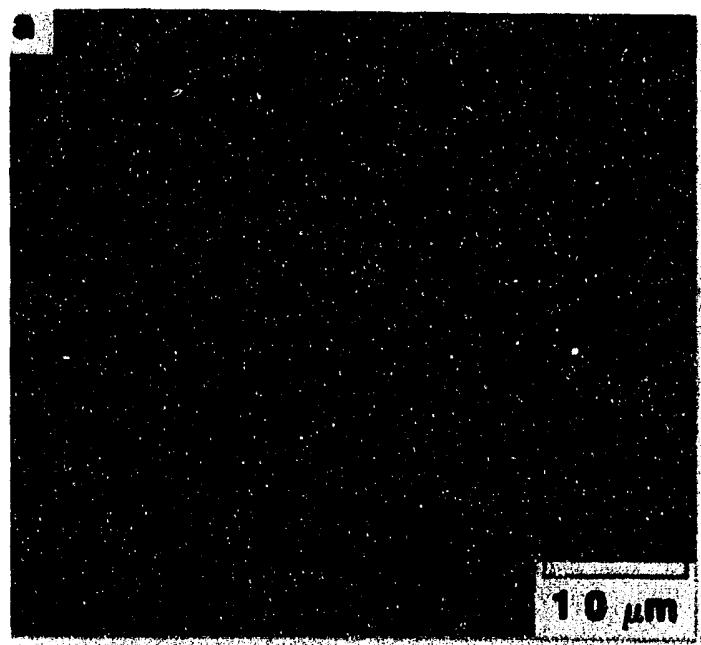

b

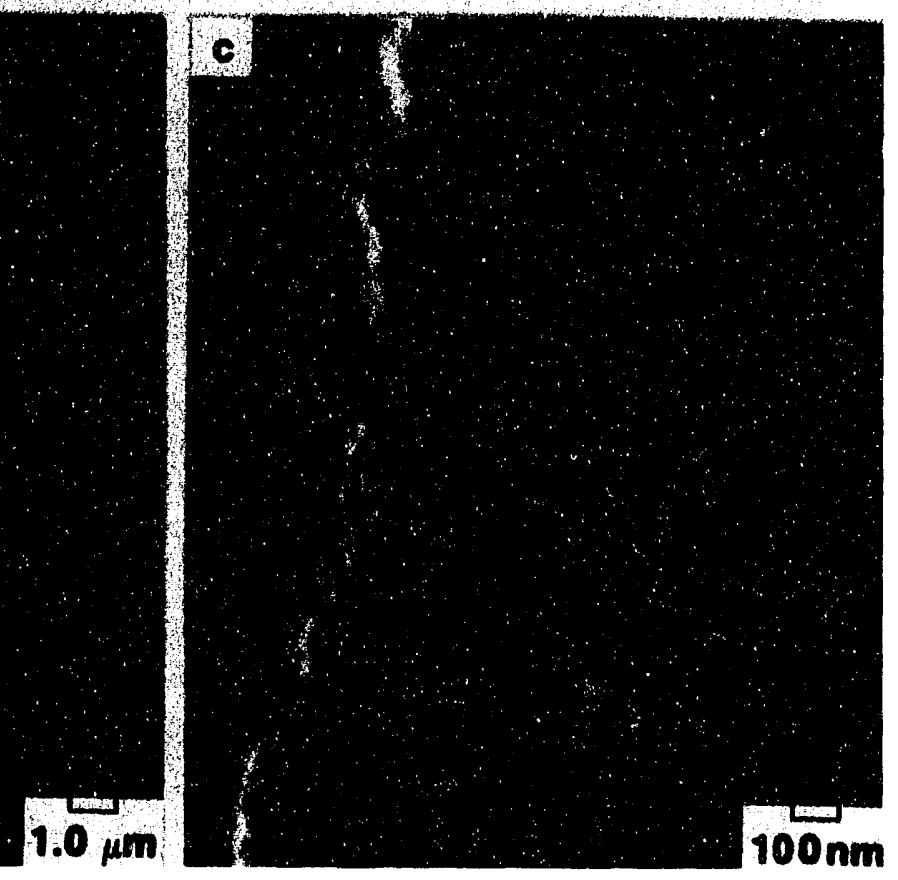

Fig. 19. SEM micrographs of irradiated SA PCA specimen surface after SL-EPR test. 
ORNL-PHOTO 6319-90

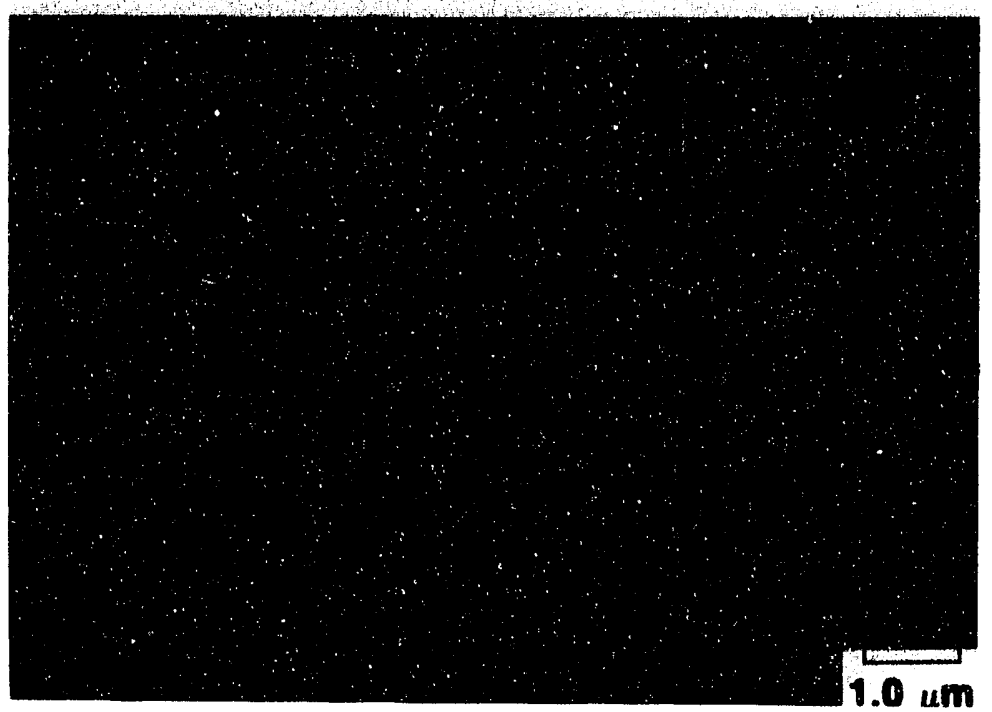

Fig. 20. SEM micrograph of irradiated $25 \% \mathrm{CW}$ PCA specimen surface after SL-EPR test.

ORNL-PHOTO 6321-90

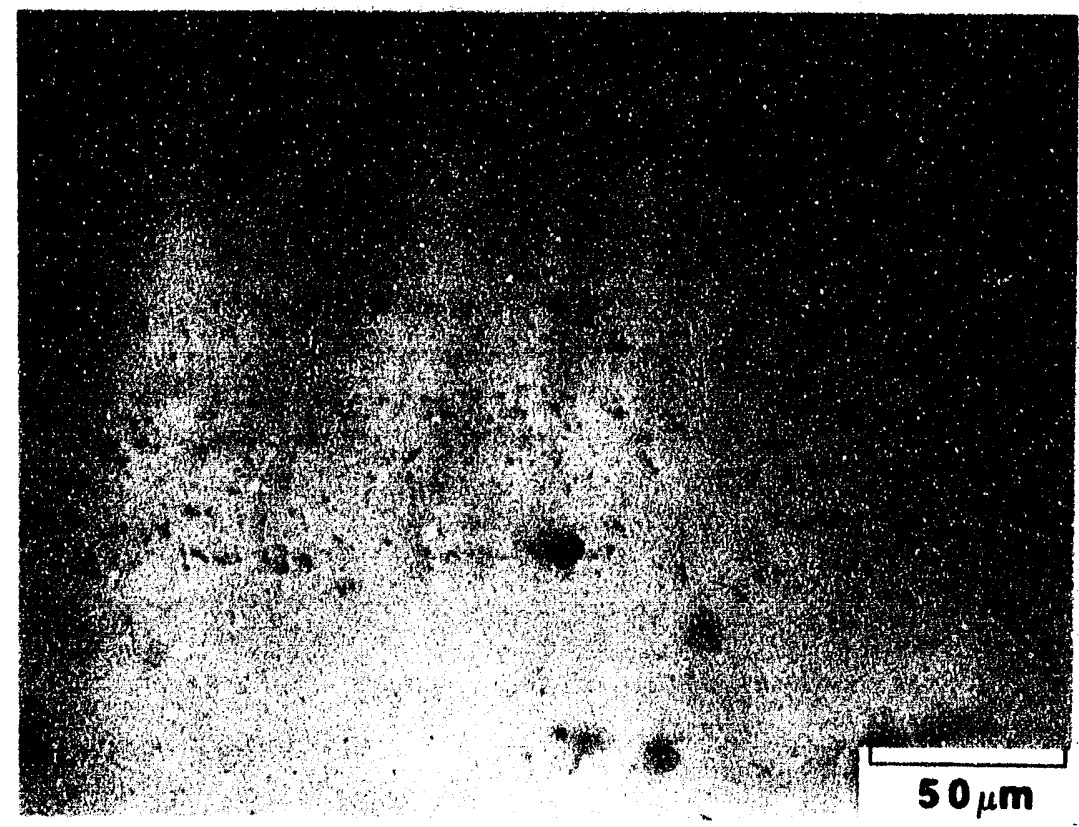

Fig. 21. Optical micrograph of irradiated SA PCA specimen surface after SL-EPR test-interrupted halfway to the peak current. 


\subsubsection{Microstructural Analysis}

The TEM microstructure of the irradiated SA PCA is shown in Fig. 22. Discontinuous precipitates were occasionally observed at some grain boundaries. In the matrix, a high density of faulted loops ( $50 \mathrm{~nm}$ diam) was observed along with a low density of voids. The formation of fine $\gamma\left(\mathrm{Ni}_{3} \mathrm{Si}\right)$ was also observed in the matrix as illustrated in a dark-field image [Fig. 23(b)]. Figure 24 shows measured composition profiles across the grain boundary in Fig. 22 for the major and minor alloying elements. Within an $\sim 10-\mathrm{nm}$-wide region at the grain boundary, chromium, iron, and molybdenum were depleted and nickel, silicon, and titanium were enriched. The local extremum (minima or maxima) of each element was always found at the position of the grain boundary. Similar, but less acute, segregation was detected at incoherent twin boundaries. No segregation was detected at coherent twin boundaries.

Figure 25 shows the TEM microstructure of the irradiated 25\% CW PCA. No precipitates were observed at grain boundaries in this case. A region of lower dislocation density was observed in the vicinity of the grain boundary. In the matrix, fine ( 40-nm-diam) faulted loops and, occasionally, voids were observed (amid the dense dislocation network induced by pre-irradiation cold working). However, the void density was significantly lower compared with SA material. Figure 26 shows measured composition profiles across the grain boundary in Fig. 25 for the major and minor alloying elements. The results show RIS similar to that in the SA material, although the profiles are asymmetric with respect to the boundary, and the local elemental extremum did not occur at the boundary.

The results of X-ray microanalysis on the grain boundaries of the irradiated PCA are summarized in Fig 27. The data for the matrix are the average of compositions measured for the SA and CW specimens. In both the SA and CW conditions, grain boundaries were depleted in chromium, molybdenum, and iron, while enriched in silicon and nickel, relative to the matrix. The degree of RIS was more pronounced in the SA condition than in the CW condition. The apparent chromium level at grain boundaries ranged from 10 to 13 at. $\%$ for the SA material and 13 to 15 at. \% for the CW material. The precipitates observed in the SA material were depleted in chromium, molybdenum, and iron, while enriched in silicon, nickel, and titanium, relative to the matrix. The apparent chromium concentration of the precipitates was 12 at. \%, the same as the grain boundaries in the SA material.

$\mathrm{X}$-ray microanalysis of defects in grain interiors, voids, and faulted loops was also carried out for the SA PCA in order to examine RIS behavior at the defects. As shown in Fig. 28, regions near voids were depleted in chromium, molybdenum, and iron, while 


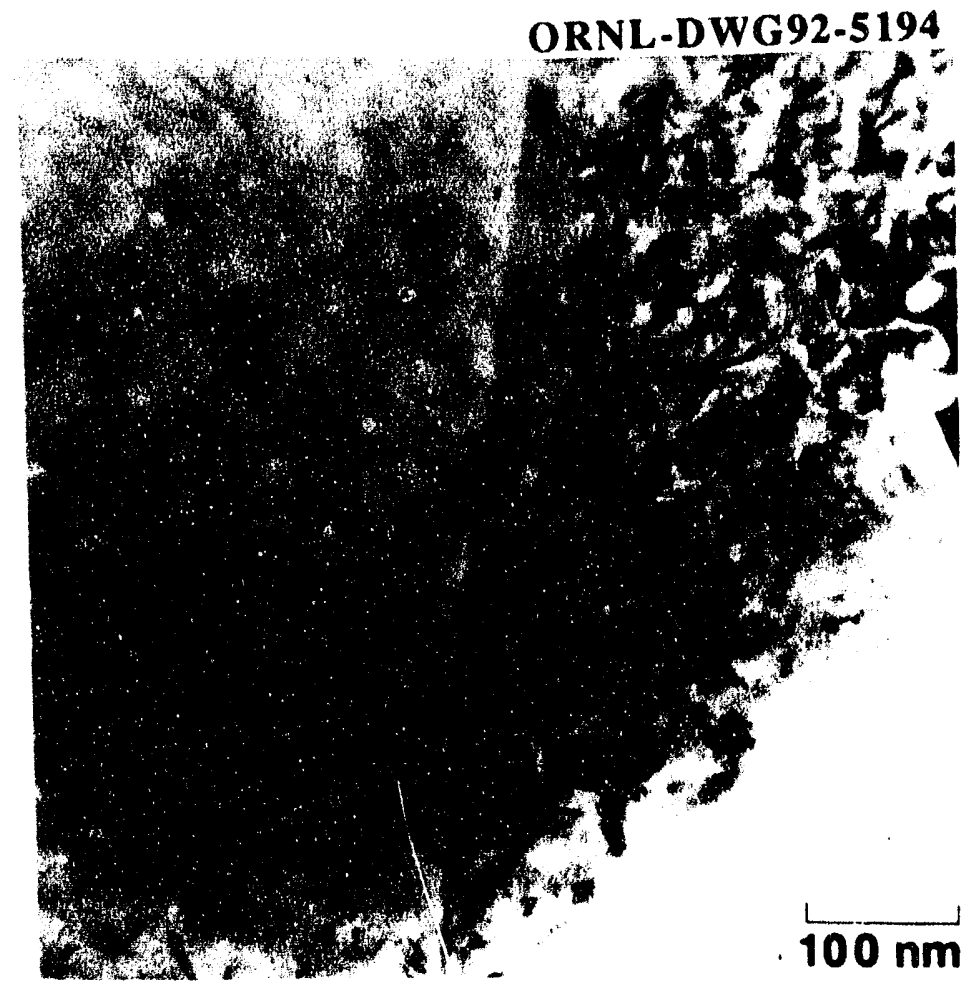

Fig. 22. TEM micrograph of SA PCA irradiated in FFTF/MOTA at $420^{\circ} \mathrm{C}$ to $9 \mathrm{dpa}$.
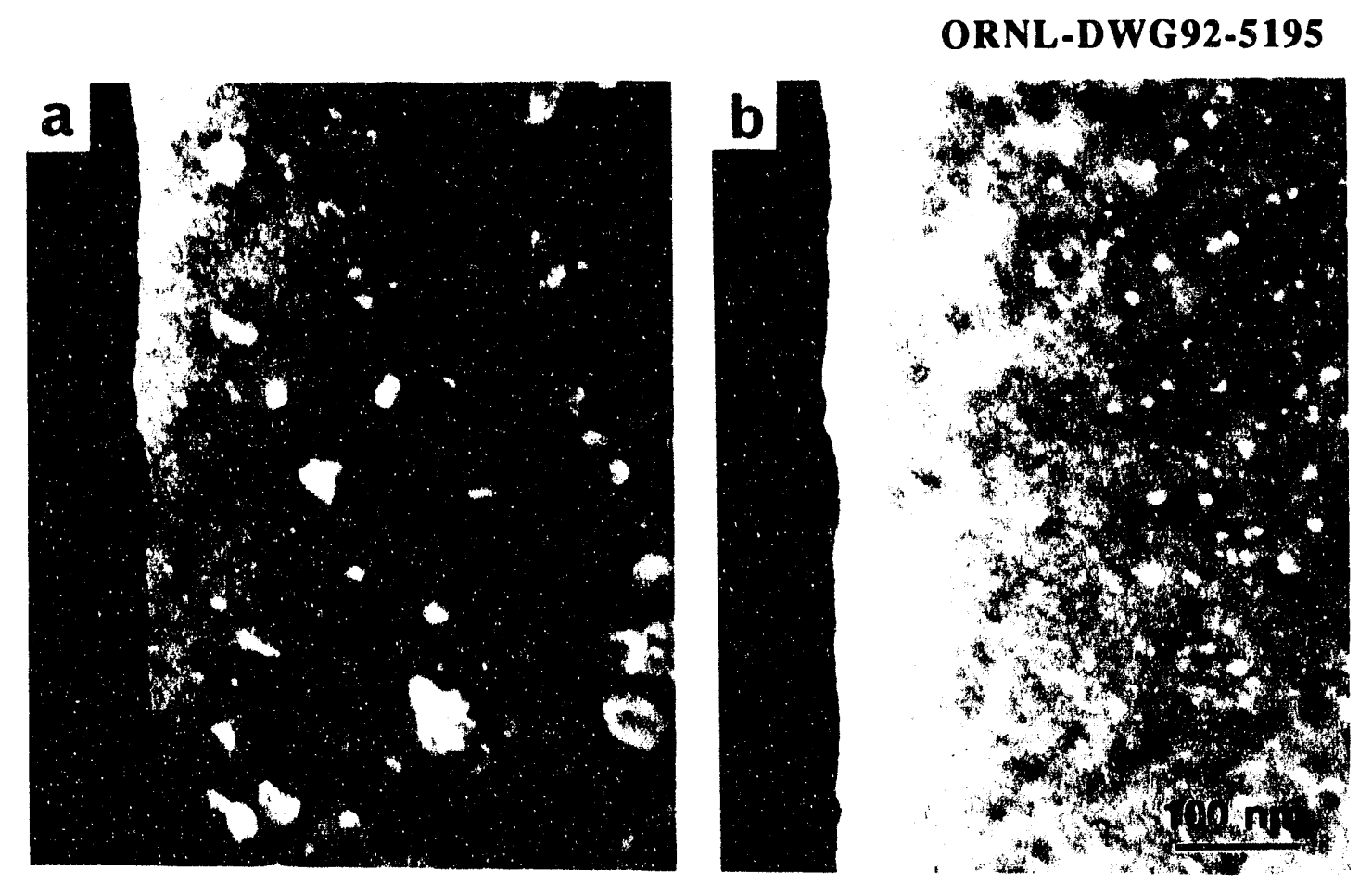

Fig. 23. Dark-field images of SA PCA irradiated in FFTF/MOTA at $420^{\circ} \mathrm{C}$ to 9 dpa: (a) dislocation loops, $1 / 2113$ reflection and $(b) \gamma\left(\mathrm{Ni}_{3} \mathrm{Si}\right), 110$ reflection. 
ORNL-DWG92-5196

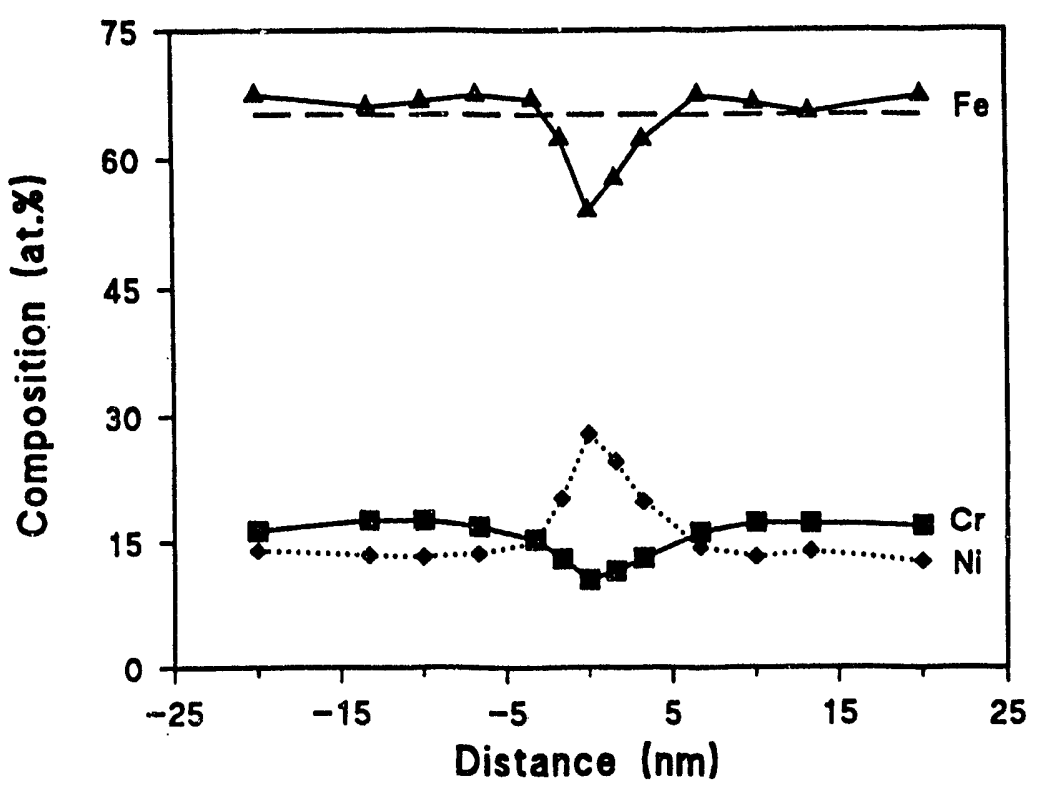

(a)

ORNL-DWG92-5197

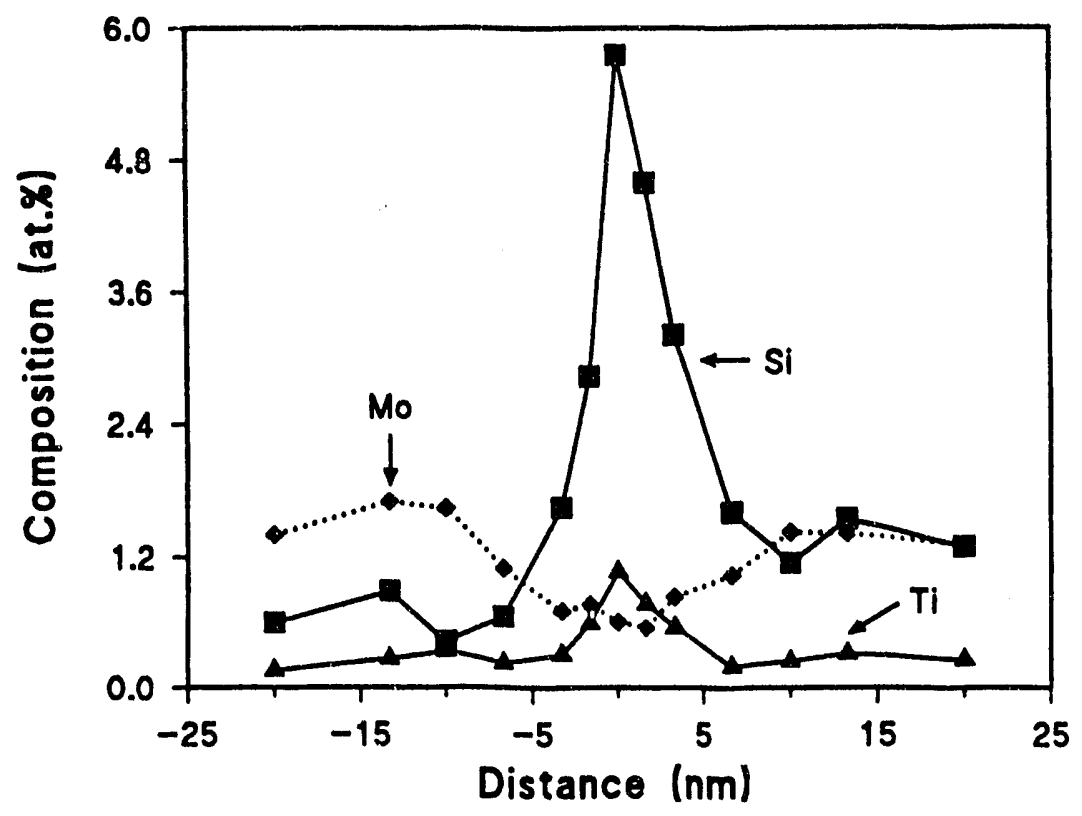

(b)

Fig. 24. (a) Iron, nickel, and chromium profiles across grain boundary of SA PCA irradiated in FFTF/MOTA at $420^{\circ} \mathrm{C}$ to $9 \mathrm{dpa}$ and $(b)$ molybdenum, silicon, and titanium profiles across grain boundary of SA PCA irradiated in FFTF/MOTA at $420^{\circ} \mathrm{C}$ to $9 \mathrm{dpa}$. 

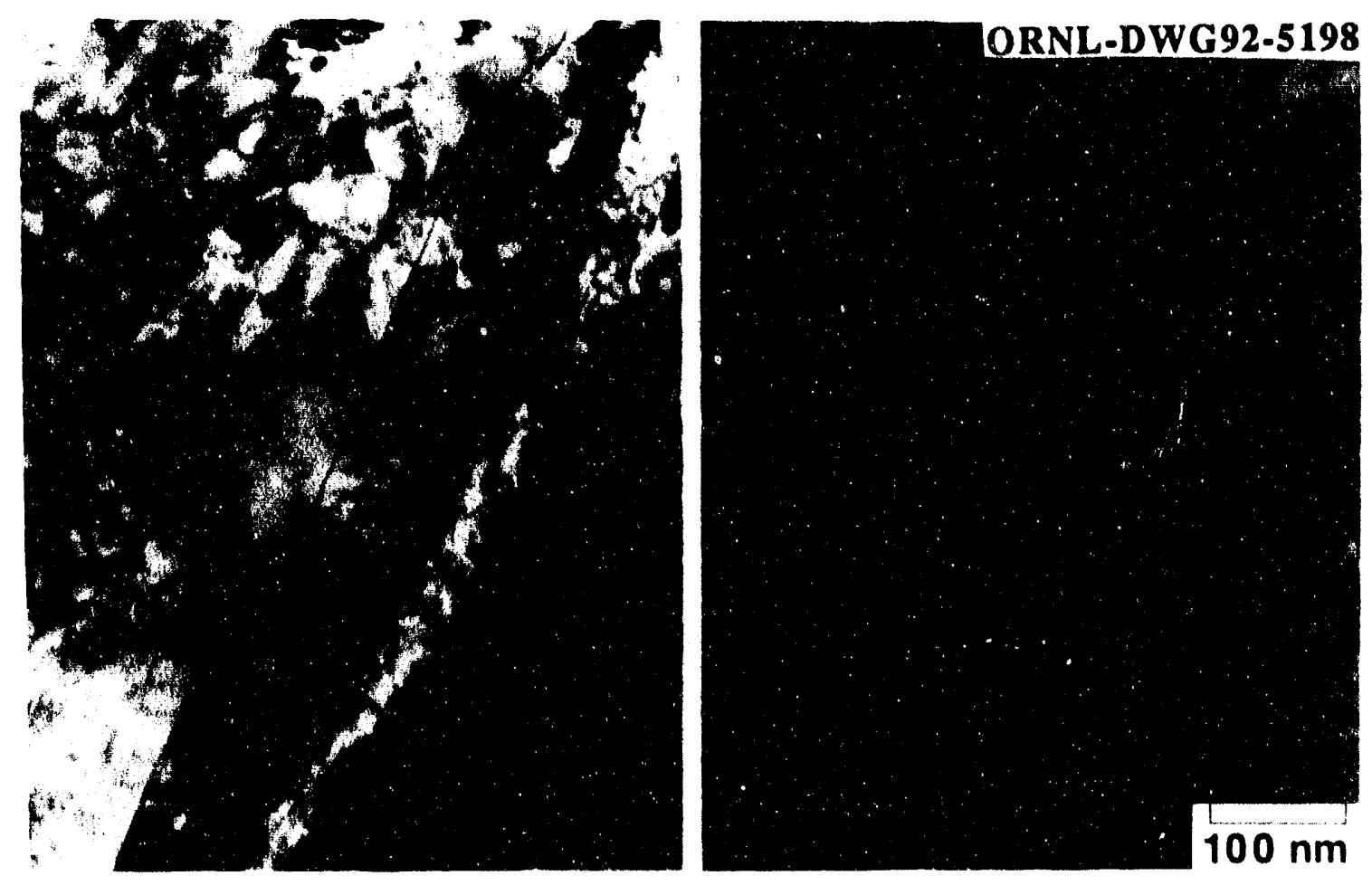

Fig. 25. TEM micrographs of $25 \% \mathrm{CW}$ PCA irradiated in FFTF/MOTA at $420^{\circ} \mathrm{C}$ to $9 \mathrm{dpa}$.

ORNL-DWG92-5199
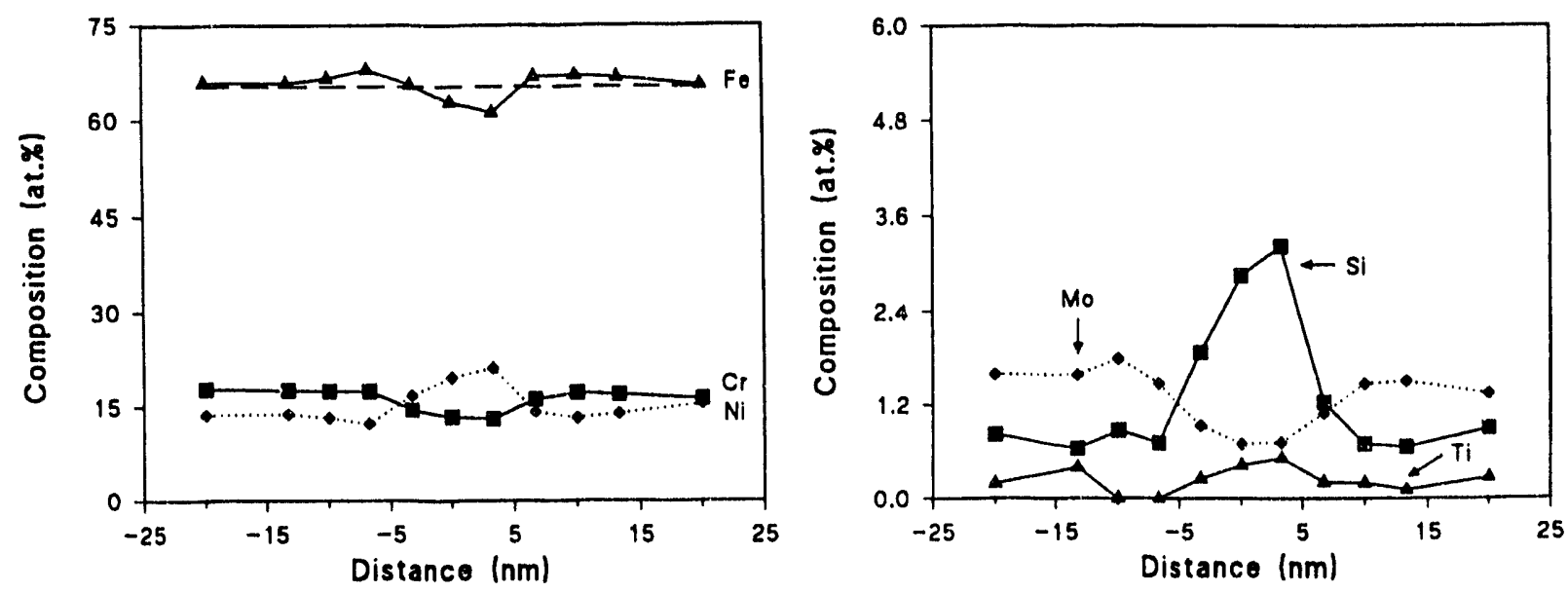

(a)

(b)

Fig. 26. (a) Iron, nickel, and chromium profiles across grain boundary of $25 \% \mathrm{CW}$ PCA irradiated in FFTF/MOTA at $420^{\circ} \mathrm{C}$ to 9 dpa and $(b)$ molybdenum, silicon, and titanium profiles across grain boundary of $25 \% \mathrm{CW}$ PCA irradiated in FFTF/MOTA at $420^{\circ} \mathrm{C}$ to $9 \mathrm{dpa}$. 


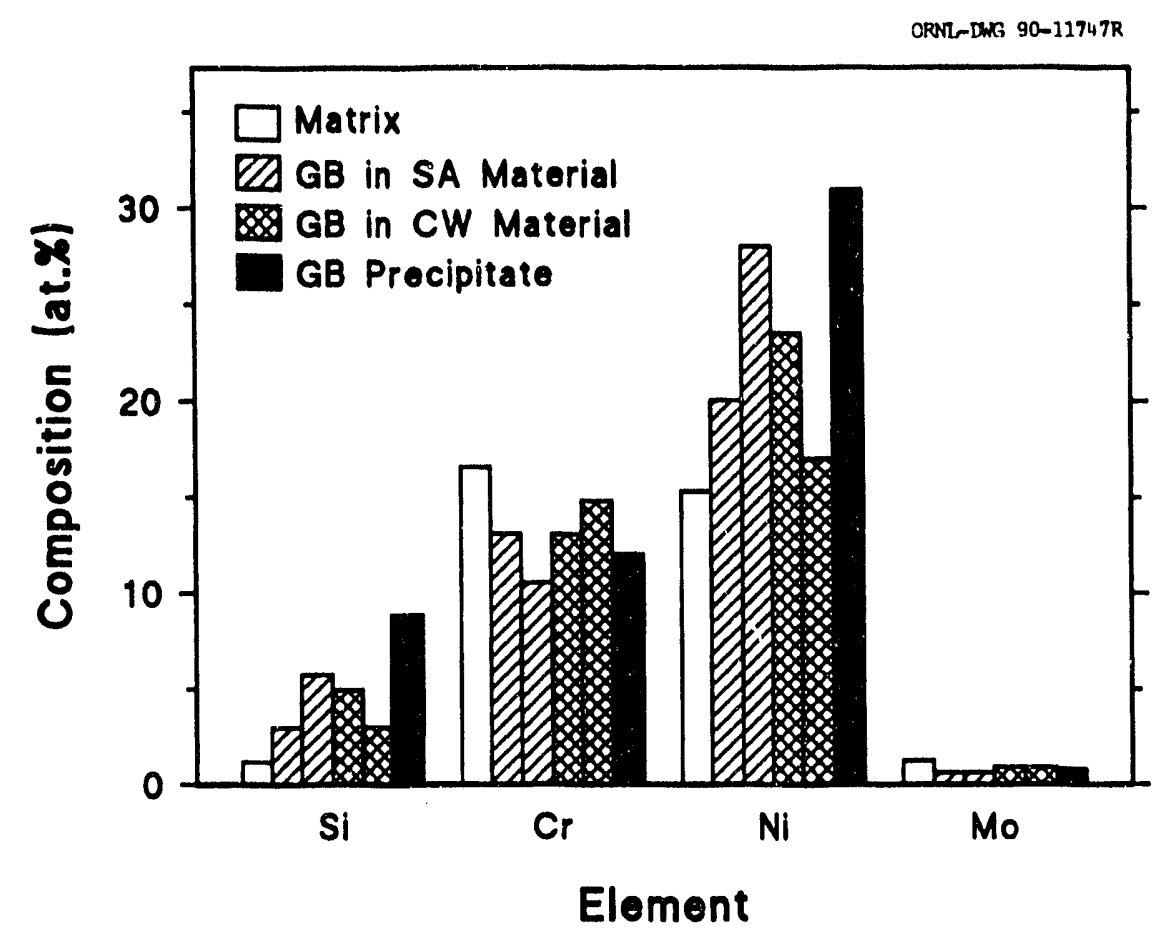

Fig. 27. Composition of two grain boundaries and precipitates in SA PCA and two grain boundaries in 25\% CW PCA, both irradiated in FFTF/MOTA at $420^{\circ} \mathrm{C}$ to $9 \mathrm{dpa}$.

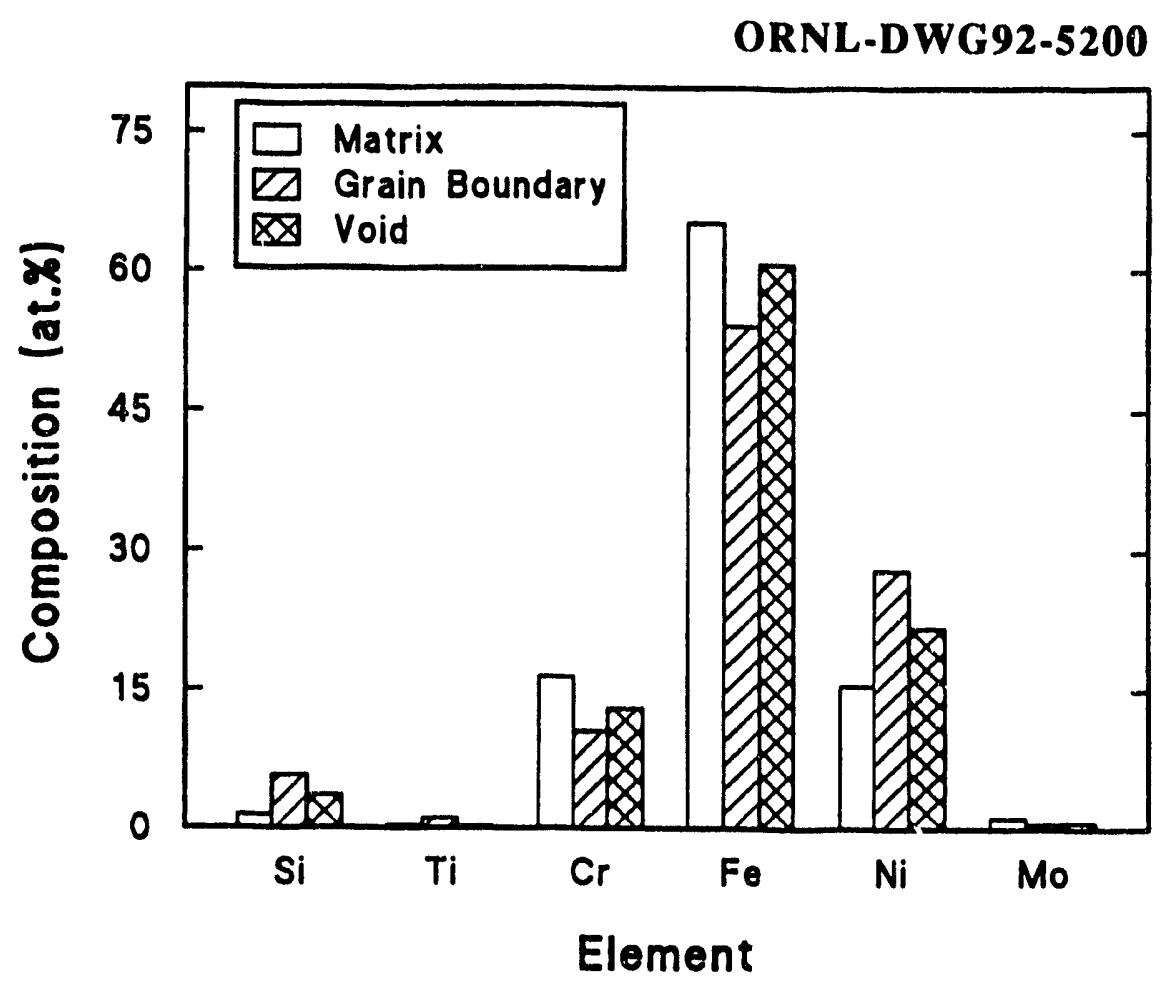

Fig. 28. Composition of voids in SA PCA irradiated in FFTF/MOTA at $420^{\circ} \mathrm{C}$ to 9 dpa. 
enriched in silicon and nickel, relative to the matrix. Faulted loops showed similar RIS, although at a reduced level (Fig. 29).

\subsubsection{Specimens from ORR-MFE6J/7J}

\subsubsection{SL-EPR Test}

Reactivation curves for the CW PCA irradiated at 60 to $400^{\circ} \mathrm{C}$ and for an unirradiated material are shown in Fig. 30. Note the difference in scan rate $(3 \mathrm{~V} / \mathrm{h}$ vs $6 \mathrm{~V} / \mathrm{h})$, as compared to the FFTF/MOTA specimens. As compared to the unirradiated material, the peak current density was increased by the irradiation at $200^{\circ} \mathrm{C}$ and above. The increase in the peak current density was greatest at higher irradiation temperatures. The Flade potential was obviously increased by the irradiation at $400^{\circ} \mathrm{C}$, but there were no significant differences in measured Flade potentials for specimens irradiated at the lower temperatures. Irradiation at $60^{\circ} \mathrm{C} \mathrm{did} \mathrm{not}$ appear to have any effect on the reactivation behavior of this material.

The calculated Pa values of the irradiated CW PCA are shown as a function of irradiation temperature in Fig. 31. The Pa values were normalized by total tested area in order to avoid overestimation as described later in Sect. 4.2. No significant effect of irradiation on the $\mathrm{Pa}$ value was observed at $60^{\circ} \mathrm{C}$. The $\mathrm{Pa}$ value was increased by irradiation at $200^{\circ} \mathrm{C}$ and above as compared to the unirradiated material, and at an irradiation temperature of $200^{\circ} \mathrm{C}$, the $\mathrm{Pa}$ value was more than an order of magnitude higher than that of the unirradiated material. The $\mathrm{Pa}$ value increased with increasing irradiation temperature and, at $400^{\circ} \mathrm{C}$, it was an order of magnitude higher than that at $200^{\circ} \mathrm{C}$.

\subsubsection{Surface Examination}

Optical micrographs of the irradiated specimen surfaces after SL-EPR testing are shown in Fig. 32 Fine-scale etching across grain faces appeared for the specimens irradiated at $200^{\circ} \mathrm{C}$ and above, and the density of the etching increased with increasing irradiation temperature. The grain-boundary etching was observed only for the specimen irradiated at $400^{\circ} \mathrm{C}$, similar to the FFTF/MOTA specimens irradiated at $420^{\circ} \mathrm{C}$. Etching along slip lines was also observed in the $400^{\circ} \mathrm{C}$ specimen (again, similar to the FFTF/MOTA specimens).

SEM micrographs of the surfaces after SL-EPR testing are shown for the 200 to $400^{\circ} \mathrm{C}$ specimens in Fig. 33. Discontinuous grain-boundary etching was found at the irradiation temperature of $400^{\circ} \mathrm{C}$, but at irradiation temperatures of 200 and $330^{\circ} \mathrm{C}$, grain-boundary etching was not observed, and only grain face etching was found. In the specimen irradiated at $200^{\circ} \mathrm{C}$, grain face etching took the form of pitting-type attack. The pits varied in size 


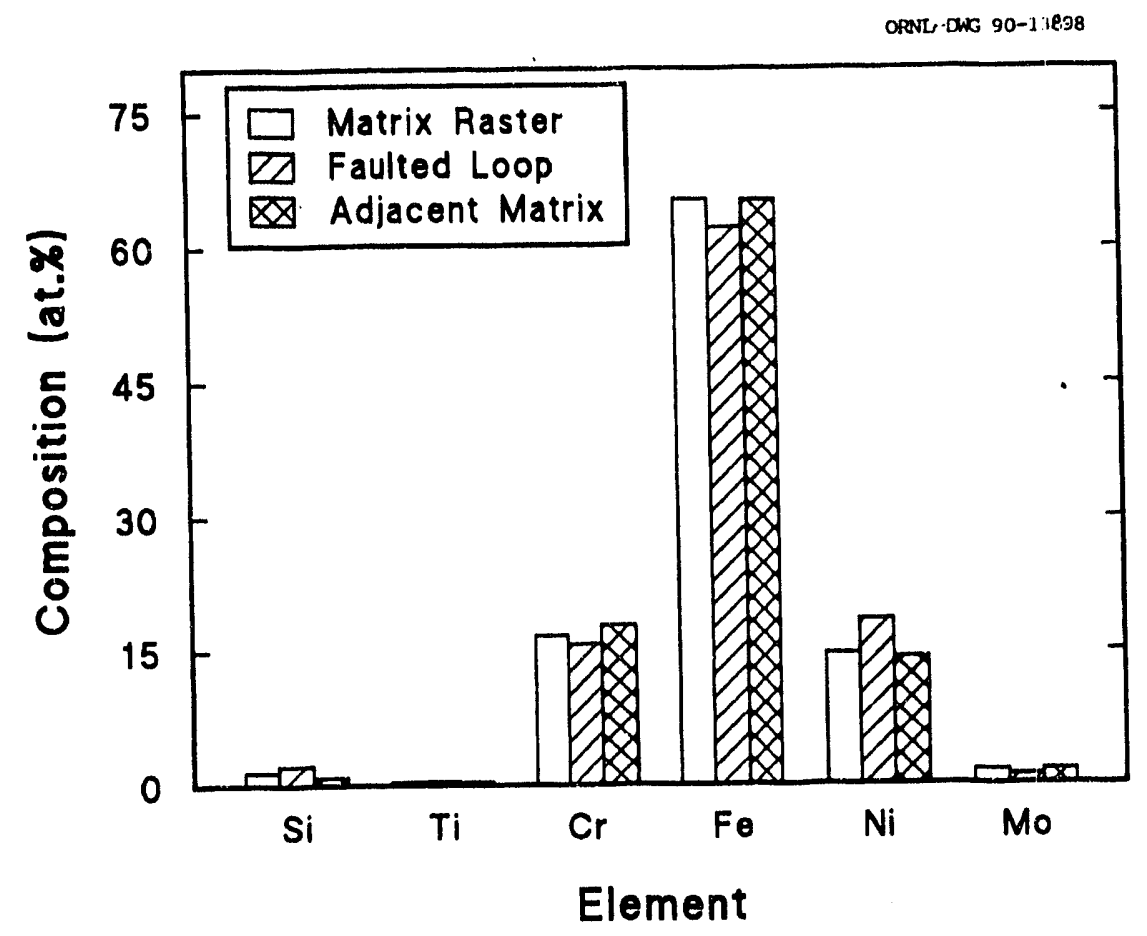

Fig. 29. Composition of dislocation loops in SA PCA irradiated in FFTF/MOTA at $420^{\circ} \mathrm{C}$ to $9 \mathrm{dpa}$.

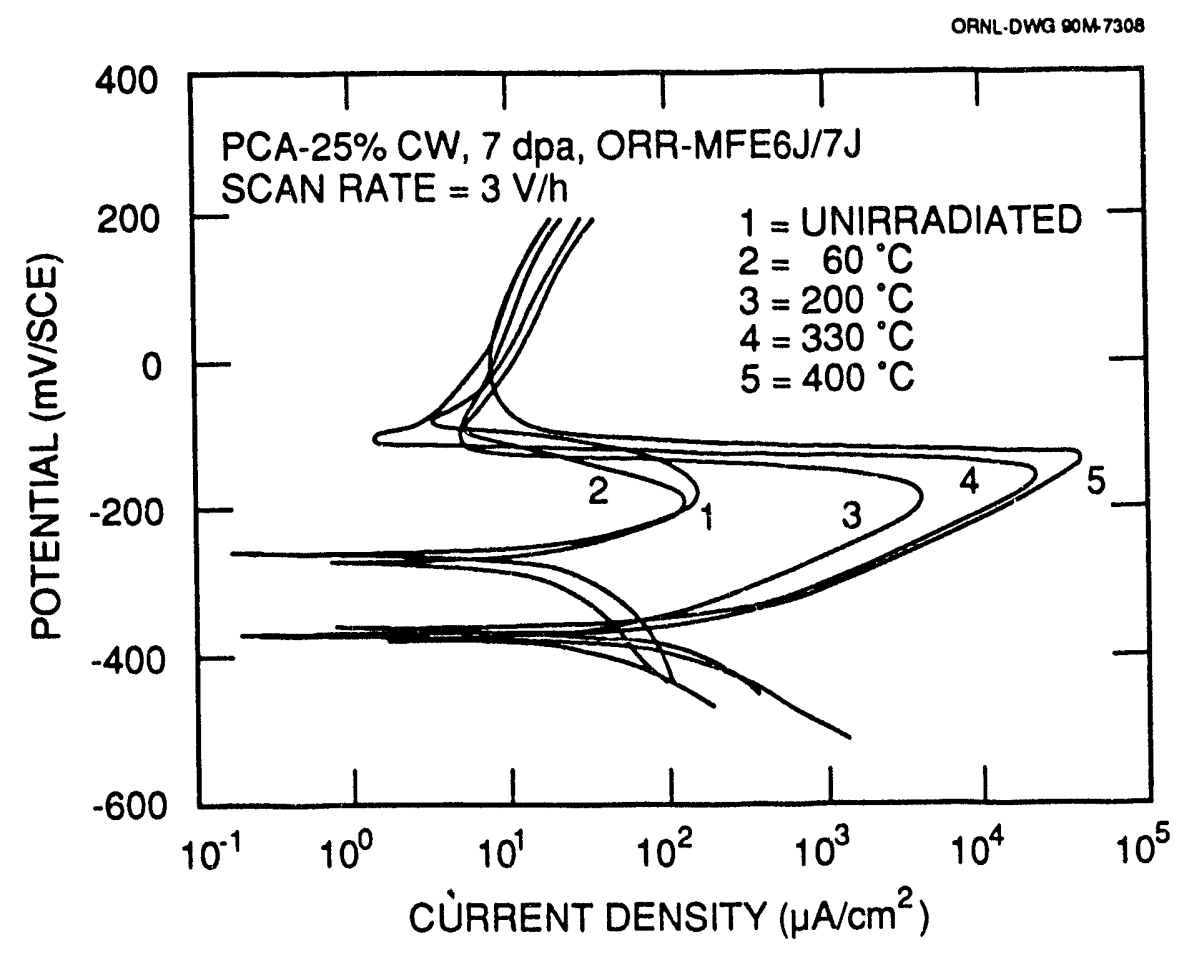

Fig. 30. Reactivation curves of $25 \%$ CW PCA irradiated in ORR-MFE $6 \mathrm{~J} / 7 \mathrm{~J}$ at 60 to $400^{\circ} \mathrm{C}$ to about $7 \mathrm{dpa}$. 


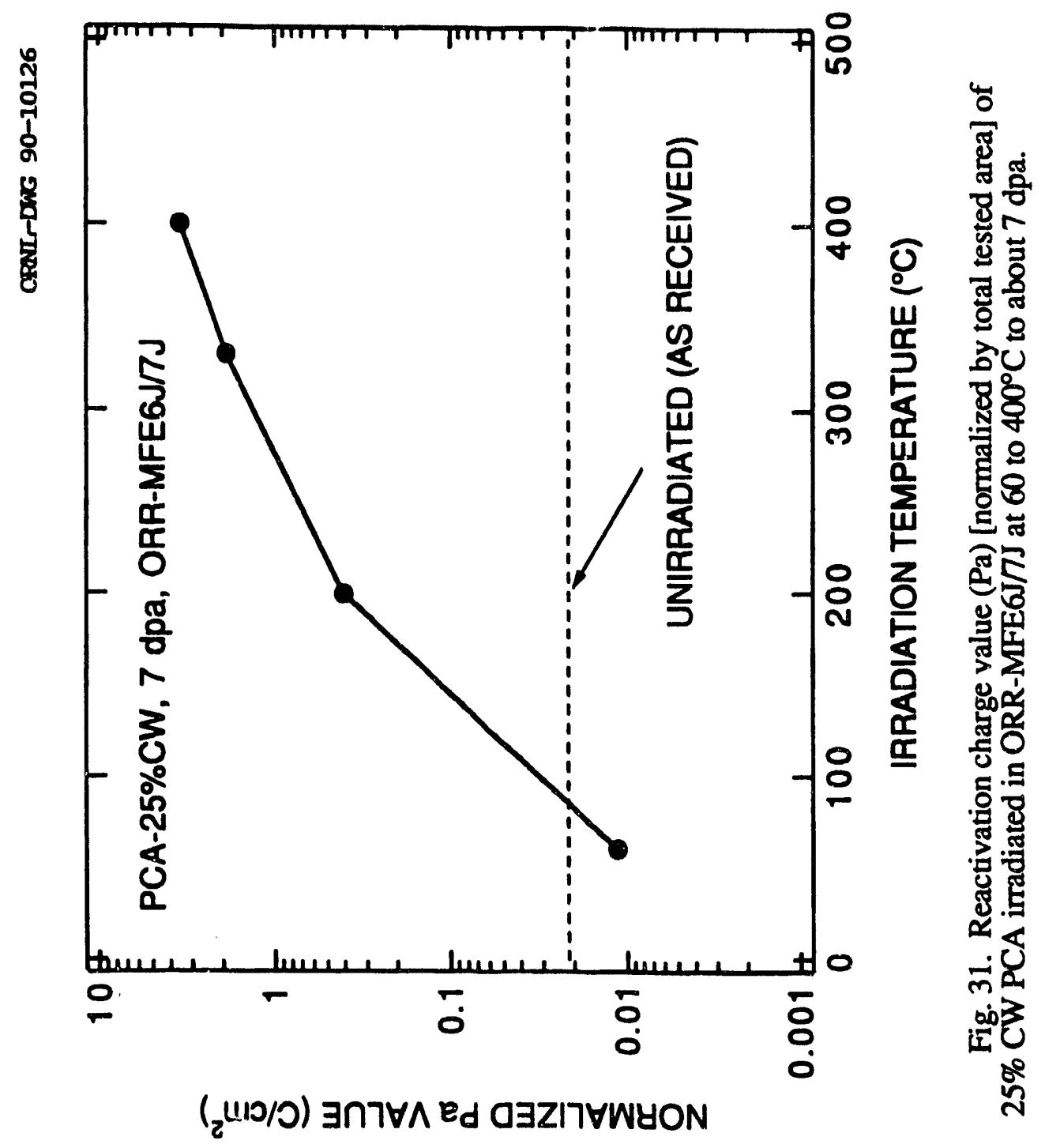


ORNL-DWG92-5201
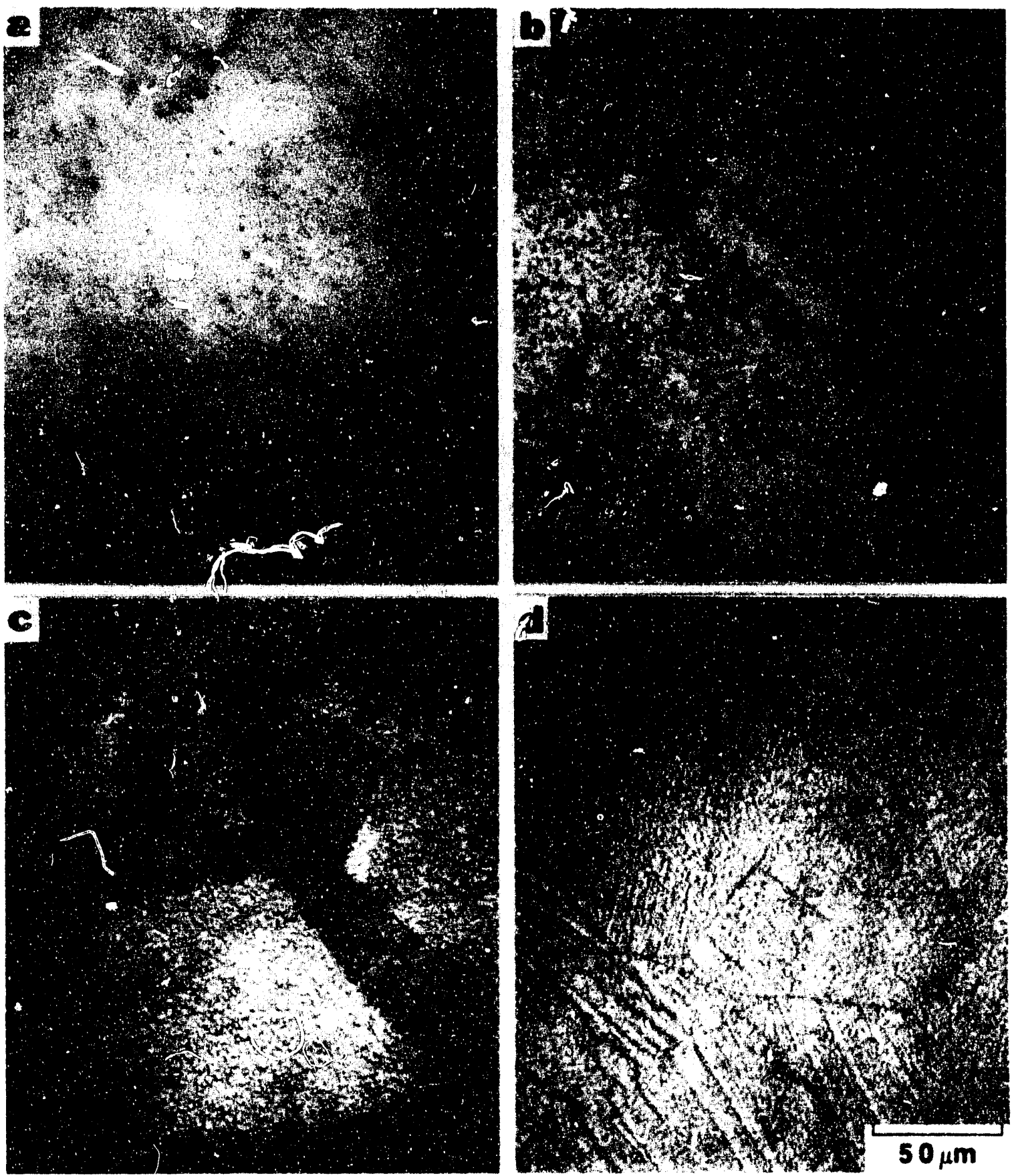

Fig. 32. Optical micrographs of irradiated 25\% CW PCA after SL-EPR testing. Specimens were irradiated to about $7 \mathrm{dpa}$ at: $(a) 60^{\circ} \mathrm{C}$, (b) $200^{\circ} \mathrm{C},(c) 330^{\circ} \mathrm{C}$, and (d) $400^{\circ} \mathrm{C}$. 
ORNL-DWG92-5203
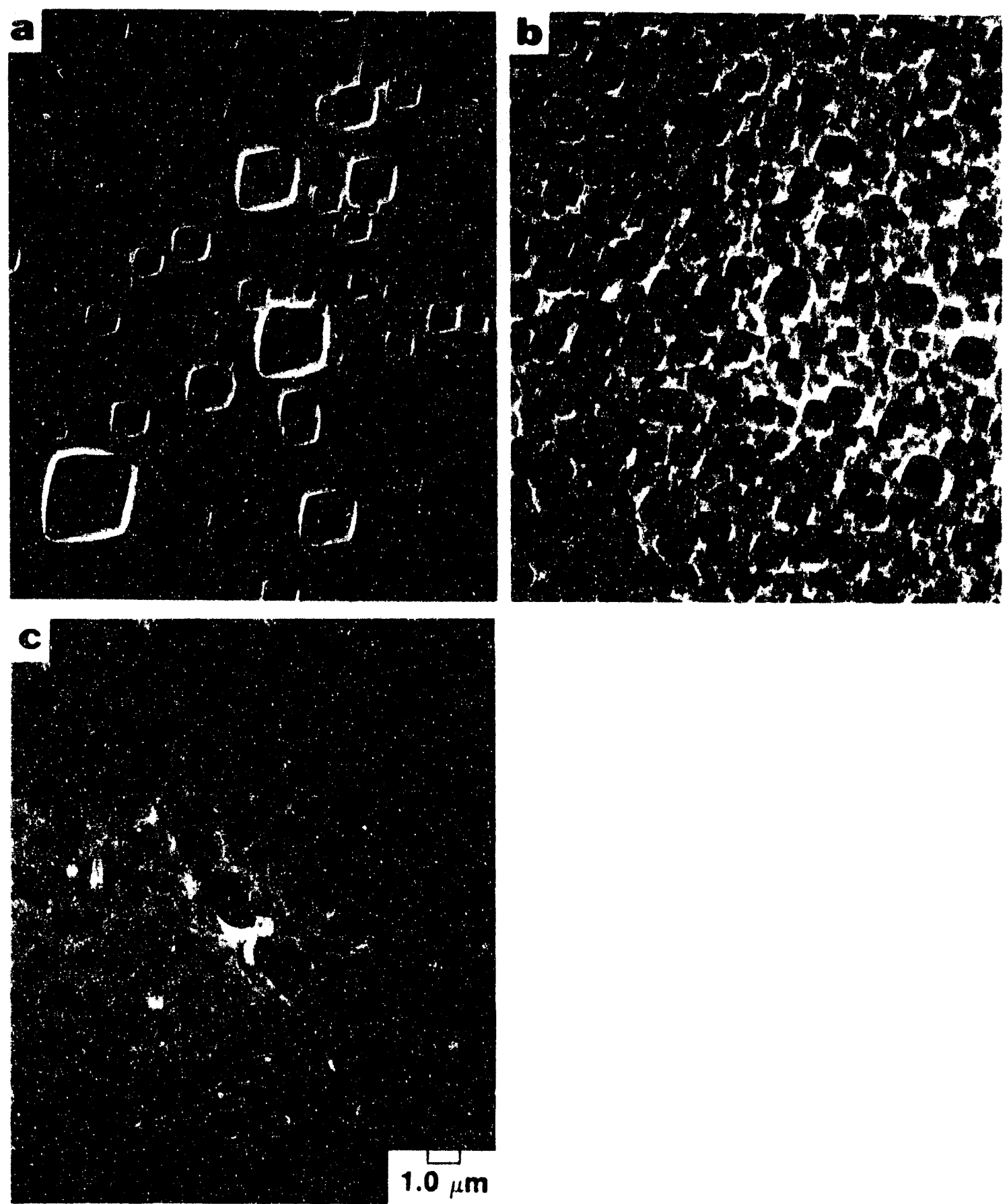

Fig. 33. SEM micrographs of irradiated $25 \% \mathrm{CW}$ PCA after SL-EPR testing. Specimens were irradiated to about $7 \mathrm{dpa}$ at: $(a) 200^{\circ} \mathrm{C},(b) 330^{\circ} \mathrm{C}$, and (c) $440^{\circ} \mathrm{C}$. 
ranging from less than 0.2 to $2 \mu \mathrm{m}$. Some of the pits appeared to have initiated as smaller pits, then grew and coalesced. Note that the original smooth, electropolished surface remained intact between the pits. At the irradiation temperature of $330^{\circ} \mathrm{C}$, the specimen surface showed dimple-shape attack across the grain face. The dimple diameters ranged from 0.2 to $1 \mu \mathrm{m}$. Similar dimple-shape corrosion was observed on the grain face of the $400^{\circ} \mathrm{C}$ specimen, but the individual dimples were not as clear as those at $330^{\circ} \mathrm{C}$.

SL-EPR testing was interrupted during the reactivation process for the specimen irradiated at $200^{\circ} \mathrm{C}$ in order to examine the relationship between increase in the reactivation current and the development of the grain face attack on the specimen surface. Figure 34 shows the optical micrographs of each specimen surface after interrupting the test. No etching was observed at the Flade potential. Etching appeared at halfway to the peak current density, and the density of the etching increased with increasing current density and saturated at the peak current density.

\subsection{EVALUATION OF SENSITIZATION INDUCED BY HEAVY-ION IRRADIATION}

\subsubsection{SL-EPR Test}

The SL-EPR test results for the heavy-ion-irradiated and thermally aged control specimens of the LS1A are shown in Fig. 35 and Table 4. The thermally aged control specimens $\left(515^{\circ} \mathrm{C}\right.$ for $9 \mathrm{~h}$ ) behaved similarly to an SA specimen (i.e., did not exhibit a reactivation peak) indicating no electrochemically detectable thermal sensitization even during the longest HII ( $30 \mathrm{dpa}$ ). Therefore, any changes in electrochemical behavior are likely due to irradiation by heavy ions. The irradiation by heavy ions at $515^{\circ} \mathrm{C}$ to only $1 \mathrm{dpa}$ was sufficient to cause the appearance of a Flade potential and a corresponding reactivation peak. Similar SL-EPR curves were obtained for the 10 and 30 dpa specimens. In general, the Flade potential increased with increasing damage, while the reactivation charge did not increase beyond $10 \mathrm{dpa}$.

\subsubsection{Surface Examination}

SEMS of the post-SL-EPR test specimen surfaces of the heavy-ion-irradiated LS1A are shown in Fig. 36. The thermally aged control specimen was not etched or pitted during the SL-EPR test and is not shown. Light grain face etching in the form of pitting was found for the $1 \mathrm{dpa}$ specimen and accounted for the existence of a Flade potential and reactivation peak 
ORNL-DWG92-11892

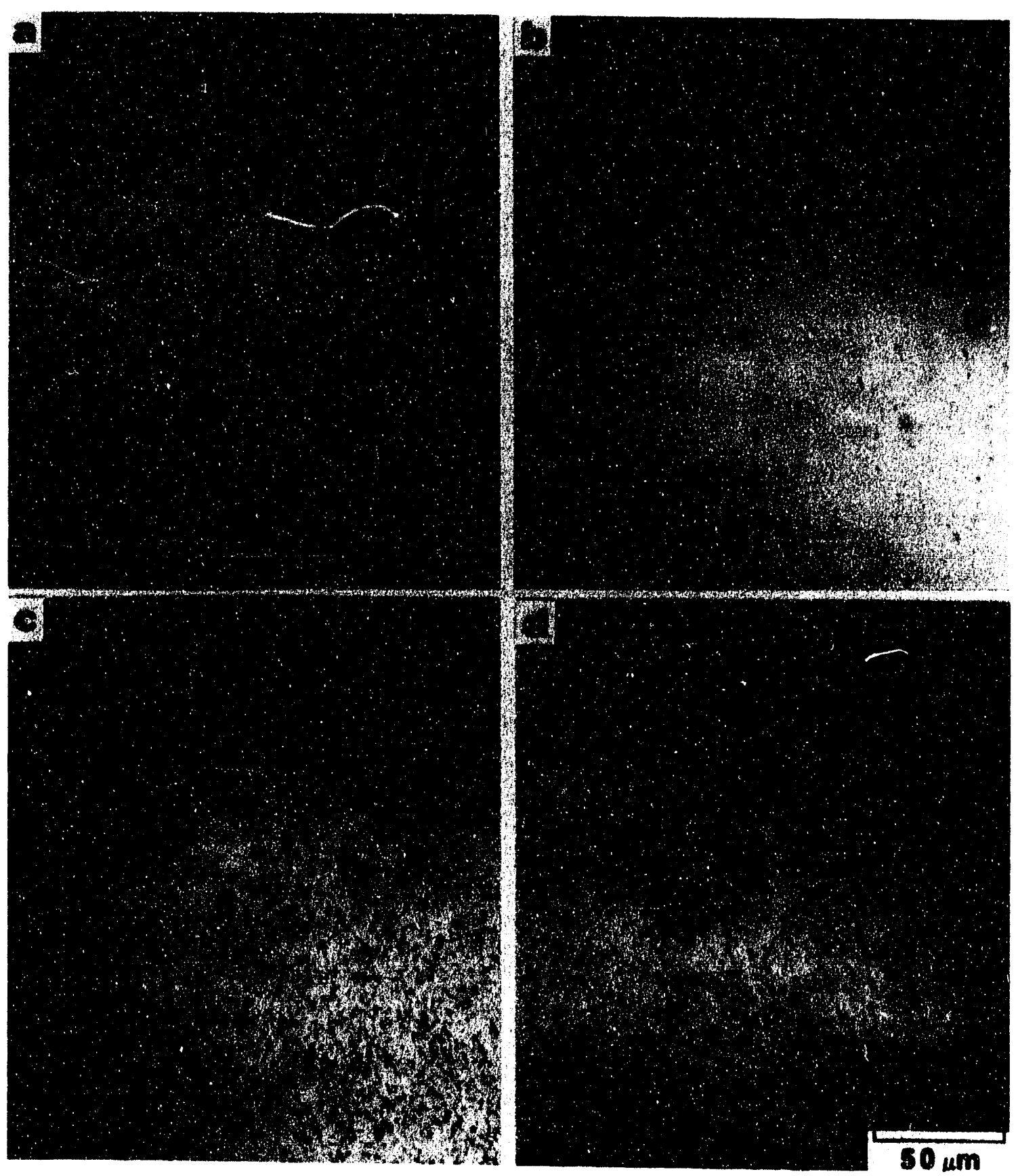

Fig. 34. Optical micrographs of $25 \% \mathrm{CW}$ PCA irradiated at $200^{\circ} \mathrm{C}$. SL-EPR testing was interrupted at: (a) Flade potential, $(b) 1 / 2$ peak, (c) peak, and (d) $-1909 \mathrm{mV}$ from peak. 
ORNL-DWG92-11891

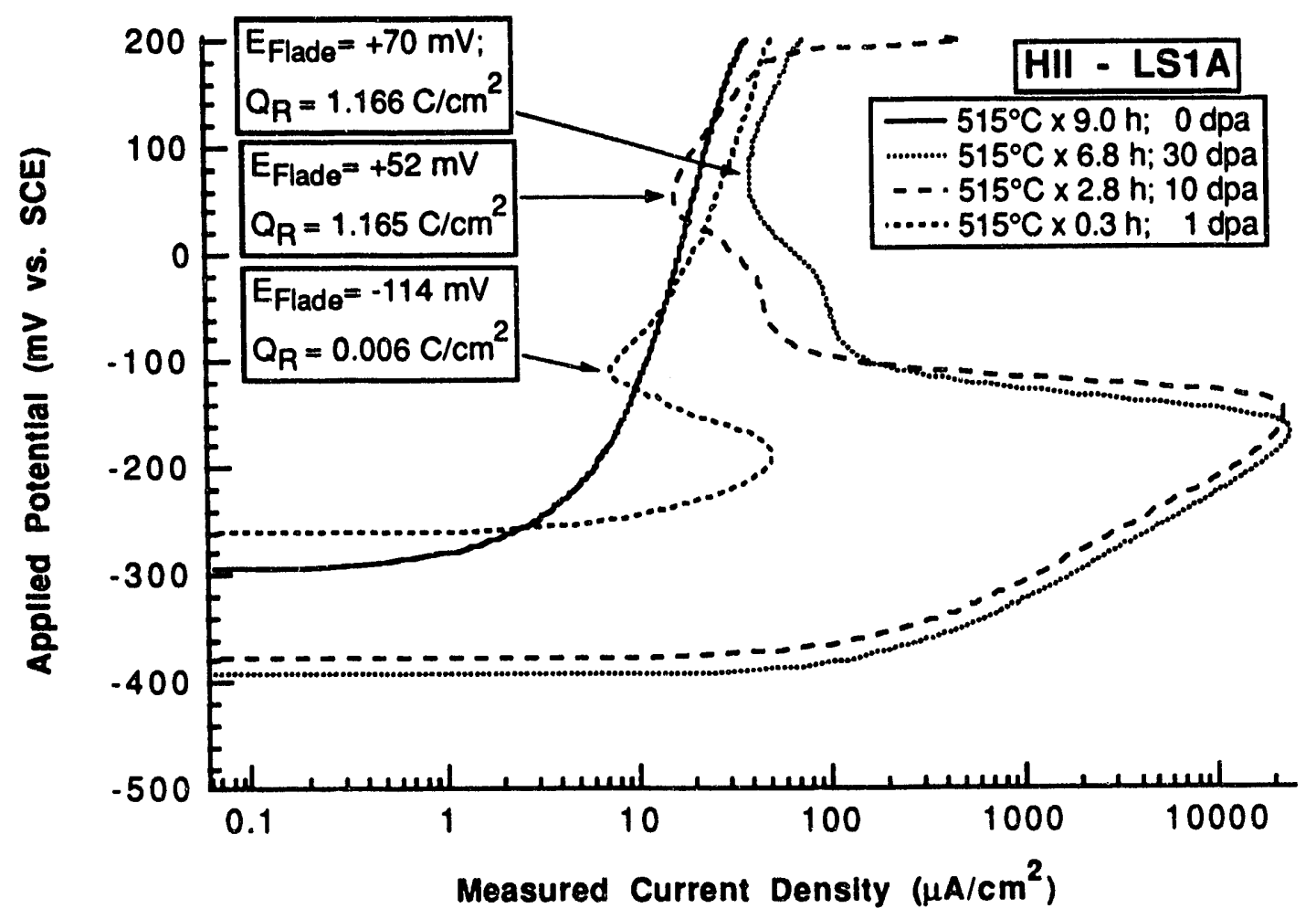

Fig. 35. Reactivation curves of heavy-ion-irradiatred LS1A.

Table 4. Flade potentials and reactivations charges of thermally aged and heavy-ion-irradiated LSIA

Heating time
at $515^{\circ} \mathrm{C}$

(h)
Dose

(dpa)
Flade potential, $\mathrm{E}_{\mathrm{F}}$

( $\mathrm{mV}$ versus $\mathrm{SCE}$ )
Reactivation charge, $\mathrm{Pa}^{*}$ (coulombs $/ \mathrm{cm}^{2}$ )

\begin{tabular}{lrcc}
\hline 9.0 & & N/A & N/A \\
0.3 & 0 & -114 & 0.001 \\
2.8 & 1 & +52 & 1.165 \\
6.9 & 10 & +70 & 1.166 \\
\hline
\end{tabular}

*Total reactivation charge per unit tested area. 

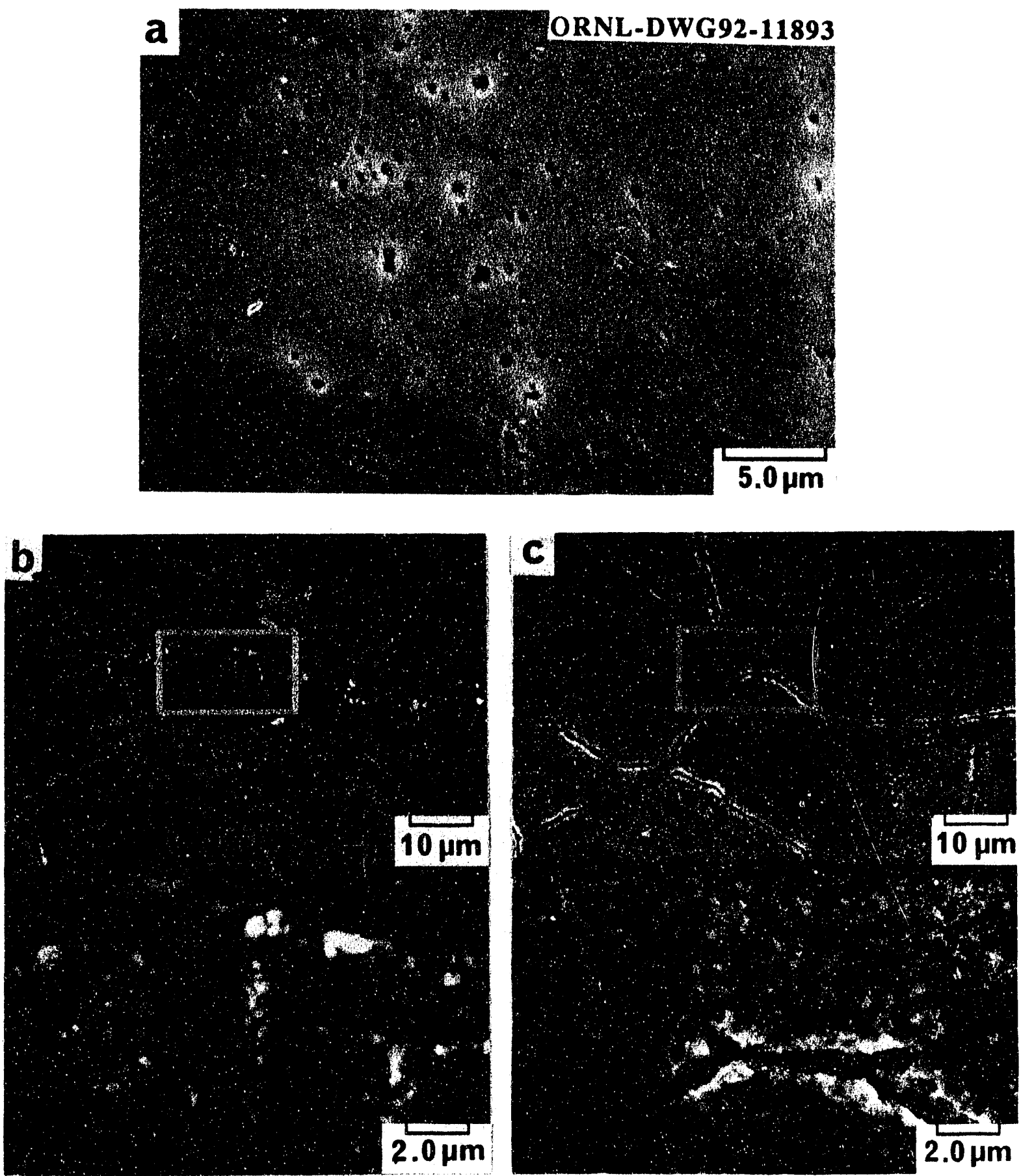

Fig. 36. SEM micrographs of irradiatred LS1A after SL-EPR tests. Specimens were irradiated at $515^{\circ} \mathrm{C}$ to: $(a) 1 \mathrm{dpa},(b) 10 \mathrm{dpa}$, and (c) $30 \mathrm{dpa}$. 
(charge). No grain-boundary etching was observed for the $1 \mathrm{dpa}$ specimen. The 10 and 30 dpa specimens were similar in appearance to each other and showed etching of both grain boundaries and grain faces after SL-EPR testing. Qualitatively, the $30 \mathrm{dpa}$ specimen was more heavily etched at grain boundaries, as compared to the $10 \mathrm{dpa}$ specimen. The etching of the grain face coarsened with increasing damage.

\subsubsection{Microstructural Analysis}

After irradiation to $1 \mathrm{dpa}$ at $515^{\circ} \mathrm{C}$, only a high density $\left(\sim 5\right.$ by $\left.10^{20} \mathrm{~m}^{-3}\right)$ of small defects ( $10 \mathrm{~nm}$ diam) was observed in the LS1A [Fig. 37(a)]. Their contrast behavior was consistent with that for faulted dislocation loops. No grain-boundary precipitation was observed, nor was any grain-boundary segregation detected. In the $10 \mathrm{dpa}$ specimen, both faulted dislocation loops ( $60 \mathrm{~nm}$ diam) and similarly sized precipitates were observed [Fig. 37(b)]. The precipitates were enriched in silicon and nickel and had large, interplanar spacings consistent with $G$ and eta phase silicides. Both $G$ and eta phase were identified at the grain boundaries from $\mathrm{X}$-ray microanalysis and electron diffraction. The two phases were distinguished via the chromium level in the precipitate relative to the matrix ( $\mathrm{G}$ phase contains $\sim 5 \mathrm{wt} \% \mathrm{Cr}$, whereas eta phase contains $\sim 30 \mathrm{wt} \% \mathrm{Cr}$ ). ${ }^{37}$ Figure 38 shows a grain boundary with a $\mathrm{G}$ phase precipitate. X-ray microanalysis indicated the occurrence of RIS at the boundary. Chromium was depleted from an $\sim 10-\mathrm{nm}$-wide region at the boundary, whereas nickel, silicon, and iron were enriched near the boundary.

In the material irradiated to $30 \mathrm{dpa}$, precipitates of $\mathrm{G}$ and eta phase dominated the matrix with dislocation segments and faulted loops [Fig. 37(c)]. No voids or cavities were observed. $\mathrm{G}$ and eta phases were also observed at grain boundaries. $\mathrm{X}$-ray microanalysis was performed on a similar alloy with lower silicon content, which was irradiated to $30 \mathrm{dpa}$ at the same time. Figure 39 shows the grain-boundary composition profiles typical for this specimen. Similar to the $10 \mathrm{dpa}$ specimen, the chromium was depleted in an $\sim 10-\mathrm{nm}$-wide region at the boundary with a minimum value of $11 \mathrm{wt} \% \mathrm{Cr}$. Whereas iron was locally depleted at the grain boundary, a region approximately 4 to $20 \mathrm{~nm}$ on either side of the boundary was enriched in iron relative to the surrounding matrix. A similar but less pronounced enrichment was observed for chromium. Molybdenum was also depleted at the grain boundary, whereas enrichment of silicon $(\sim 2 \mathrm{wt} \%)$ and nickel $(\sim 25 \mathrm{wt} \%)$ occurred in a narrow band at the grain boundary. Just outside of that region, depletion of silicon and nickel relative to the matrix was observed. 

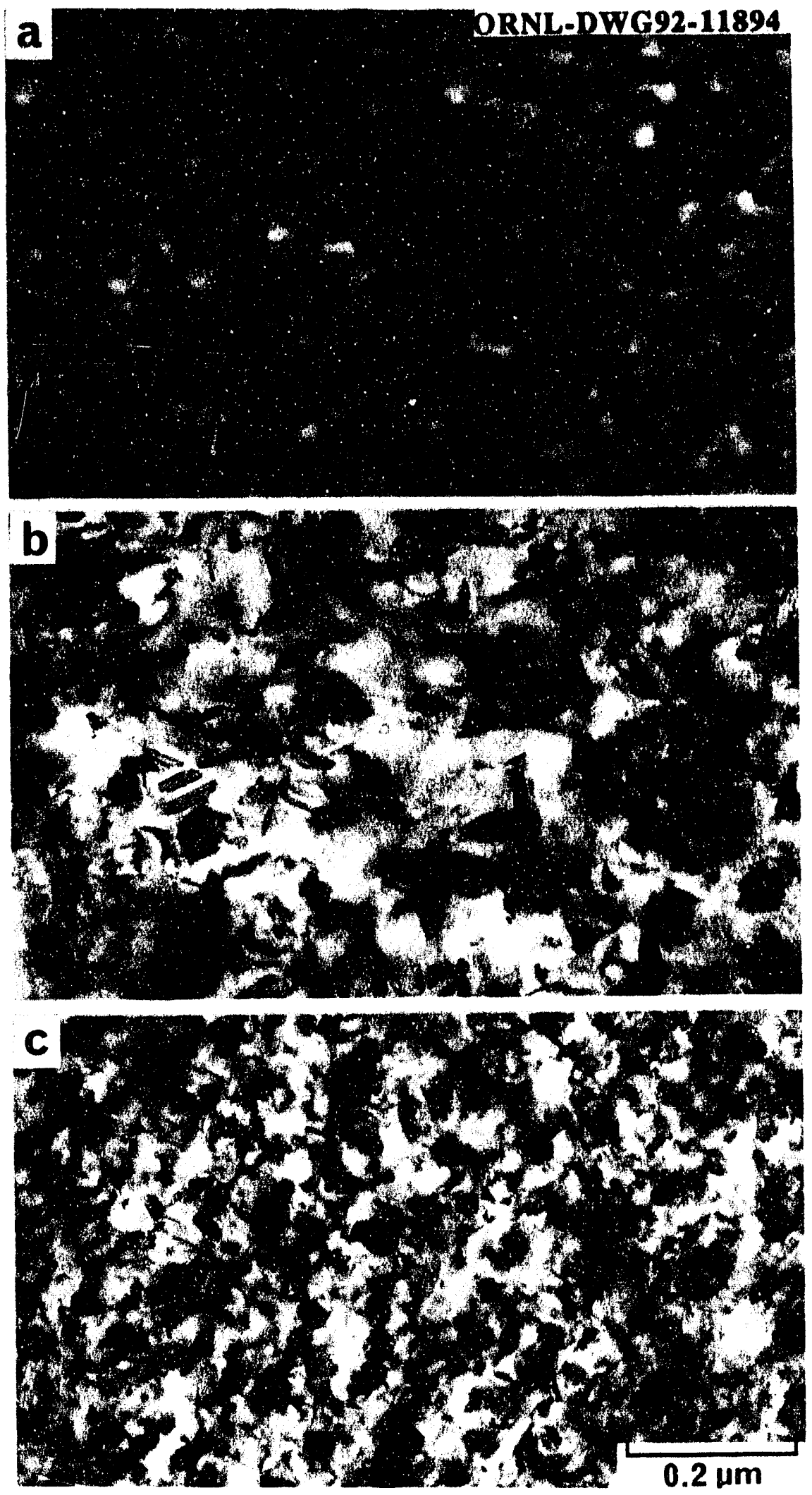

Fig. 37. TEM micrographs of irradiated LS1A. Specimens were irradiated at $515^{\circ} \mathrm{C}$ to: $(a) 1 \mathrm{dpa},(b) 10 \mathrm{dpa}$, and (c) $30 \mathrm{dpa}$. 

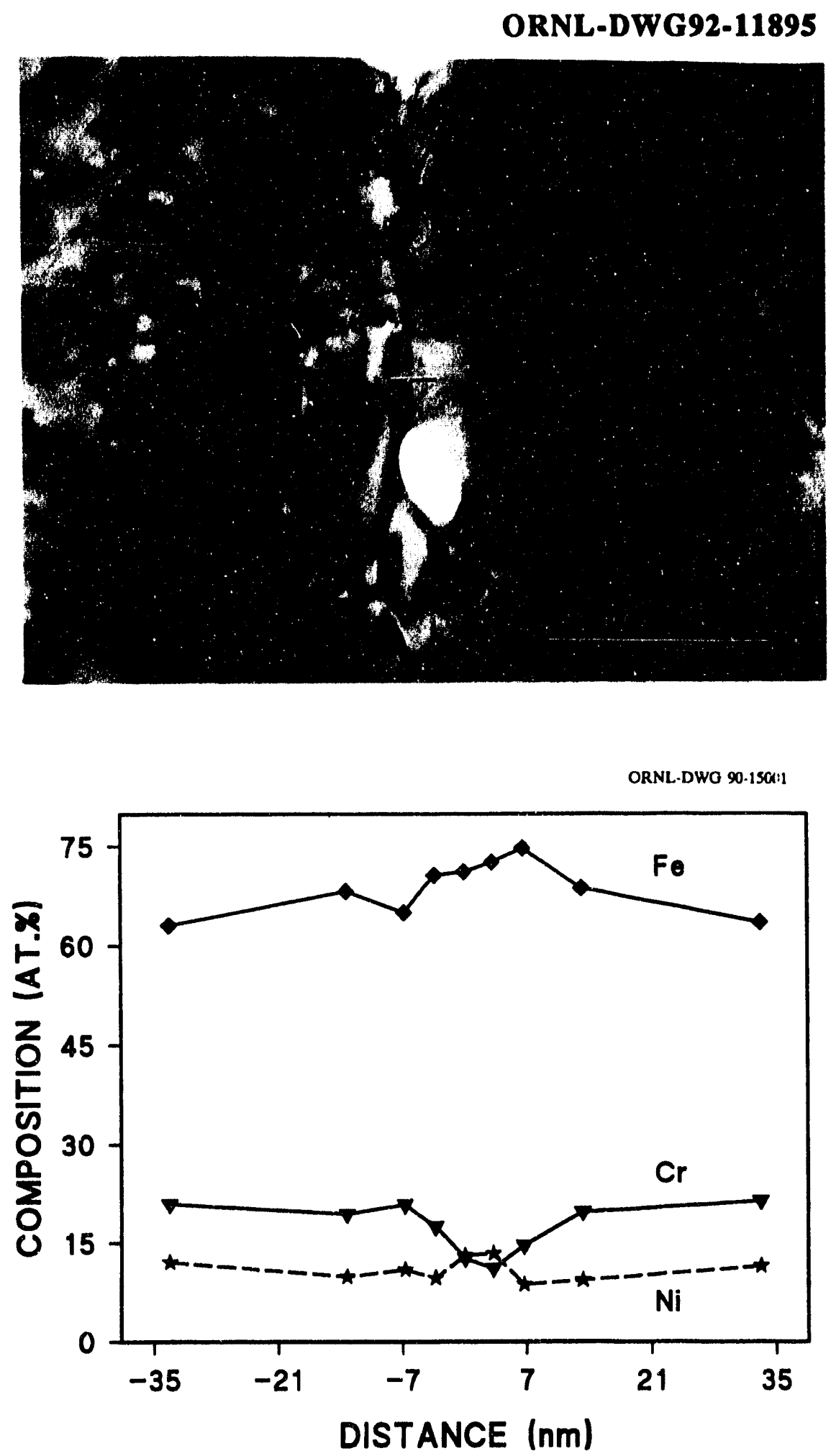

Fig. 38. Grain boundary in LS1A irradiated at $515^{\circ} \mathrm{C}$ to $10 \mathrm{dpa}$. 


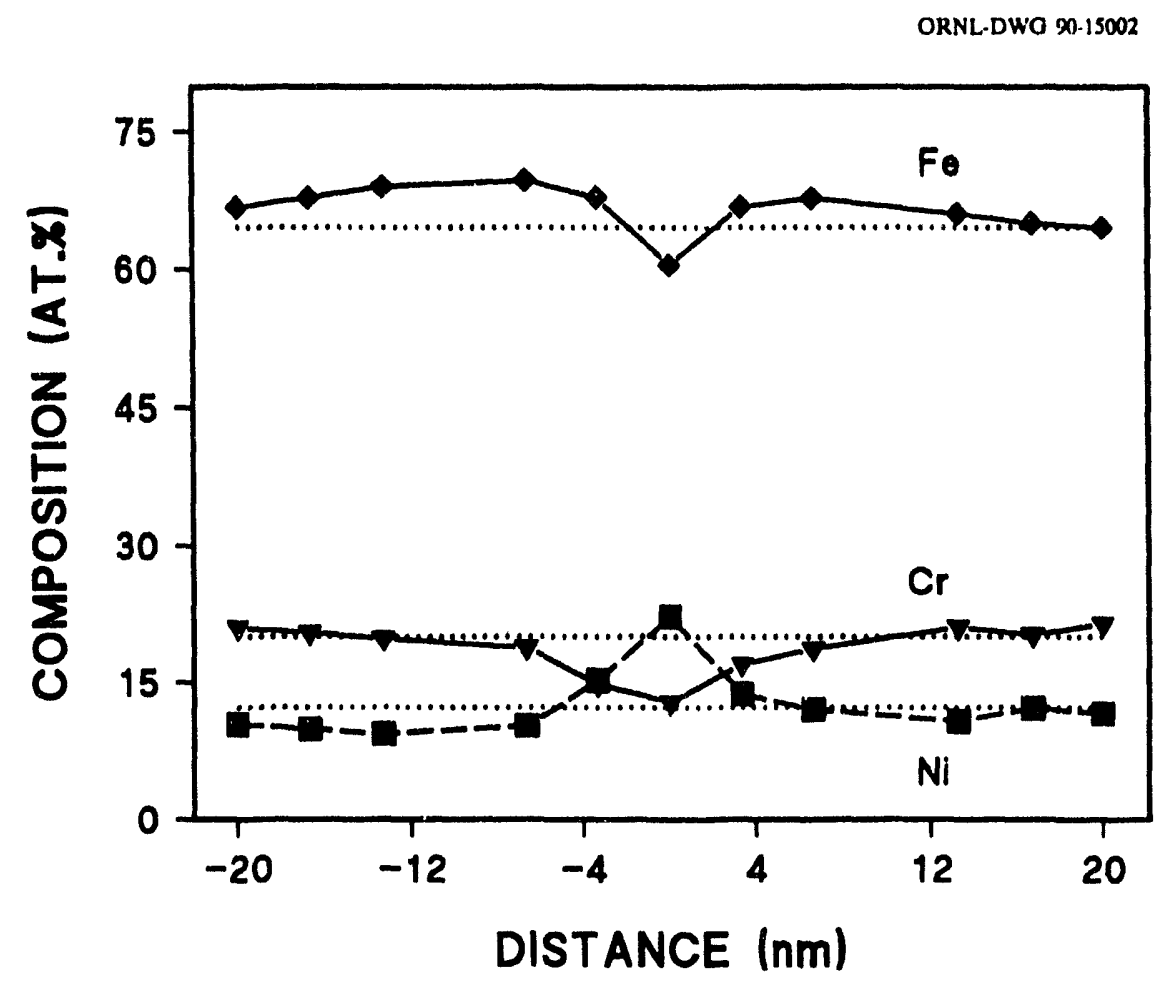

Fig. 39. Iron, chromium, and nickel profiles at grain boundary of stainless steel similar to LS1A irradiated at $515^{\circ} \mathrm{C}$ to $30 \mathrm{dpa}$.

\section{DISCUSSION}

\subsection{VALIDITY OF THE MINIATURIZED TEST TECHNIQUE FOR THE SL-EPR}

In order to adopt a miniaturized test technique for electrochemical measurements (SL-EPR), several questions must be resolved: Does the smaller tested area decrease the sensitivity of the test technique? Does the holder cause crevice effects? Does surface preparation by electropolishing affect the test results? As shown in Fig. 9, reactivation curves for the miniaturized test technique and the standard test technique do not show any significant difference (for example, the existence of crevice could have resulted in increased passivation current). This result indicates that, for the SL-EPR test, the miniaturized test technique can provide the same level of sensitivity as the standard test technique, and the specimen holder did not produce crevice effects. 
The specimen surface condition (e.g., oxide films and roughness) can significantly affect the SL-EPR test results. ${ }^{27,32}$ Mechanical polishing with $1-\mu \mathrm{m}$ diamond paste or $0.05-\mu \mathrm{m}$ alumina slurry is recommended for the maximum sensitivity of SL-EPR testing. ${ }^{28}$ As shown in Fig. 10, there was no significant difference between the results for the adopted electropolishing method and the recommended mechanical polishing. This indicates that the electropolishing technique developed for this study can be used to prepare specimen surfaces for SL-EPR testing without compromising the results.

Figure 12 shows that the $\mathrm{Pa}$ value of the SA PCA was increased above 10 coulombs $/ \mathrm{cm}^{2}$ by aging at $550^{\circ} \mathrm{C}$ for $1000 \mathrm{~h}$. Jones and Bruemmer have developed a computer code that calculates (predicts) sensitization based on chromium carbide precipitation and diffusion kinetics, and they have predicted the thermal sensitization behavior of PCA using this code. ${ }^{38}$ Their calculated results showed that PCA could be sensitized above a $\mathrm{Pa}$ value of 5 coulombs $/ \mathrm{cm}^{2}$ by aging at $550^{\circ} \mathrm{C}$ for $1000 \mathrm{~h}$. Their calculation is in general agreement with the results obtained in this study and indicates that thermally induced sensitization can be reliably evaluated using the miniaturized specimen technique.

\subsection{IGSCC SUSCEPTIBILITY OF NEUTRON-IRRADIATED STAINLESS STEELS}

Optical microscopy and SEM of the specimen surface after SL-EPR testing showed etching along grain boundaries of the PCA irradiated at 400 and $420^{\circ} \mathrm{C}$. This indicates that the material was sensitized by the neutron irradiation and that the sensitization was detectable by the SL-EPR test technique in the same manner as thermally induced sensitization. The X-ray microanalysis revealed that the chromium concentration at grain boundaries was decreased to $\sim 13$ at. \% ( 12 wt \%) for both the SA and $25 \% \mathrm{CW} 420^{\circ} \mathrm{C}$ specimens (Fig. 27). Since the measured chromium concentration is the average value of the excited volume, which contains the grain boundary and adjacent matrix, the actual concentration at grain boundaries should be lower than $12 \mathrm{wt} \%$, the minimum chromium level required to form protective films on austenitic steel surfaces. This decrease in chromium concentration would be sufficient to reduce the local stability of the passive film and cause its breakdown and the resulting grainboundary etching. Both RIS and radiation-enhanced precipitation can be the mechanisms for such a chromium depletion under irradiation. In the present study, fine grain-boundary precipitates were observed only for the SA PCA irradiated at $420^{\circ} \mathrm{C}$ (Fig. 22). However, $\mathrm{X}$-ray microanalysis showed that these precipitates were not enriched in chromium as compared to the matrix or the grain boundaries, while they were enriched in nickel and silicon 
(Fig. 27). Therefore, such precipitates cannot result in chromium depletion at grain boundaries. Furthermore, the depletion of oversized solutes (chromium, iron, and molybdenum) and enrichment of undersized solutes (silicon and nickel) at grain boundaries, and the narrow width of the solute segregation at grain boundaries $(\sim 10 \mathrm{~nm})$ in this study, are in good agreement with the reported characteristics of RIS.14,15 Therefore, RIS is considered to be the mechanism by which chromium depletion occurred at the grain houndaries and the cause of the resulting sensitization.

The reactivation charge [ $\mathrm{Pa}$ (time integral of current density)] is an accepted criterion to determine the DOS of a material to IGSCC. A good correlation between IGSCC susceptibility of austenitic stainless steels (type 304) and the Pa value has been demonstrated.27,28,39 For thermal sensitization, the $\mathrm{Pa}$ value is generally normalized to represent the charge-per-unit, grain-boundary area under the assumption that most of the reactivation current comes from grain boundaries. ${ }^{27,28,39}$ It has been suggested that IGSCC can occur when the Pa value exceeds about 2 coulombs/ $/ \mathrm{cm}^{2}$ for type 304 stainless steels. 27 The standard $\mathrm{Pa}$ values calculated for the PCA irradiated in FFTF/MOTA (Table 3) are more than an order of magnitude higher than this critical value.

The $\mathrm{Pa}$ value is calculated by:

$$
\mathrm{Pa}=\frac{\mathrm{QTotal}}{\mathrm{GBA}},
$$

where $\mathrm{Q}_{\text {Total }}$ is the total reactivation charge and GBA is the grain-boundary area, under the assumption that:

$$
\mathrm{Q}_{\text {Total }}=\mathrm{Q}_{\mathrm{GB}} \text {, }
$$

where $\mathrm{Q}_{\mathrm{GB}}$ is the reactivation charge from the region near the grain boundaries. However, as shown in Figs. $9(b)$ and $10(b)$, both the grain boundaries and the grain faces were etched during the reactivation process. This indicates that the grain faces contributed to the reactivation current and, thus,

$$
\mathrm{Q}_{\mathrm{Total}}=\mathrm{Q}_{\mathrm{GB}}+\mathrm{Q}_{\mathrm{GF}}
$$

where $\mathrm{Q}_{\mathrm{GF}}$ is the contribution of the grain faces to the total reactivation charge. Therefore, if Eq. (1) is used for the definition of Pa:

$$
\mathrm{Pa}=\frac{\mathrm{QTotal}}{\mathrm{GBA}}>\frac{\mathrm{QGB}}{\mathrm{GBA}},
$$


so that the obtained $\mathrm{Pa}$ value overestimates the actual reactivation charge associated with the grain boundaries. If it is assumed that the reactivation current density is the same for grain boundaries and grain faces:

$$
\frac{Q G B}{G B A}=\frac{Q G F}{G F A}
$$

where GFA is the grain face area, then,

$$
\begin{gathered}
Q_{\mathrm{GB}} \cdot \mathrm{GFA}=\mathrm{Q}_{\mathrm{GF}} \cdot \mathrm{GBA} \\
\mathrm{Q}_{\mathrm{GB}} \cdot \mathrm{GFA}+\mathrm{Q}_{\mathrm{GB}} \cdot \mathrm{GBA}=\mathrm{Q}_{\mathrm{GF}} \cdot \mathrm{GBA}+\mathrm{Q}_{\mathrm{GB}} \cdot \mathrm{GBA} \\
\mathrm{Q}_{\mathrm{GB}} \cdot(\mathrm{GFA}+\mathrm{GBA})=\mathrm{GBA} \cdot\left(\mathrm{Q}_{\mathrm{GF}}+\mathrm{Q}_{\mathrm{GB}}\right)
\end{gathered}
$$

and

$$
P a=\frac{Q G B}{G B A}=\frac{\left(Q G F+Q_{G B}\right)}{(G F A+G B)}=\frac{Q_{\text {Total }}}{\text { ATotal }},
$$

where $\mathrm{A}_{\text {Total }}$ is the total tested area. The $\mathrm{Pa}$ values for the $420^{\circ} \mathrm{C}$ specimens were thus normalized to represent the charge-per-unit, grain-boundary area using the total tested area of the specimens, and the results are shown in Table 5. These Pa values underestimate the contribution from the grain boundaries: based on the relative deep etching at the grain boundaries as compared to the dimples in the grain faces, the reactivation current density at the

Table 5. Reactivation charge value $(\mathrm{Pa})$ normalized by total tested area

\begin{tabular}{cc}
\hline Steel & $\mathrm{Pa}$, coulombs $/ \mathrm{cm}^{2}$ \\
\hline PCA solution annealed & 1.85 \\
PCA 25\% cold worked & 1.73 \\
& 1.53 \\
& 1.56 \\
\hline
\end{tabular}


grain boundaries was actually higher than that at the grain faces, in contrast with the assumption of uniform current density across both regions, which led to Eq. (5). Nevertheless, the Pa values of the irradiated specimens are still an order of magnitude higher than those of the thermally aged specimens and close to 2 coulombs $/ \mathrm{cm}^{2}$, the critical value for type 304 stainless steels to be susceptible to IGSCC. For molybdenum-containing austenitic stainless steels (e.g., type 316), lower critical Pa values have been reported than those for type 304 stainless steels for the same degree of thermally induced sensitization (as determined by the Strauss test). 40 It has also been reported that type 316 stainless steels could be susceptible to IGSCC with Pa values less than 1 coulomb/cm² (refs. 31, 41, and 42). Molybdenum is believed to influence chromium diffusion so that the chromium depletion becomes narrower and dissolution current decreases. ${ }^{31,41}$ Therefore, a lower critical value of $\mathrm{Pa}$, as compared to type 304 stainless steel, may be required for PCA to be susceptible to IGSCC. We suggest that neutron irradiation at $420^{\circ} \mathrm{C}$ up to $9 \mathrm{dpa}$ could have increased the DOS of PCA to a level at which IGSCC could occur. However, radiation-induced sensitization and thermally induced sensitization are substantially different processes, and direct application of the EPR-DOS criterion developed for thermally sensitized materials is not strictly valid. The post-SL-EPR microstructure shown by the irradiated specimens apparently differs from that of thermally sensitized specimens with similar Pa values (an example is shown in Fig. 40). For the irradiated specimens, grain-boundary etching was narrower. This can be attributed to a narrower width of chromium depletion and suggests that initial flaw cracks created by preferential dissolution along chromium-depleted areas may have smaller widths in the irradiated materials. Therefore, the strain at the tip of a flaw will be higher, and the potential for rupture of the oxide film at the flaw/crack tip would be increased. Changes in the mechanical properties by irradiation (e.g., matrix hardening and decrease in ductility) ${ }^{43-45}$ may also affect the susceptibility of the irradiated PCA to IGSCC. Further investigations including stress corrosion cracking tests, e.g., slow strain rate tensile test (SSRT) in highpurity aqueous environments which simulate the anticipated operating environment for fusion reactors, are necessary to rigorously correlate the SL-EPR test results obtained in the present study with the IGSCC susceptibility of the materials.

The higher He/dpa ratio relative to LWRs is one of the important characteristics of the fusion reactor environment that may affect RIS. ${ }^{24}$ Therofore, spectrally tailored experiment in ORR was designed to provide dose rates and He/dpa ratios typical of those in fusion reactors. Figure 41 shows the comparison of the reactivation curves of PCA from the spectrally tailored experiment in ORR $\left(400^{\circ} \mathrm{C}, 7.4 \mathrm{dpa}, 1.8\right.$ by $\left.10^{-7} \mathrm{dpa} / \mathrm{s}, \mathrm{He} / \mathrm{dpa}: 16\right)$ [ref. 25] with those from the irradiation in FFTF/MOTA $\left(420^{\circ} \mathrm{C}, 9 \mathrm{dpa}, 9\right.$ by $10^{-7} \mathrm{dpa} / \mathrm{s}$, He/dpa:0.4) [ref. 46]. 
ORNI-PHOTO 6320 90

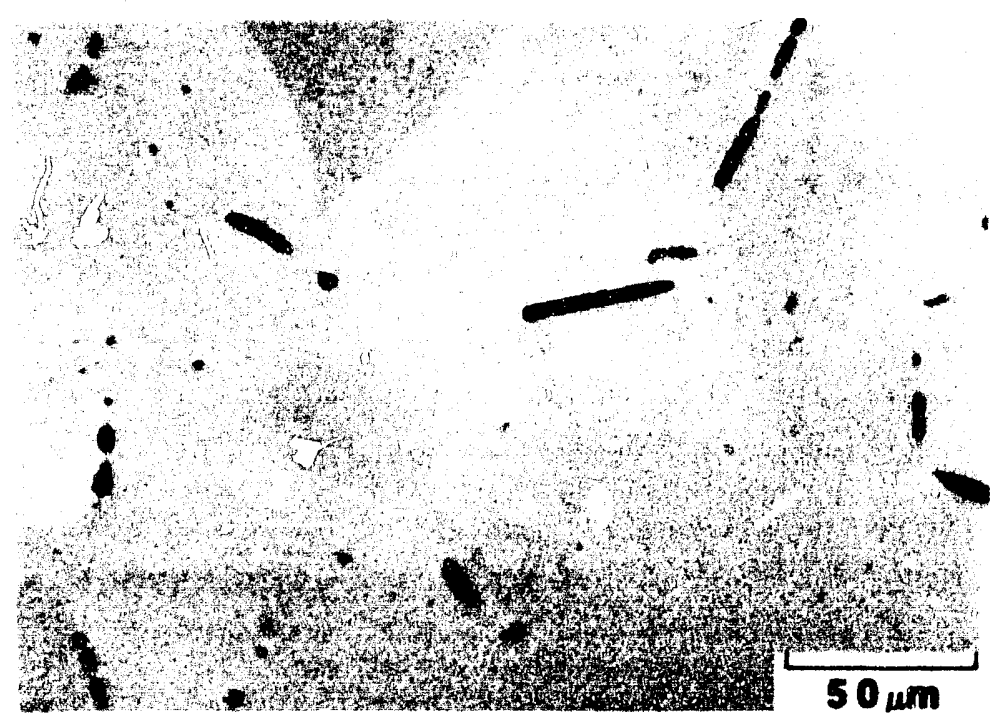

Fig. 40. Optical micrograph of thermally sensitized $25 \% \mathrm{CW}$ PCA after SL-EPR test (aged at $620^{\circ} \mathrm{C}$ for $2 \mathrm{~h}$, $\mathrm{Pa}=1.64 \mathrm{C} / \mathrm{cm}^{2}$ ).

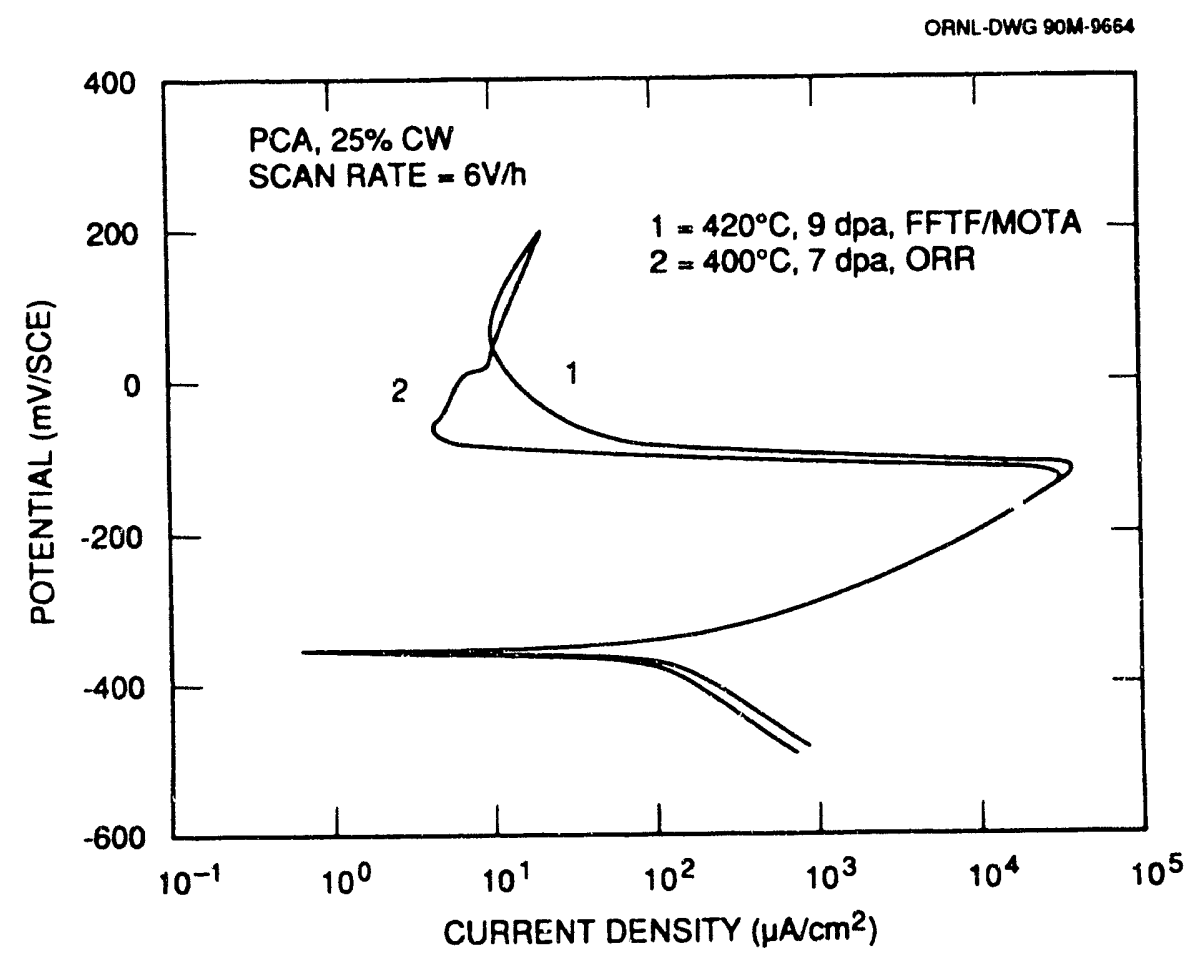

Fig. 41. Comparison of reactivation curves for different irradiation conditions. 
Specimens from both irradiation experiments showed similar reactivation curves. Although the Flade potential was higher for the specimen from FFTF, the degree of sensitization can be considered to be similar for both irradiation conditions. A definitive answer for the effect of each irradiation parameter is not yet possible from this comparison. However, since the difference in dose rate may compensate for the difference in temperature 22.23 and RIS appears to saturate at displacement damage levels between 5 to $10 \mathrm{dpa}$ (ref. 15), this comparison may reflecr the difference in He/dpa ratio. Therefore, the similar reactivation behavior after both irradiation conditions suggests that He/dpa ratio does not strongly affect the radiation-induced sensitization of this material.

In the case of ITER, the temperatures in normal service condition for water-cooled components, such as an FWB, are designed to be in the range of 50 to $200^{\circ} \mathrm{C}$ (ref. 26). The degree of radiation-induced sensitization is expected to be less because of the decreased mobility and the increased number of recombinations of vacancies and interstitials at the lower temperatures of ITER. Furthermore, the higher dose rate in ITER relative to LWRs may also increase recombination, 22,23 thereby leading to a further decrease in RIS at the lower temperatures. In the spectrally tailored experiment in ORR, the 25\% CW PCA was irradiated to $7 \mathrm{dpa}$ at 60 and $200^{\circ} \mathrm{C}$, the design temperature range for ITER. Irradiation at $60^{\circ} \mathrm{C}$ did not increase the $\mathrm{Pa}$ value nor cause grain-boundary etching of the specimen surface during SL-EPR testing. After irradiation at $200^{\circ} \mathrm{C}$, the $\mathrm{Pa}$ value of the material increased by more than an order of magnitude as compared to the unirradiated condition (Fig. 31), but grainboundary etching, an indicator of increasing IGSCC susceptibility, was not found on the specimen surface after the SL-EPR testing. This indicates that the IGSCC susceptibility of this material may not have been increased by irradiation at either 200 or $60^{\circ} \mathrm{C}$. Since RIS has been reported to saturate at this level of displacement damage, ${ }^{15}$ these results suggest that IGSCC associated with chromium depletion may not occur for this material in the normal operating environment of ITER.

\subsection{GRAIN FACE ATTACK OF IRRADIATED STAINLESS STEELS}

Grain face attack was observed after SL-EPR testing the austenitic stainless steels irradiated by neutrons at $200^{\circ} \mathrm{C}$ and above and heavy ions at $515^{\circ} \mathrm{C}$ (Figs. 19, 20, 33, and 36). Since only grain boundaries are etched while grain faces remain intact for thermally sensitized materials (Fig. 40), the grain face attack can be considered a result of radiation effects, e.g. microstructural changes. Chemical changes in the SL-EPR solution due to 
$\gamma$-radiolysis from the radioactive specimens ${ }^{1,5,47}$ could also be a cause for the attack. However, grain face attack was also observed for the material irradiated by heavy ions, which do not emit $\gamma$-rays and, therefore, cannot cause $\gamma$-radiolysis (Fig. 36). Therefore, the grain face attack that was observed can be considered a result of irradiation-induced microstructural changes and not an artifact of testing radioactive specimens.

Since the SL-EPR test detects the instability of passive films associated with chromium depletion, the occurrence of grain face attack suggests there was localized chromium depletion within the matrix. It has been demonstrated that, under irradiation, chromium depletion can occur at defects in grain interiors (e.g., voids, dislocation loops) as well as at grain boundaries via RIS. ${ }^{36,48,49}$ Similar RIS was observed in the present study. Both voids and dislocation loops were found to be depleted in chromium for the SA PCA irradiated at $420^{\circ} \mathrm{C}$ to $9 \mathrm{dpa}$ in FFTF/MOTA (Figs. 28 and 29). At voids, the chromium level was reduced to $\sim 13$ at. $\%$ $(\sim 12 \mathrm{wt} \%)$, a sufficiently low level to cause breakdown of passive films. However, the density of voids was not sufficient to account for the etching of the grain faces, particularly in the $\mathrm{CW}$ material. The $\mathrm{CW}$ material exhibited similar grain face etching to the SA material, although the density of voids was much less. At dislocation loops, the measured level of RIS was not as pronounced as at voids and grain boundaries. However, the measured compositions are biased toward the matrix composition because of defects not extending through the entire foil thickness and the finite size of the excited volume associated with incident probe size and beam broadening effects. Thus, chromium depletion at the dislocation loops may be similar in magnitude to that at voids and grain boundaries. The results of TEM on the CW PCA irradiated at 60 to $400^{\circ} \mathrm{C}$ in ORR are given in Fig. 42 (ref. 50). Large dislocation loops were formed at the irradiation temperatures above $200^{\circ} \mathrm{C}$, and coarsening occurred at $400^{\circ} \mathrm{C}$. This temperature dependence of loop formation is similar to that of the grain face etching shown in Figs. 32 and 33. Therefore, chromium depletion at the dislocation loops by RIS can be considered a likely candidate for the observed grain face attack. The formation of fine $\gamma\left(\mathrm{Ni}_{3} \mathrm{Si}\right)$ was observed in the matrix of the SA PCA irradiated at $420^{\circ} \mathrm{C}$ to $9 \mathrm{dpa}$ in FFTF/MOTA (Fig. 23). These Ni-rich precipitates could also contribute to the grain face attack as well as chromium-depleted dislocation loops. Radiation-enhanced, spinodal-type decomposition can also create local chromium depletion in grain interiors. ${ }^{51}$ Such a decomposition results in periodic fluctuations of the chromium concentration with a wavelength of less than $100 \mathrm{~nm}$ and could also be responsible for the observed etching.

The absence of the grain-boundary etching at $330^{\circ} \mathrm{C}$ and below indicates that at lower temperatures, the extent of chromium depletion at grain boundaries was apparently less than that at matrix defects. Under the inverse Kirkendall effect, which has been considered a major 


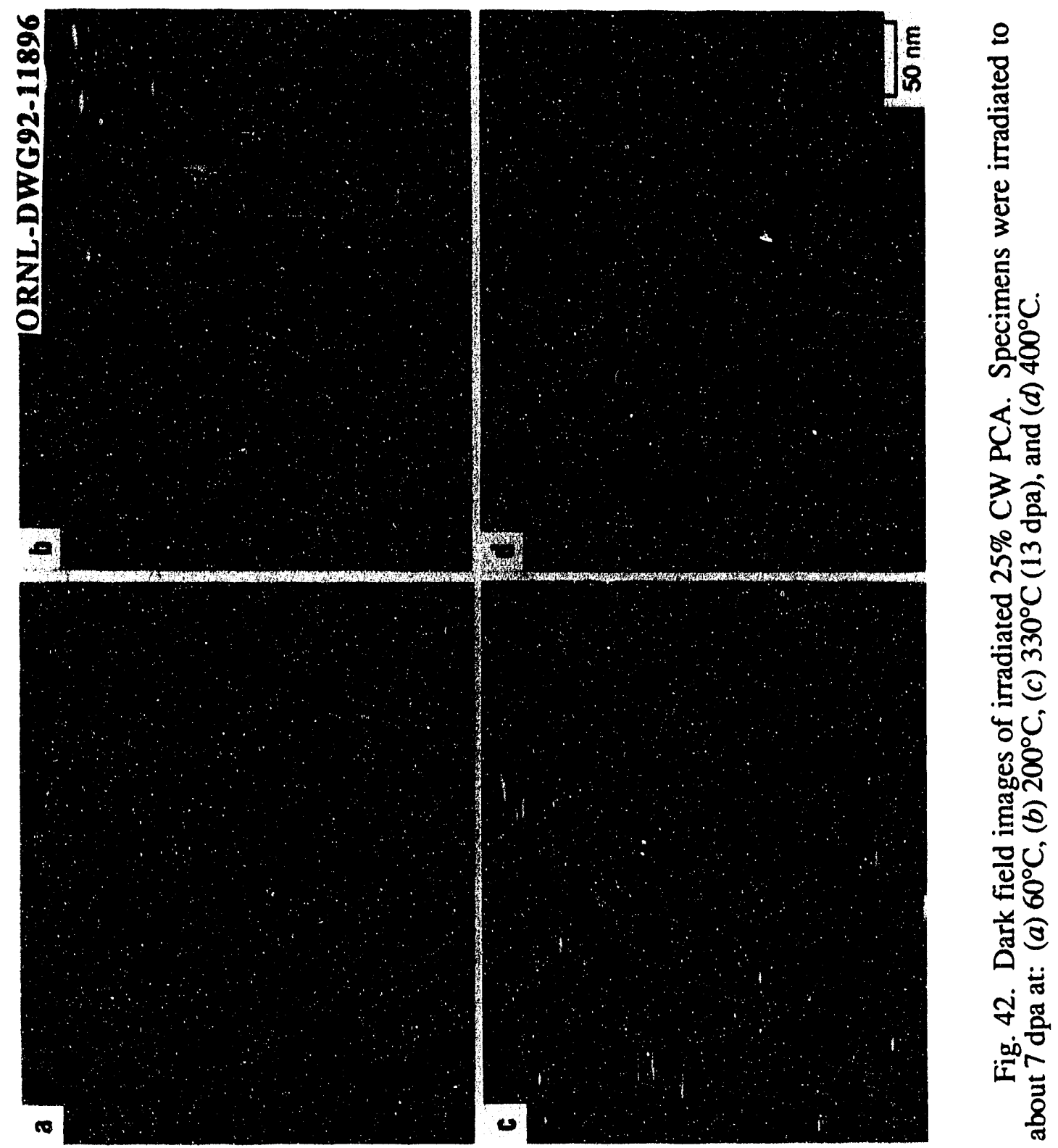


RIS mechanism, both a vacancy flux and an interstitial flux toward defect sinks contribute to RIS. ${ }^{22}$ The vacancy flux causes depletion of elements that diffuse exclusively via a vacancy mechanism (normally oversized solute, such as chromium and molybdenum for stainless steels), while the interstitial flux causes enrichment of elements that diffuse exclusively via an interstitial mechanism (normally undersized solute, such as nickel, silicon, and phosphorus for stainless steels). ${ }^{22}$ Both the vacancy and interstitial fluxes finally would decrease the relative chromium concentration at defect sinks through depletion of chromium atoms and enrichment of nickel, silicon, and phosphorus atoms, respectively. Since removal of a chromium atom can reduce the relative chromium concentration at a sink more effectively than capture of a nickel (or silicon, phosphcı us) atom, increasing the contribution of interstitials and decreasing the contribution of vacancies may result in a lower level of chromium depletion. Dislocation loops are normally more interstitially biased than grain boundaries, and a lower level of chromium depletion is expected. However, the EPR test results indicated a higher level of chromium depletion at dislocation loops. The total point defect flux-per-unit interface area is larger for dislocation loops than for grain boundaries because the source volume for the diffusion-per-unit interfacial area is larger for dislocation loops. This difference in the total point defect flux may be a cause for the lower RIS at grain boundaries than at dislocation loops. At lower irradiation temperatures, the level of chromium depletion at dislocation loops due to RIS becomes sufficient to lower the chromium concentration to less than the critical level needed for formation of passive films, Cc (i.e., $\sim 12 \mathrm{wt} \%$ for type 304 stainless steel), while the chromium content at grain boundaries may remain above this critical value. At higher irradiation temperatures, the overall flux of vacancies and interstitials increases and, therefore, the level of chromium at both dislocations and grain boundaries decreases below C. (Fig. 43).

The results of potentiostatic measurements on ORR/MFE- $6 \mathrm{~J} / 7 \mathrm{~J}$ irradiated CW PCA are shown in Fig. 44 as a function of irradiation temperature at a dose of 7.4 dpa. Changes in current density as a function of time at a passivating potential were measured. Passivation rates are slower for the specimens irradiated at higher temperatures, which exhibited severe grain face attack in the SL-EPR tests. The localized instability of passive films in the matrix may account for the changes in the passivation rates. Therefore, it can be suggested that such a localized instability of passive films in the matrix would become the initiation sites for transgranular stress corrosion cracking (TGSCC) and also would result in an increase of the general corrosion rate under high-temperature water environments. The CW PCA irradiated :I $200^{\circ} \mathrm{C}$ exhibited only grain face etching, and the increase in the reactivation current c:an conclusively be related to the development of the fine grain face etching (Fig. 34). In such a 
ORNL-DWG92-11918
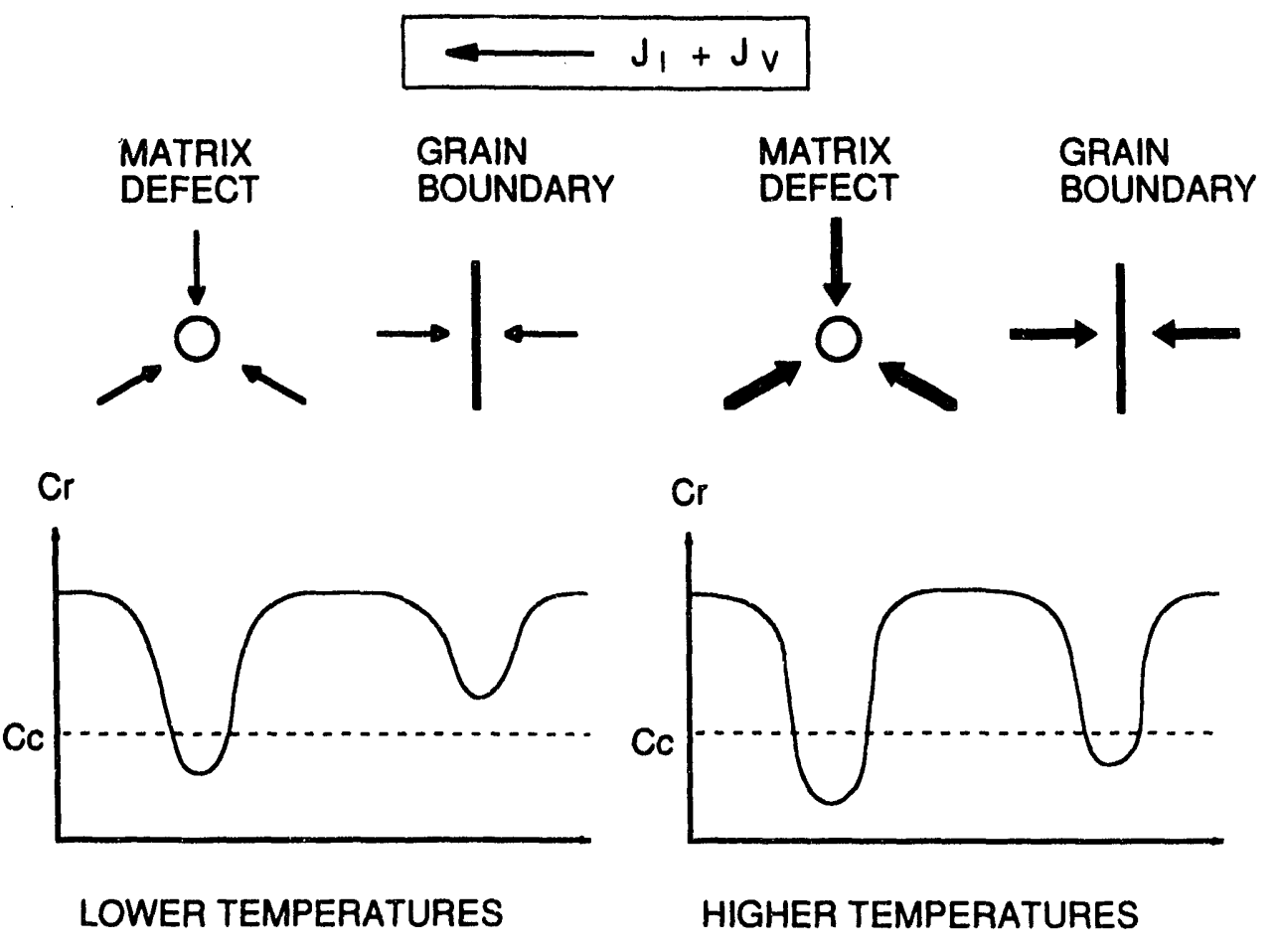

Fig. 43. Schematic of hypothesized RIS mechanism.

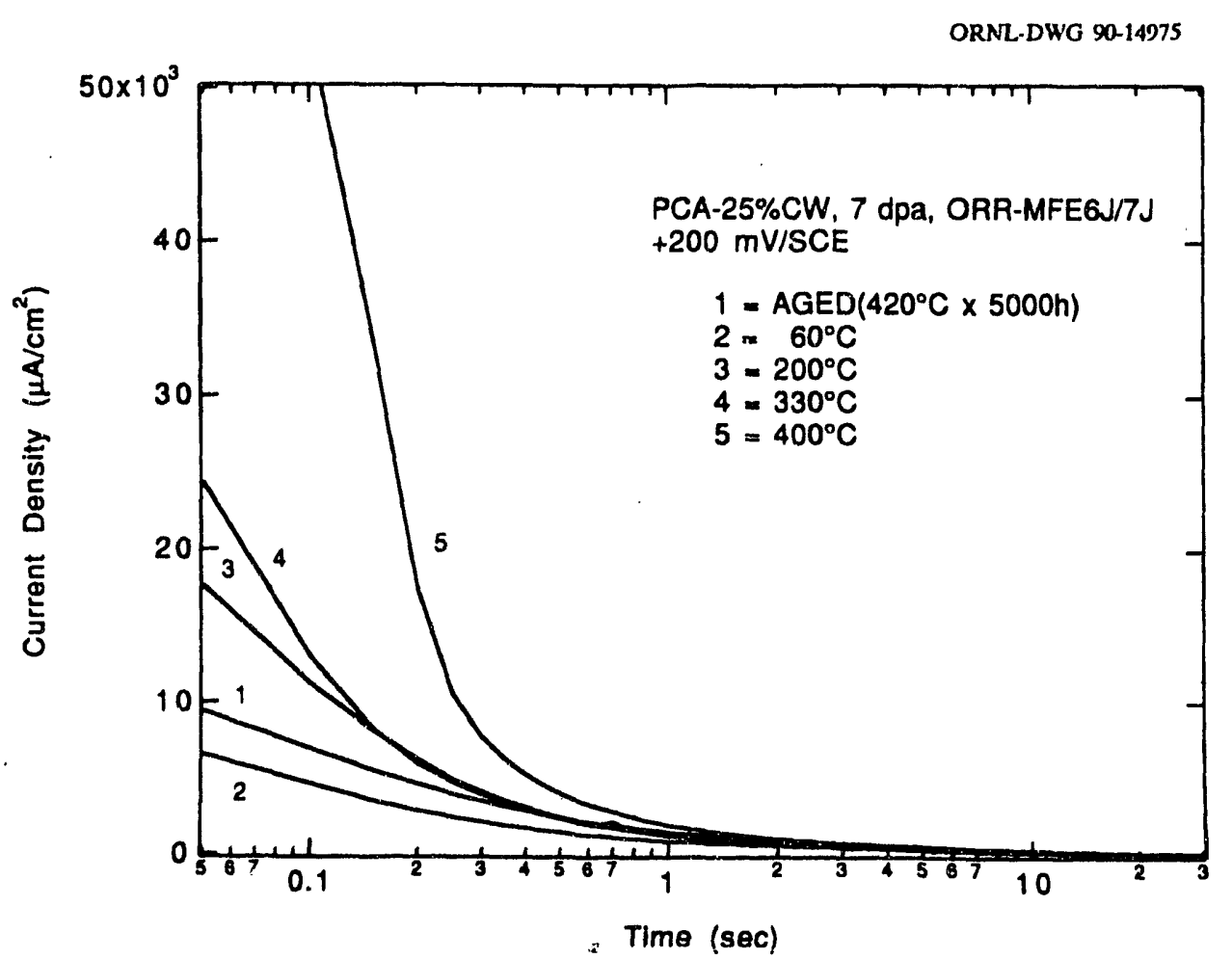

Fig. 44. Changes in current density of irradiated $25 \% \mathrm{CW}$ PCA as a function of time at a potential of $+200 \mathrm{mV}$ versus SCE. 
case, the $\mathrm{Pa}$ value represents the degree of localized instability of passive films on the matrix and might be used as an indicator of TGSCC susceptibility and/or general corrosion rate.

\subsection{EFFECT OF CHEMICAL COMPOSITION ON RADIATION- INDUCED SENSITIZATION}

Among the CW materials irradiated at $420^{\circ} \mathrm{C}$ to $9 \mathrm{dpa}$ in FFTF/MOTA, the PCA exhibited grain-boundary etching, but the type 316 stainless steels did not (Fig. 18). This indicates that the type 316 stainless steels are less susceptible to radiation-induced, grain-boundary sensitization. Chromium is critical to the formation of protective passive films, while molybdenum increases the stability of passive films for most austenitic stainless steels. Higher chromium and molybdenum contents in the type 316 stainless steels can account for their lower susceptibility to the grain-boundary sensitization relative to the PCA.

The $\mathrm{Pa}$ values calculated using total tested area for these steels are given as a function of $(\mathrm{Cr}+\mathrm{Mo})$ content in Fig. 45. The $\mathrm{Pa}$ value decreases with increasing $(\mathrm{Cr}+\mathrm{Mo})$ content. Since the grain-boundary etching was not observed for the type 316 stainless steels

ORNL.DWG 90-14974

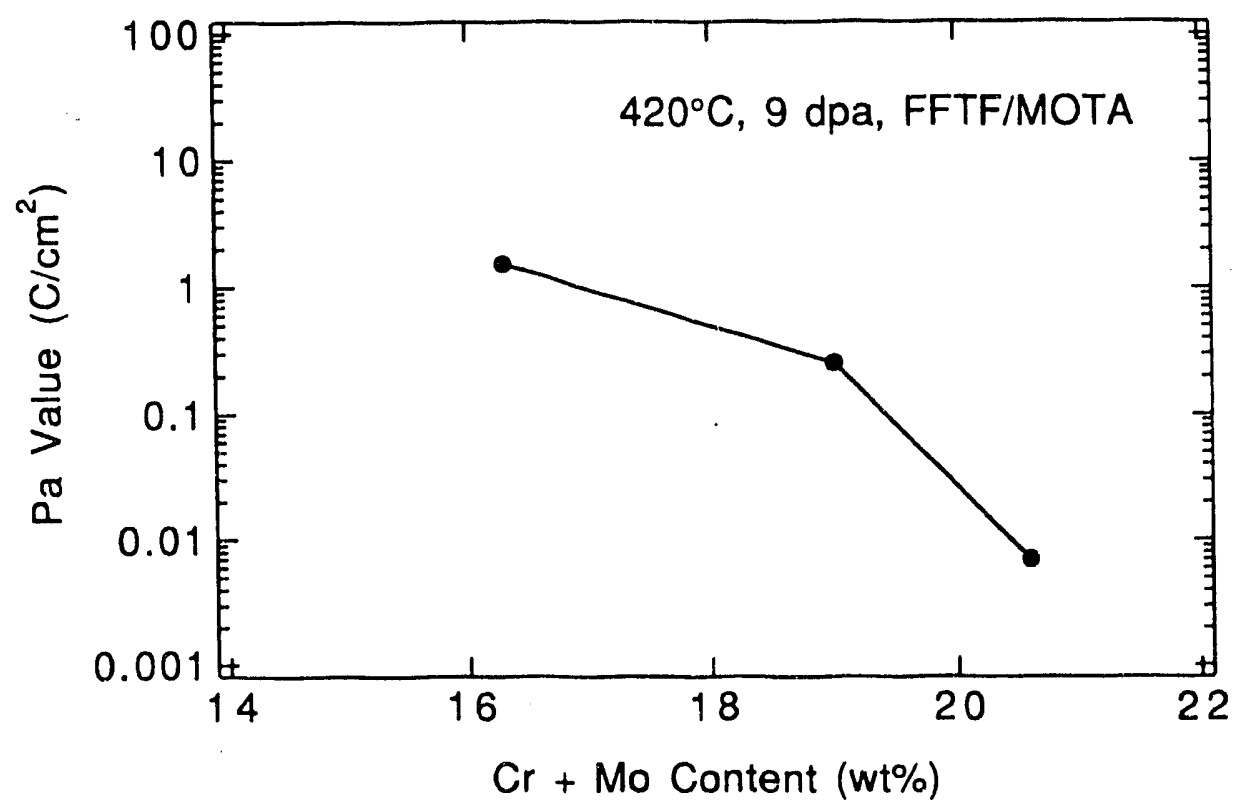

Fig. 45. Effect of chromium and molybdenum content of $\mathrm{Pa}$ values of cold-worked austenitic stainless steels irradiated in FFTF/MOTA at $420^{\circ} \mathrm{C}$ to $9 \mathrm{dpa}$. 
(Fig. 18), the $\mathrm{Pa}$ values of these steels $(\mathrm{Cr}+\mathrm{Mo}=\sim 19$ and $21 \mathrm{wt} \%$ for $316 \mathrm{~N}$-lot and 316 DO-heat, respectively) can be considered to represent the degree of instability of the passive film on the matrix. The $\mathrm{Pa}$ value for the $\mathrm{PCA}(\mathrm{Cr}+\mathrm{Mo}=\sim 16 \mathrm{wt} \%)$ is also representative of the instability of the passive film on the matrix because of the relatively larger contribution of matrix etching to the reactivation charge. Therefore, the results indicate that passive film instability in the matrix was caused by the local depletion of chromium and molybdenum and can be reduced by increasing the bulk content of both of these elements.

\subsection{HEAVY-ION IRRADIATION FOR A SIMULATION OF RADIATION- INDUCED SENSITIZATION}

Bruemmer et al..$^{52}$ have measured chromium depletion profiles at grain boundaries in similar austenitic stainless steels to LS1A irradiated by heavy ion at $500^{\circ} \mathrm{C}$. They found that the RIS profiles were fully developed by the damage displacement level of $5 \mathrm{dpa}$ with a chromium depletion width of $10 \mathrm{~nm}$ on either side of a grain boundary. In the present study, the measured chromium depletion at grain boundaries of the $30 \mathrm{dpa}$ specimen did not significantly increase as compared to that of the $10 \mathrm{dpa}$ specimen, in good agreement with the results of Bruemmer et al. Furthermore, the measured reactivation charge did not significantly increase at a damage displacement beyond $10 \mathrm{dpa}$. Since the reactivation charge is more sensitive to the contribution from grain faces than that from grain boundaries (because of the much larger, dissolved area for grain faces), this indicates that RIS at defects in the matrix has also saturated at $10 \mathrm{dpa}$. Although it was not evident from the reactivation charges, electrochemical changes continued to occur at damage displacements beyond $10 \mathrm{dpa}$. Flade potentials increased with increasing damage displacement up to $30 \mathrm{dpa}$, although significantly larger changes occurred between 1 and $10 \mathrm{dpa}$. The higher Flade potential for the $30 \mathrm{dpa}$ specimen implies less stability of passive films relative to the $10 \mathrm{dpa}$ specimen, even though no significant difference was observed between the reactivation charges of these two specimens. In the present study, the results for materials irradiated by heavy ions were very similar to those of neutron-irradiated materials. The LS1A irradiated at $515^{\circ} \mathrm{C}$ to $10 \mathrm{dpa}$, and the SA PCA irradiated at $420^{\circ} \mathrm{C}$ to $9 \mathrm{dpa}$ in FFTF/MOTA; both specimens showed the increase in the reactivation charge and in the Flade potential as compared to unirradiated materials. In addition to grain-boundary etching, similar grain face etching was observed on the specimen surface after SL-EPR testing both materials. The measured RIS profiles were also quite similar. This good agreement between the data from different irradiation conditions was not unexpected when considering the temperature and dose 
rate dependence of RIS. In this case, the difference in the irradiation temperatures would partly be compensated by the difference in the dose rates. ${ }^{22}$ One apparent difference between the results of these two materials is the appearance of the shoulder in the reactivation peak for the heavy-ion-irradiated LS1A (Fig. 35). Such a shoulder did not appear in the $316 \mathrm{~N}$-lot (which had similar chemical composition to the LS1A) irradiated under the same conditions as the SA PCA, and, thus, the differences in chemical compositions between the LS1A and the PCA were not the cause. The appearance of the shoulder suggests that two different levels of local film instability existed. One possible explanation is the preferential dissolution of the G-phase. Since the G-phase contains only $\sim 5 \mathrm{wt} \%$ chromium, it may dissolve at higher potentials than required for a film breakdown at grain boundaries and matrix defects. Precipitation of the eta-phase may locally reduce the chromium level of the adjacent matrix and could also be a cause for the shoulder. The shoulder did not appear for the $1 \mathrm{dpa}$ specimen, which may not have contained either G- or eta-phase. The results suggest that, with the appropriate combination of irradiation temperature and dose rate, HII may simulate radiationinduced sensitization caused by neutron irradiation quite well and, thus, can be a useful method for both basic research and alloy development. Compared to neutron irradiation, higher temperatures should be chosen for HII, because the higher dose rate results in higher excess vacancy concentrations and greater defect recombination rates. ${ }^{22}$ However, in this case, effects of changes in thermal equilibrium and diffusion (e.g., precipitation) should carefully he considered.

\section{CONCLUSIONS}

An electrochemical testing methodoloy for evaluating miniaturized radioactive specimens was developed. Radiation-induced sensitization of several austenitic stainless steels after neutron or HII was evaluated by the SL-EPR technique. The following conclusions can be made:

1. SL-EPR testing of miniaturized specimens can provide reliable data that are comparable to data obtained with standard (larger) specimens.

2. Significant changes in electrochemical properties, such as increased reactivation current and Flade potential, were detected for PCA and type 316 stainless steels irradiated at 200 to $420^{\circ} \mathrm{C}$ up to 7 to $9 \mathrm{dpa}$ in FFTF/MOTA and ORR-MFE6J/7J.

3. Irradiation at $60^{\circ} \mathrm{C}$ to $7 \mathrm{dpa}$ in ORR-MFE6J/7J did not affect the electrochemical properties of PCA. 
4. Optical microscopy and SEM of the specimen surface after SL-EPR testing showed grain-boundary etching of both the SA and $25 \% \mathrm{CW}$ PCA irradiated above $400^{\circ} \mathrm{C}$. This indicates grain-boundary sensitization, which may lead to increased susceptibility to IGSCC. Sensitization was not observed for $20 \% \mathrm{CW}$ type 316 stainless steels at the same irradiation condition.

5. X-ray microanalysis indicated significant RIS at grain boundaries in both the SA and $25 \% \mathrm{CW}$ PCA irradiated at $420^{\circ} \mathrm{C}$ to $9 \mathrm{dpa}$ in FFTF/MOTA. Grain boundaries were depleted in chromiurn, iron, and molybdenum, while they were enriched in silicon and nickel. Depletion of chromium to apparent levels of 10 to $12 \mathrm{wt} \%$ was observed within an $\sim 10$-nm-wide region at grain boundaries. This chromium depletion can be considered the cause for the radiation-induced, grain-boundary sensitization. Chromium-rich carbide precipitation was not observed at grain boundaries and was not the cause of the sensitization.

6. Localized grain face attack was observed in the form of pitting and dimple-shape corrosion on specimen surfaces after SL-EPR testing of both the SA and 25\% CW PCA and $20 \% \mathrm{CW}$ type 316 stainless steels irradiated at 200 to $420^{\circ} \mathrm{C}$. The attack became more severe with increasing irradiation temperature.

7. X-ray microanalysis indicated that RIS resulted in chromium depletion from dislocation loops and voids in the matrix by and from grain boundaries for the SA PCA irradiated at $420^{\circ} \mathrm{C}$ to $9 \mathrm{dpa}$ in FFTF/MOTA. This local chromium depletion may be a cause for localized passive film instability in matrix and resulting grain face attack during SL-EPR testing. $\gamma$ precipitates observed in the material may also contribute to the film instability.

8. The degree of the radiation-induced, grain-boundary sensitization and the passive film instability in the matrix decreases with increasing chromium and molybdenum content.

9. Due to the occurrence of the grain face attack during SL-EPR testing, the reactivation charge normalized by total grain-boundary area, an accepted EPR-DOS criterion for the IGSCC susceptibility of thermally sensitized stainless steels, should be modified in evaluating radiation-induced sensitization under the irradiation conditions investigated.

10. The results of SL-EPR test and X-ray microanalysis for heavy-ion-irradiated material were quite similar to those of neutron-irradiated materials. At the temperature range in this study, HII may be a useful method for simulating radiation-induced sensitization by neutron irradiation.

11. Further investigations including stress corrosion cracking tests, e.g., SSRT, on the same irradiated materials are necessary to rigorously correlate the SL-EPR test results obtained here with the IGSCC susceptibility of the materials. 


\section{ACKNOWLEDGMENTS}

The authors gratefully acknowledge the contributions of Drs. T. Kondo, E. E. Bloom, and A. Hishinuma in planning this research program. The effort of Dr. P. J. Maziasz in supplying control material and microstructural information regarding irradiated materials was greatly appreciated. The technical assistance of Mr. L. T. Gibson in the preparation and handling of radioactive specimens was invaluable. This work was performed while one of the authors (T. Inazumi) was a visiting scientist at Oak Ridge National Laboratory under the Program for U.S./Japan Collaborative Testing of First Wall and Blanket Structural Materials with Mixed Spectrum Fission Reactors. The authors also thank M. L. Hodges for final report preparation and K. Spence for editorial review.

\section{REFERENCES}

1. A. J. Jacobs and G. P. Wozadlo, pp. 173-80 in Proceedings of the International Conference on Nuclear Power Plant Aging, Availability Factor and Reliability Analysis, Materials Park, Ohio, 1985.

2. W. L. Clarke and A. J. Jacobs, pp. 153-60 in Proceedings of the International Conference on Materials in Nuclear Energy, American Society for Metals, Materials Park, Ohio, 1982.

3. R. N. Duncan, Stainless Steel Failure Investigation Program, Final Summary Report , GEAP-5530, General Electric Company, San Jose, Calif., 1968.

4. B. M. Gordon and G. M. Gordon, Materials Aspects of BWR Plant Life Extension, Nucl. Eng. Des. 98, 109-21 (1987).

5. P. L. Andresen and F. P. Ford, Modeling Irradiation Effects on Stress Corrosion Crack Growth Rates, pp.497/1-27 in Corrosion/89, New Orleans, Louisiana, Paper No. 497, National Association of Corrosion Engineers, Houston, Tex., 1989.

6. K. Fukuya, S. Nakahigashi, S. Ozaki, M. Terasawa, and S. Shima, Grain Boundary Segregation of Impurity Atoms in Irradiated Austenitic Stainless Steel, pp. 665-71 in Proceedings of the Third International Symposium on Environmental Degradation of Materials in Nuclear Power System - Water Reactors, TMS, New York, 1987.

7. H. Hanninen and I. Aho-Mantila, Environment-Sensitive Cracking of Reactor Internals, pp. 77-92 in Proceedings of the Third International Symposium on Environmental Degradation of Materials in Nuclear Power System - Water Reactors, TMS, New York, 1987. 
8. F. Garzarolli, D. Alter, P. Dewes, and J. L. Nelson, Deformability of Austenitic Stainless Steels and Ni-Base Alloys in the Core of a Boiling and Pressurized Water Reactor, pp. 657-64 in Proceedings of the Third International Symposium on Environmental Degradation of Materials in Nuclear Power System-Water Reactors, TMS, New York, 1987.

9. A. J. Jacobs, G. P. Wozadlo, N. Nakata, T. Yoshida, and I. Masaoka, Radiation Effects on the Stress Corrosion and Other Selected Properties of Type-304 and Type-316 Stainless Steel, pp. 673-81 in Proceedings of the Third International Symposium on Environmental Degradation of Materials in Nuclear Power System-Water Reactors, TMS, New York, 1987.

10. E. P. Simonen and R. H. Jones, Calculated Solute Segregation Kinetics Related to Irradiation Assisted Stress Corrosion Cracking, pp. 683-90 in Proceedings of the Third International Symposium on Environmental Degradation of Materials in Nuclear Power System-Water Reactors, TMS, New York, 1987.

11. I. Aho-Mantila and H. Hanninen, Electrochemical Methods to Estimate IASCC Susceptibility of Stainless Steels, pp. 349-56 in Proceedings of the International Conference on Materials for Nuclear Reactor Core Applications 1, British Nuclear Energy Society, London, 1987.

12. A. J. Jacobs, R. E. Clausing, L. Heatherly, and R. M. Kruger, IrradiationAssisted Stress Corrosion Cracking and Grain-Boundary Segregation in Heat-Treated Type 304SS, CONF-880613--3, Martin Marietta Energy Systems, Inc., Oak Ridge Natl. Lab., 1988.

13. P. L. Andresen, F. P. Ford, S. Murphy, and J. Perks, Proceedings of the Fourth International Symposium on Environmental Degradation of Materials in Nuclear Power System - Water Reactors, to be published.

14. D.I.R. Norris, C. Baker, and J. M. Titchmarch, "Radiation-Induced Sensitization of Stainless Steels," pp. 86-98 in Proceedings of the Symposium of the Berkeley Nuclear Laboratories, September 23, 1986, CEGB, Berkeley, Gloucestershire, United Kingdom, 1987.

15. J. M. Perks, A. D. Marwick, and C. A. English, "Radiation-Induced Sensitization of Stainless Steels," pp. 15-34 in Proceedings of the Symposium of the Berkeley Nuclear Laboratories, September 23, 1986, CEGB, Berkeley, Gloucestershire, United Kingdom, 1987.

16. C. Taylor, "Radiation-Induced Sensitization of Stainless Steels," pp. 60-73 in Proceedings of the Symposium of the Berkeley Nuclear Laboratories, September 23, 1986, CEGB, Berkeley, Gloucestershire, United Kingdom, 1987. 
17. G. E. C. Bell, E. A. Kenik, and L. Heatherly, Jr., to be published in J. Nucl. Mater., ICFRM-5 (1992).

18. A. J. Jacobs, C. Shepherd, G. E. C. Bell, and G. P. Wozadlo, "High-Temperature Solution Annealing as an IASCC Mitigation Technique," pp 917-39 in Proceedings of the Fifth International Symposium on Environmental Degradation in Nuclear Systems - Water Reactors, Monterey, California, August 25-30, 1991.

19. C. C. Baker, U.S. ITER Shield and Blanket Design Activities, Fusion Technol. 15, 849-57 (1989).

20. R. H. Jones, Assessment of Stress-Corrosion "Cracking for Near-Term Fusion Reactors," pp. 184-88 in Fusion Reactor Materials, Semiannual Progress Report, DOE/ER0313/4, U.S. DOE, Office of Fusion Energy, March 31, 1988.

21. P. J. Maziasz, B. L. Cox, T. K. Roche, and E. E. Bloom, "Time-TemperaturePrecipitation Curve Determination of the Path A Prime Candidate Alloy for Microstructural Design," pp. 103-27 in Alloy Development for Irradiation Perfo: mance, Quarterly Progress Report, DOE/ET-0058/7, U.S. DOE, Office of Fusion Energy, September 30, 1979.

22. P. R. Okamoto and L. E. Rehn, "Radiation-Induced Segregation in Binary and Ternary Alloys," J. Nucl. Mater. 83, 2-23 (1979).

23. H. Wiedersich, P. R. Okamoto, and N. Q. Lam, "Radiation-Induced Segregation in Concentrated Alloys," J. Nucl. Mater. 83, 98-108 (1979).

24. S. Ohnuki, H. Takahashi, and R. Nagasaki, "Effect of Helium on RadiationInduced Segregation in Stainless Steel," J. Nucl. Mater. 155-157, 823-27 (1988).

25. L. R. Greenwood, "Neutron Dosimetry and Damage Calculations for the ORR-MFE-7J Experiment, pp. 23-25 in Fusion Reactor Materials, Semiannual Progress Report, DOE/ER-0313/6, U.S. DOE, Office of Fusion Energy, March 31, 1989.

26. U.S. ITER Nuclear Group, ITER and Blanket Work Package Report, ANL/FPP/88-1, Argonne National Laboratory, Argonne, Ill., 1988.

27. W. L. Clarke, V. M. Romero, and J. C. Danko, Detection of Sensitization in Stainless Steel Using Electrochemical Techniques, GEAP-21382, General Electric Company, San Jose, Calif., 1976.

28. W. L. Clarke, R. L. Cowan, and W. L. Walker, Comparative Methods for Measuring Degree of Sensitization in Stainless Steel, pp. 99-132 in Intergranular Corrosion of Stainless Alloys, ASTM STP 656, American Society for Testing and Materials, Philadelphia, 1978.

29. W. L. Clarke and D. C. Carlson, "Nondestructive Measurement of Sensitization of Stainless Steel: Relation to High Temperature Stress Corrosion Behavior," Mater. Perform. 19, 16-23 (1980). 
30. V. Cihal, "A Potentiokinetic Reactivation Method for Predicting the ICC and IGSCC Sensitivity of Stainless Steel and Alloys," Corros. Sci. 20, 737-44 (1980).

31. W. L. Clarke, The EPR Method for the Detection of Sensitizution in Stainless Steels, GEAP-24888, R5, General Electric Company, San Jose, Calif., 1981.

32. A. P. Majidi and M. A. Streicher, "Potentiodynamic Reactivation Method for Detecting Sensitization in AISI 304 and 304L Stainless Steels," Corrosion 40(8), 393-408 (1984).

33. B. Badger, Jr., D. L. Plumton, S. J. Zinkle, R. L. Sindelar, G. L. Kulcinski, R. A. Dodd, and W. G. Wolfer, pp. 297-316 in Effects of Radiation on Materials - Twelfth International Symposium, ASTM STP 870, American Society for Testing and Materials, Philadelphia, 1984.

34. R. L. Sindelar, R. A. Dodd, and G. L. Kulcinski, pp. 330-43 in Effects of Radiation on Materials - Twelfth International Symposium, ASTM STP 870, American Society for Testing and Materials, Philadelphia, 1984.

35. K. F. Russell and L. L. Horton, "Specimen Preparation of Near Surface Ion Irradiated Samples," pp. 170-71 in Proceedings of the 43rd Annual Meeting of the Electron Microscopy Society of America, Electron Microscopy Society of America, Ithaca, N.Y., 1985.

36. E. A. Kenik, "Measurement of Equilibrium and Non-equilibrium Segregation by X-Ray Microanalysis," Proc. Mater. Res. Soc. Symp. 62, 209-16 (1986).

37. E. A. Kenik and E. H. Lee, pp. 234 in Proceedings of the 4lst Annual Meeting of the Electron Microscopy Society of America, San Francisco Press, San Francisco, 1983.

38. R. H. Jones and S. M. Bruemmer, "Assessment of Stress-Corrosion Cracking in a Water-Cooled ITER," pp. 389-96 in Fusion Reactor Materials, Semiannual Progress Report, DOE/ER-0313/6, U.S. DOE, Office of Fusion Energy, March 31, 1989.

39. A. J. Giannuzzi, Studies on AISI Type 304 Stainless Steel Fiping Weidments for Use in BWR Application, EPRI NP-944, Electric Power Research Institute, Palo Alto, Calif., 1978.

40. F. Umemura and T. Kawamoto, Boshoku Gijutsu 28, 24-31 (1979).

41. W. L. Clarke and N. R. Hughes, "Effect of Sensitization on the SCC Behavior of Type 316/316L Stainless Steels," pp. 186-1-186-12 in Corrosion/80, Chicago, Ill., Paper No. 186, National Association of Corrosion Engineers, Houston, Tex., 1980.

42. P. Muraleedharan, J. B. Gnanamoorthy, and K. P. Rao, "EPR Method Versus ASTM A262 Practice E for Measuring DOS in Austenitic Stainless Steels," Corrosion 45(2), $142-49$ (1989). 
43. P. J. Maziasz and D. N. Braski, "Modification of the Grain Boundary Microstructure of the Austenitic PCA Stainless Steel to Improve Helium Embrittlement nzsistance," J. Nucl. Mater. 141-143, 973-77 (1986).

44. M. P. Tanaka, S. Hamad, A. Hishinuma, and M. L. Grossbeck, "Post Irradiation Tensile and Fatigue Behavior of Austenitic PCA Stainless Steel Irradiated in HFIR," J. Nucl. Mater. 155-157, 957-62 (1988).

45. M. L. Grossbeck, "Development of Tensile Property Relations for ITER Data Base," pp. 243-57 in Fusion Reactor Materials, Semiannual Progress Report, DOE/ER-0313/6, U.S. DOE, Office of Fusion Energy, March 31, 1989.

46. R. E. Stoller, P. J. Maziasz, and A. F. Rowcliffe, "Swelling Behavior of Austenitic Stainless Steels in a Spectrally Tailored Reactor Experiment: Implications for NearTerm Fusion Machines," J. Nucl. Mater. 155-157, 1328-34 (1988).

47. ,H. Khalak, A. B. Hull, and T. F. Kassner, "Aqueous Stress Corrosion of Austenitic Steels," pp. 379-83 in Fusion Reactor Materials, Semiannual Progress Report, DOE $:=$ R-0313/6, U.S. DOE, Office of Fusion Energy, March 31, 1989.

48. H. Takahashi, S. Ohnuki, H. Osanai, T. Takeyama, and K. Shiraishi, "Effect of Minor Alloying Elements and Their Segregation on Void Suppression in Modified 316 Stainless Steel," J. Nucl. Mater. 122 \& 123, 327-31 (1984).

49. C. M. Shepherd and T. M. Williams, Proceedings of the Fourth International Symposium on Environmental Degradation of Materials in Nuclear Power System-Water Reactors, to be published.

50. P. J. Maziasz, Oak Ridge Natl. Lab., unpublished data.

51. T. M. Williams, R. M. Boothby, and J. M. Titchmarsh, "Radiation-Indinced Sensitization of Stainless Steels," pp. 116-34 in Proceedings of the Symposium of the Berkeley Nuclear Laboratories, September 23, 1986, CEGB, Berkeley, Gloucestershire, United Kingdom, 1987.

52. S. A. Bruemmer, L. A. Charlot, and E. P. Simonen, Grain Boundary Chemistry Effects on Irradiation Assisted Stress Corrosion Cracking, Corrosion/90, Las Vegas, Nev., Paper No. 507, National Association of Corrosion Engineers, Houston, Tex., 1990. 


\section{INTERNAL DISTRIBUTION}

1-2. Central Research Library

3. Document Reference Section

4-5. Laboratory Records Department

6. Laboratory Records, ORNL RC

7. ORNL Patent Section

8-10. M\&C Records Office

11-30. G. E. C. Bell

31. J. Bentley

32. D. N. Braski

33. M. L. Grossbeck

34. F. M. Haggag

35. L. L. Horton

36. J. R. Keiser

37-41. E. A. Kenik

42-46. K. Kiuchi
47. J. S. Pawel

48. R. E. Pawel

49. P. L. Rittenhouse

50. P. S. Skiad

51. G. W. Slaughter

52. R. E. Stoller

53. P. F. Tortorelli

54. D. F. Wilson

55. Y. A. Chang (Consultant)

56. H. W. Foglesong (Consultant)

57. J. J. Hren (Consultant)

58. M. L. Savitz (Consultant)

59. J. G. Simon (Consultant)

60. K. E. Spear (Consultant)

\section{EXTERNAL DISTRIBUTION}

61-70. ALLOY AND CORROSION LABORATORY, Steel Research Center, NKK Corporation, 1-1 Minamiwatarida-cho, Kawasaki-Ku, Kawasaki, 210 Japan T. Inazumi

71-73. ARGONNE NATIONAL LABORATORY, 9700 S Cass Avenue, Argonne, IL 60439
A. B. Hull
T. Kassner
D. Smith

74. GENERAL ELECTRIC CORPORATE RESEARCH AND DEVELOPMENT CENTER, 1 River Road, K1-3A43, Schenectady, NY 12301

P. L. Andresen

75-78. JAPAN ATOMIC ENERGY RESEARCH INSTITUTE, Department of Fuels and Materials Reserch, Tokai-mura, Ibaraki-ken, 319-11 Japan
A. Hishinuma
T. Kondo
K. Shiba
T. Tsukada 
79-81. PACIFIC NORTHWEST LABORATORY, P.O. Box 999, Richland, WA 99352
S. A. Bruemmer
R. H. Jones
E. P. Simonen

82. PLANT MATERIALS TECHNOLOGY, GE Nuclear Energy, 175 Curtner Avenue, MC 785, San Jose, CA 95125
A. J. Jacobs

83-85. RENSSELAER POLYTECHNIC INSTITUTE, Troy, NY 12180

D. Duquette

D. Steiner

86. UNIVERSITY OF TOKYO, Department of Nuclear Engineering, Bunkyo-ku, Tokyo, 113 Japan

S. Ishino

87. U.S. DOE, OFFICE OF FUSION ENERGY, Washingtoil, DC 20585

F. W. Wiffen

88. U.S. DOE, OAK RIDGE FIELD OFFICE, P.O. Box 2001, Oak Ridge, TN 37831

Assistant Manager for Energy Research and Development

89-90. U.S. DOE, OFFICE OF SCIENTIFIC AND TECHNICAL INFORMATION, P.O. Box 62, Oak Ridge, TN 37831

For distribution by microfiche as shown in DOE/OSTI-4500, Distribution Category UC-424 Magnetic Fusion Energy Systems 

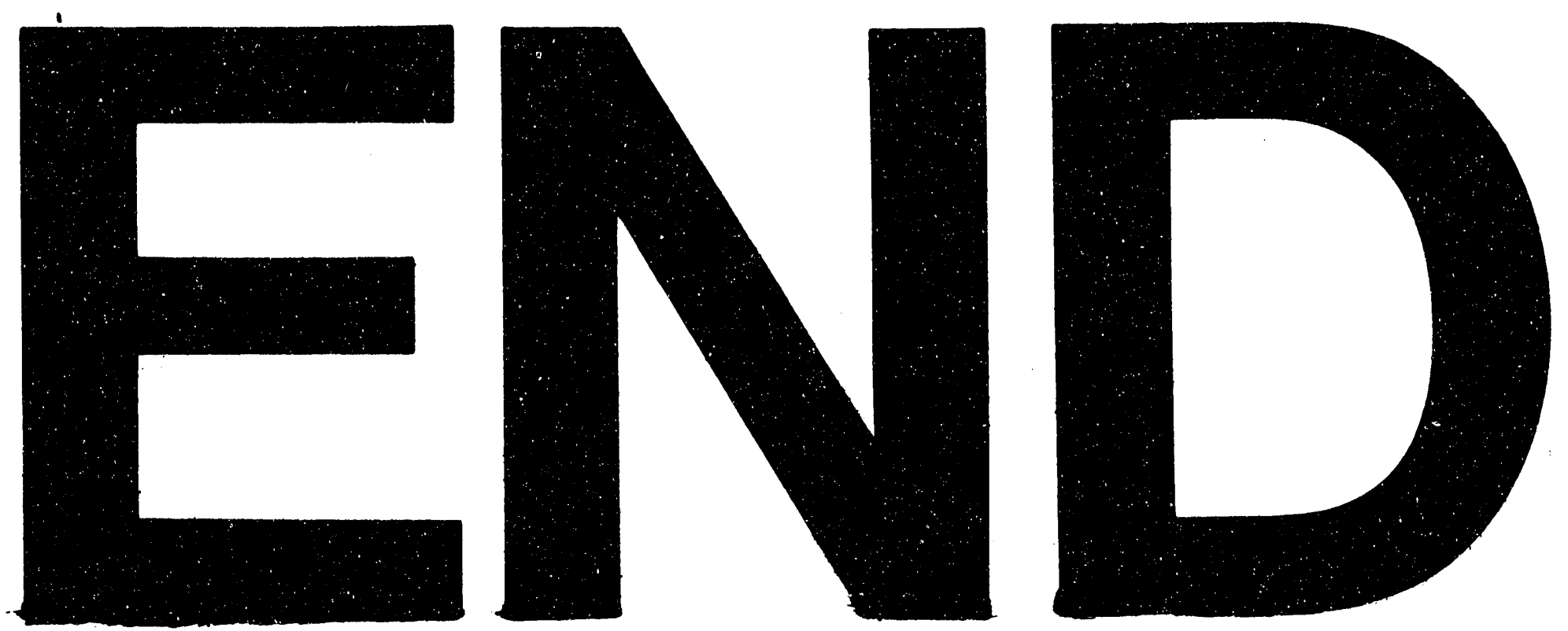

15

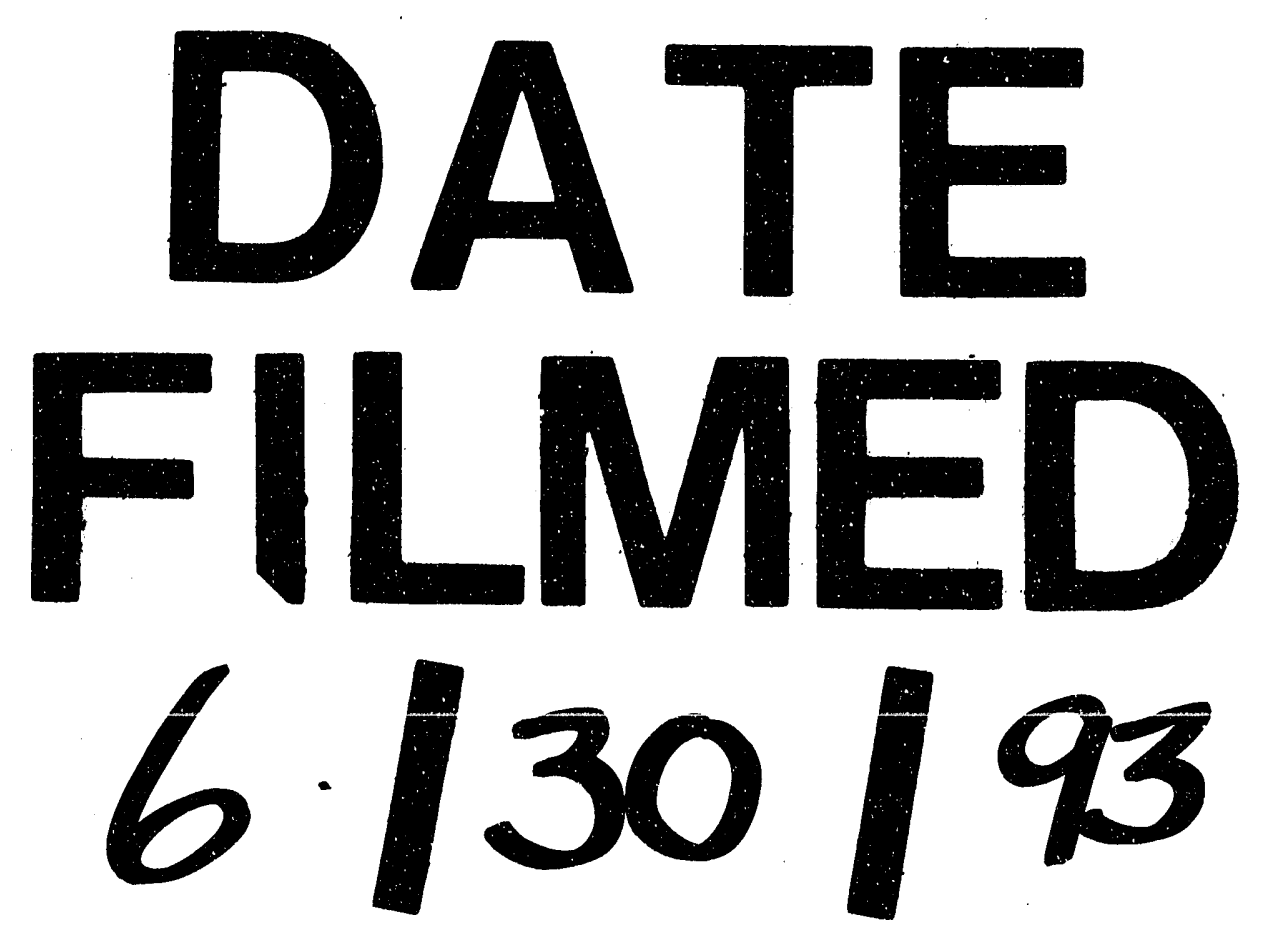


1 